Florida International University

FIU Digital Commons

FIU Electronic Theses and Dissertations

University Graduate School

6-16-2010

\title{
Assessing the influence of organizational personality, applicants' need motivation, expectancy beliefs, and person-organization fit on applicant attraction.
}

Paul J. Gregory

Florida International University, pgreg003@fiu.edu

DOI: $10.25148 /$ etd.FI10081002

Follow this and additional works at: https://digitalcommons.fiu.edu/etd

Part of the Industrial and Organizational Psychology Commons, and the Organizational Behavior and Theory Commons

\section{Recommended Citation}

Gregory, Paul J., "Assessing the influence of organizational personality, applicants' need motivation, expectancy beliefs, and personorganization fit on applicant attraction." (2010). FIU Electronic Theses and Dissertations. 247.

https://digitalcommons.fiu.edu/etd/247 


\title{
FLORIDA INTERNATIONAL UNIVERSITY
}

Miami, Florida

\begin{abstract}
ASSESSING THE INFLUENCE OF ORGANIZATIONAL PERSONALITY, APPLICANTS' NEED MOTIVATION, EXPECTANCY BELIEFS, AND PERSON-ORGANIZATION FIT ON APPLICANT ATTRACTION
\end{abstract}

A dissertation submitted in partial fulfillment of the requirements of the degree of DOCTOR OF PHILOSOPHY

in

PSYCHOLOGY

by

Paul Joseph Gregory

2010 
To: Dean Kenneth Furton

College of Arts and Sciences

This dissertation, written by Paul Joseph Gregory, and entitled Assessing the Influence of Organizational Personality, Applicants' Need Motivation, Expectancy Beliefs, and Person-Organization Fit on Applicant Attraction, having been approved in respect to style and intellectual content, is referred to you for judgment.

We have read this dissertation and recommend that it be approved.

Nathan Hiller

Victoria Pace Wood

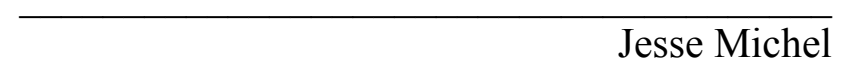

Chockalingam Viswesvaran, Major Professor

Date of Defense: June 16, 2010

The dissertation of Paul Joseph Gregory is approved.

\begin{tabular}{r}
$\begin{array}{r}\text { Dean Kenneth Furton } \\
\text { College of Arts and Sciences }\end{array}$ \\
\hline Interim Dean Kevin O'Shea \\
University Graduate School
\end{tabular}

Florida International University, 2010 
(C) Copyright 2010 by Paul Joseph Gregory

All rights reserved. 


\section{DEDICATION}

I dedicate this dissertation to my wife, Amy Hyman Gregory. Without her love, support, patience, and understanding, the completion of this work would not have been possible. 


\section{ACKNOWLEDGMENTS}

I would like to thank the members of my committee for their guidance, support, and patience. This thesis would not have been possible without their combined efforts. Dr. Nathan Hiller, Dr. Victoria Pace Wood, and Dr. Jesse Michel have helped me to better understand the demands and expectations of our field. I would like to especially

thank my major professor, Dr. Chockalingam Viswesvaran. His support of my work and confidence in my abilities has kept me committed to completing my degree and making him proud.

I would also like to thank my friends and family. Their empathy and love have helped me to persevere throughout my graduate career. I would like to give special thanks to my good friend Aldo Gonzalez. His help programming the online random assignment and manipulation features of my research were essential to helping me complete my work. 


\begin{abstract}
OF THE DISSERTATION
ASSESSING THE INFLUENCE OF ORGANIZATIONAL PERSONALITY, APPLICANTS' NEED MOTIVATION, EXPECTANCY BELIEFS, AND PERSONORGANIZATION FIT ON APPLICANT ATTRACTION
\end{abstract}

by

Paul Joseph Gregory

Florida International University, 2010

Miami, Florida

Professor Chockalingam Viswesvaran, Major Professor

This research explored the thesis that organizational personality is related to applicants' attraction to an organization through a process which involves need motivation, expectancy beliefs, and applicants' perceptions of person-organization fit. Organizational personality may be defined as a collection of trait-like characteristics that individuals use to describe organizational practices, policies, values, and culture. Specifically, this research investigated the hypothesis that organizational personality information is useful to applicants because it helps individuals to determine their perceptions of fit. A sample of students $(\mathrm{N}=198)$ and working adults $(\mathrm{N}=198)$ participated in an online experiment. Findings indicated that individuals' beliefs about the instrumentality of desirable work related outcomes are essential to determining their perceptions of fit and organizational attraction. Additionally, organizational personality perceptions interacted with need motivation to affect perceptions of fit and organizational attraction. For instance, perceptions of fit mediated the influence of the interaction between need for achievement and perceptions of innovativeness on organizational attraction. The interaction of need 
motivation and perceptions of organizational personality helped individuals to better determine their perceptions of fit and subsequent attraction toward organizations. 


\section{TABLE OF CONTENTS}

CHAPTER

PAGE

I. INTRODUCTION 1

Role of Recruitment in Attracting Employees 2

Significance of Image and Personality in Recruitment 6

Human Motivation Theories and Organizational Preference 7

Need for Achievement Theory Explanation $\quad 8$

Expectancy Theory Explanation $\quad 9$

II. LITERATURE REVIEW 11

Organizational Image \& Organizational Personality 11

Need Motivation Model 16

Valence-Instrumentality-Expectancy (VIE) Motivation Model 21

VIE Model Hypotheses 26

Defining P-O Fit 28

Measuring P-O fit 29

Importance of Person-Organization Fit (P-O Fit) in Attracting Employees 31

Importance of P-O Fit to Organizational Performance 32

Linking Organizational Personality and P-O Fit 35

Need Motivation Model and P-O Fit Hypotheses 36

$\begin{array}{ll}\text { III. METHOD } & 44\end{array}$

$\begin{array}{ll}\text { Participants } & 44\end{array}$

Procedure $\quad 44$

$\begin{array}{ll}\text { Measures } & 47\end{array}$

IV. RESULTS

Comparison of Motivation Models 58

Incremental Variance of VIE Models $\quad 59$

Bivariate Hypothesized Relationships $\quad 61$

Moderated Regression Hypothesized Relationships $\quad 73$

Mediated Regression Hypothesized Relationships $\quad 87$

V. DISCUSSION 94

Valence-Instrumentality-Expectancy beliefs Model Findings 95

Need Motivation Model Findings $\quad 99$

Crossing Need Motivation and Expectancy beliefs 102

$\begin{array}{ll}\text { Non-Findings } & 107\end{array}$

$\begin{array}{ll}\text { Limitations and Future Research } & 108\end{array}$

$\begin{array}{ll}\text { Concluding Remarks } & 111\end{array}$

$\begin{array}{ll}\text { REFERENCES } & 113\end{array}$ 
APPENDICES

VITA 


\section{LIST OF TABLES}

TABLE

PAGE

1. Univariate Analysis of Variance Comparing Students and Working Adults Mean 55 Ratings of Boy Scoutishness.

2. Univariate Analysis of Variance Comparing Students and Working Adults Mean 55 Ratings of Innovativeness.

3. Univariate Analysis of Variance Comparing Students and Working Adults Mean 56 Ratings of Dominance.

4. Univariate Analysis of Variance Comparing Students and Working Adults Mean 56 Ratings of Thriftiness.

5. Univariate Analysis of Variance Comparing Students and Working Adults Mean 57 Ratings of Stylishness.

6. Comparison of the Predictive Strength of Valence-Instrumentality-Expectancy Regression Models for Students and Working Adults.

7. Comparison of the Incremental Variance Explained by Competing VIE Regression Models for Students.

8. Comparison of the Incremental Variance Explained by Competing VIE Regression Models for Working Adults.

9. Intercorrelations of Organizational Personality Ratings and Instrumentality of Work Related Outcomes for Student Participants.

10. Predicting Organizational Personality Perceptions by Instrumentality Beliefs of 66 Work Related Outcomes in Students.

11. Intercorrelations of Organizational Personality Ratings and Instrumentality of Work Related Outcomes for Working Adult Participants.

12. Predicting Organizational Personality Perceptions by Instrumentality Beliefs of 68 Work Related Outcomes in Working Adults.

13. Intercorrelations of Need Motivation Scores and Valence of Work Related Outcomes for Student Participants.

14. Intercorrelations of Need Motivation Scores and Valence of Work Related Outcomes for Working Adult Participants.

15. P-O Fit Moderated Regression Analyses by nAch Scores for Students and Working Adults.

16. Attraction Moderated Regression Analyses by nAch Scores for Students and Working Adults. 
17. P-O Fit Moderated Regression Analyses by nPow Scores for Students and Working Adults.

18. Attraction Moderated Regression Analyses by nPow Scores for Students and Working Adults.

19. P-O Fit Moderated Regression Analyses by nAff Scores for Students and Working Adults.

20. Attraction Moderated Regression Analyses by nAff Scores for Students and Working Adults.

21. Intercorrelations of Interactive Terms (Need Motivation by Organizational Personality), Perceptions of Fit, and Organizational Attraction for Student Participants.

22. Intercorrelations of Interactive Terms (Need Motivation by Organizational Personality), Perceptions of Fit, and Organizational Attraction for Working Adult Participants.

23. Mediating Effect of P-O Fit on Attraction Ratings of Students.

24. Mediating Effect of P-O Fit on Attraction Ratings of Working Adults.

25. Predicting P-O Fit through Organizational Personality Ratings. 


\section{Chapter I: Introduction}

The purpose of this dissertation was to explore the relationships between organizational personality, need motivation, person-organization $(\mathrm{P}-\mathrm{O})$ fit, and applicant attraction. Specifically, this project examined the influence of organizational personality on P-O fit and applicant attraction, the moderating role need motivation may play in this relationship, how expectancy beliefs may predict attraction, and how the relationship between organizational personality and need motivation may help us to better understand P-O fit. The primary goal of this research was to contribute to the growing body of knowledge concerning applicant attraction and the recruitment of high quality applicants/employees. A secondary goal was to evaluate whether personality differences among organizations contribute to their recruitment viability. Before delving into the details of the current project, it is necessary to review the role of recruitment in applicant attraction and also to discuss the pertinent theories and research concerning organizational personality, need motivation, expectancy beliefs, person-organization fit and applicant attraction/organizational attractiveness.

For that purpose, the dissertation was organized as follows: First, there is a discussion of the importance of recruitment for organizations during the current economic downturn and the role that employee motivation, perceptions of fit, and attraction play in this process. In the second chapter, there is a comprehensive review of the critical theories and empirical research findings related to each of the key research variables, the relevant hypotheses to be tested in the current research, and a figure presenting the research model to be tested. Following this, the third chapter presents the methodology for the current research project. Next, the fourth chapter presents the results 
of the current research. Finally, the fifth chapter presents a discussion of the research findings and their implications. Additionally, appendices are included containing all materials used in this research as well as supplementary analyses.

\section{Role of Recruitment in Attracting Employees}

With the current downturn in economies both here in the United States and globally, the ability to hire and retain quality employees will be even more essential to organizations. Jang (2003) discovered that organizations in Korea experienced marked difficulty in attracting quality employees and displayed a general unwillingness to hire new employees following the climax of their financial crisis that began in 1997 for fear that hiring new employees would hurt the bottom line of organizations and prevent economic growth. It is foreseeable that a similar set of circumstances could pervade in the United States over the next several years as both individuals and organizations struggle to maintain economic stability. It is important for organizations to realize that the recruitment of quality applicants may actually be more significant now than ever because developing the workforce of tomorrow is likely a key component of recovering from our current economic crisis (Jang, 2003).

Countercyclical hiring $(\mathrm{CCH})$ or hiring during times of economic downturn can be quite beneficial for organizations as a recovery tool. $\mathrm{CCH}$ is a contrarian staffing strategy where organizations seek to obtain bargains in hiring of managers and professional staff during times of economic downturn. When organizations engage in procyclical hiring or hiring during economic upturns, the competition for labor with other organizations will be much greater. There is a higher demand for labor during economic upturns and this makes it more difficult for organizations to obtain highly qualified key 
employees (Bright, 1976). CCH allows organizations to stockpile human resources before a need becomes evident with the idea that these highly qualified individuals will be needed in the future (Greer \& Ireland, 1992). Greer, Ireland, and Wigender (2001) found that $\mathrm{CCH}$ had a positive impact on the financial performance of organizations. Specifically, organizations that hired key managerial or professional personnel during times of economic downturn had stronger financial performance two years later than those that did not. Also, the extensiveness of $\mathrm{CCH}$ was also predictive of cumulative abnormal returns (CARs) of organizations. Organizations that engaged in $\mathrm{CCH}$ more extensively displayed greater CARs that are another form of positive financial performance.

Recruitment is a significant activity for all organizations that may be overlooked at times due to the pressures faced by human resources departments to meet hiring deadlines and quotas (Barber, 1998). This issue may be related to the disparity encountered in research on the exact definition of recruitment and what recruitment actually entails. For instance, Rynes (1991) defines recruitment as "encompassing all organizational practices and decisions that affect either the number, or types, of individuals who are willing to apply for, or to accept, a given vacancy" (p. 429). Similarly, Breaugh (1992) defines recruitment as "those activities that (1) influence the number and/or types of applicants who apply for a position and/or (2) affect whether a job offer is accepted" (p. 4). A criticism of these definitions is that they are too broad in scope because they allow any organizational practice to be classified as recruitment and do not restrict our attention to customary recruitment functions, such as designing brochures and advertisements or conducting recruitment interviews (Barber, 1998). These 
definitions combine the recruitment process with recruitment outcomes which leads to some possibly misleading interpretations of recruitment on both the part of researchers and practitioners. For instance, these definitions of recruitment would lead someone to believe that any recruitment intervention that was unsuccessful or ineffective was not recruitment or that interventions that had the unexpected impact of attracting applicants would be considered part of recruitment. Consequently, we should remain cognizant of the fact that recruitment and attraction are not the same process (Barber, 1998).

Barber (1998) defines recruitment as "those practices and activities carried on by an organization with the primary purpose of identifying and attracting potential employees" (p. 5). Barber asserts that the primary purpose of recruitment by organizations is to attract future employees. The first step in recruiting future employees is to identify an appropriate pool of applicants and then persuade them to pursue and ultimately accept employment with an organization (Barber, 1998). As such, recruitment activities are intended to help locate quality applicants, and persuade them to pursue, and accept employment. Recruitment is the first stage of the selection system of any organization. It would be ineffective for organizations to focus all their attention on selection methodology and criteria if they are working with a pool of applicants that are not appropriate to their needs and goals. Therefore, planning and evaluation of recruitment activities is becoming increasingly more crucial to the attraction and retention of high quality employees by organizations (Cooper, Robertson, \& Tinline, 2003). Recruitment planning and evaluation can be costly endeavors for organizations, but the cost of losing employees prematurely due to a lack of fit, lack of motivation, or dissatisfaction can be even more costly (Cascio \& Aguinis, 2005). This is why a 
recruitment plan which evaluates recruitment in terms of its impact on attraction is important for any organization seeking to bolster the long term viability of its selection system (Barber, 1998; Cascio \& Aguinis, 2005; Cooper et al., 2003).

Chapman, Uggerslev, Carroll, Piasentin, and Jones (2005) conducted a metaanalytic review of the extant empirical research that evaluated the impact of recruitment practices on applicant attraction and job choice behavior. This meta-analysis supported many of the reflections made by Barber (1998) concerning the relationship between recruitment and attraction including the importance of organizational image $(\rho=.48)$, recruitment materials/source $(\rho=.42)$, and recruitment information content $(\rho=.31)$ as predictors of attraction. While these findings clearly indicate that a significant relationship between recruitment and attraction exists, we need to have a better understanding of the underlying mechanisms that facilitate this relationship before we can make propositions concerning how recruitment processes may be used to improve attraction.

In the last ten years, research on the relationship between recruitment and attraction has focused on primarily three factors: recruitment source, message content, and message delivery. Within the realm of recruitment source research, the role of company web sites in applicant attraction has become a leading topic (Anderson, 2003; Cober, Brown, Levy, Keeping, \& Cober, 2003; Cober, Brown, Keeping, \& Levy, 2004; Thoms, Chinn, Goodrich, \& Howard, 2004; Williamson, Lepak, \& King, 2003). Extant research on recruitment source has focused on the impact of print recruitment ads and brochures on individuals' perceptions of organizational attractiveness. In general, this research has shown that recruitment literature in websites and other media provides 
applicants with information about organizational attributes that affect the likelihood that individuals will pursue employment with a given organization (Barber, 1998). With the rise of technology and the Internet in particular, companies are now able to provide information virtually through their web sites to millions of potential applicants at the click of a button. As a result, the effectiveness of a company at communicating employment information is a crucial determinant of an organization's ability to successfully generate qualified applicants (Cappelli, 2001). Significance of Image and Personality in Recruitment

One of the key ways in which organizations distinguish themselves from their competitors is through their corporate image (Aaker, 1997; Cable \& Turban, 2003; Lievens, 2006; Siguaw, Mattila, \& Austin, 1999; Scott \& Lane, 2000). One way that corporate images are communicated to outsiders is by means of corporate slogans. For instance, Wal-Mart believes that consumers should "Save Money. Live Better," while its main competitor Target believes that you should "Expect More, Pay Less." These slogans share similar themes of frugality yet have some subtle differences that communicate varied ideals to consumers and stakeholders. Slogans serve to engender "brands" for organizations. Marketing research has consistently shown that organizational brands are easily recognizable (Siguaw, Mattila, \& Austin, 1999), influence the attraction of job applicants to organizations (Allen, Mahto, \& Otondo, 2007), and serve to unify and embed employees within an organization (Scott \& Lane, 2000). It is arguable that organizational branding is an effective recruitment practice as well as an organizational development tool. Aaker (1997) developed the idea of brand personality to represent the "set of human characteristics associated with a brand" (p. 347). 
Similarly, organizational personality which may be thought of as traits associated with an organization due to its location, business practices, advertisements, leadership, etc., has been shown to also influence applicant attraction, job pursuit intentions, and reputation perceptions (Slaughter, Zickar, Highhouse, \& Mohr, 2004). However, to date there has not been any research that has attempted to evaluate how or why organizational personality may affect the motivation of applicants to seek employment with a particular organization. It is important for researchers to determine how applicants process information about the personality of organizations and then use this information to determine their beliefs about person-organization fit, attraction to the organization. This research will attempt to provide greater insight into the factors surrounding organizational personality that motivate applicants to seek employment with specific types of organizations.

\section{Human Motivation Theories and Organizational Preference}

Kanfer (1990) refers to motivation as a hypothetical construct because we cannot see it or feel it. However, we can observe differences in behavior and behaviorally driven outcomes that relate to varying levels of motivation. Jex \& Britt (2008) assert that motivation is like gravity. Gravity cannot be seen or felt, but its effects become very clear if someone were to jump out a window of a high-rise building. According to Pinder (2008), motivation helps to determine the form, direction, intensity, and duration of work-related behavior. Therefore, a key issue to consider when defining and understanding motivation is identifying what types of behavior organizations need to influence in order to achieve desired outcomes. 
Given the importance of motivation in psychology, several theories of human motivation have been developed over time. Two theories that are particularly relevant to the explanation of work-related behavior or employee motivation are Need Motivation Theory (McClelland, 1965) and Expectancy Theory (Vroom, 1964). Need Motivation Theory is based on the premise that work motivation may be explained in terms of the extent to which individuals satisfy important needs through the workplace. Additionally, Expectancy Theory focuses on the cognitive issues that individuals face when making decisions and choices about how to appropriate their efforts (Jex \& Britt, 2008). The current research will simultaneously evaluate human motivation from both of these theoretical standpoints to determine the utility of each in explaining job seekers organizational preferences.

As mentioned earlier, prior research has demonstrated that organizational personality may be an important aspect of recruitment because of its influence on the attraction of job seekers to various types of organizations (Slaughter et al., 2004). However, no research has delved into how or why individuals prefer certain types of organizational personalities. It is possible to formulate alternate explanations for individuals' organizational preference based on a process mechanism that involves both Need Motivation Theory and Expectancy Theory. A more detailed review of each theory will follow in the next chapter, but here is a brief discussion of how we might explain organizational preference from either of these perspectives.

\section{Need Motivation Theory Explanation}

By itself, an organization's personality may be meaningless to a job seeker. However, individuals have varying needs (achievement, affiliation, power, etc.) that are 
important to both their physical and emotional well-being (Maslow, 1943).

Organizational personality becomes relevant to a job seeker because it provides information about the organization's practices, values, policies etc. (Lievens \& Highhouse, 2003; Slaughter et al., 2004). Job seekers may then evaluate the interaction of this information and their needs to determine whether these needs will be met and if they think they can help the organization meet its needs. Based on this appraisal, job seekers are able to determine their level of fit with an organization (Cable \& Judge, 1996; Kristof, 1996). Fit perceptions then drive the attraction of job seekers to organizations (Chapman, et al., 2005). Job seekers develop a preference for organizational personalities that they believe represent organizations that will best meet their needs.

\section{Expectancy Theory Explanation}

Alternatively, the decisions and choices that job seekers must make about how to best utilize their efforts will be greatly affected not only by immediate needs, but also by their expectations about how these decisions will affect their future needs and behavior.

Once again, the information that is provided to job seekers because of their organizational personality perceptions allow them to evaluate whether their efforts to obtain a job with an organization will lead to the attainment of valued outcomes. Valued outcomes vary across individuals and may be socially determined (e.g., prestige, influence, wealth) or based on individual desires (e.g., challenge, excitement, comfort). Job seekers can use the probability that accepting a position with a certain type of organization will either increase or decrease their chances of attaining these outcomes. If a job seeker believes that an organization will increase their likelihood of attaining valued outcomes, they will be more willing to pursue employment with that organization. Therefore, job seekers 
develop a preference for organizational personalities that they believe will increase the likelihood that their efforts will be rewarded with the attainment of valued outcomes.

Furthermore, because job seekers have inherent needs that they would like to fulfill, these needs will predict the value they place on certain outcomes.

The next chapter will provide a comprehensive review of the key research variables and set the stage for the research hypotheses. It is important to review what has already been learned about organizational personality, need motivation, expectancy beliefs, perceptions of fit, and organizational attraction so that we can develop a better understanding of how these variables are likely to relate to each other and also how their combined influence can be important when it comes to the recruitment of high quality employees. 


\section{Chapter II: Literature Review}

This chapter will begin with a review of the literature on organizational image and personality. Organizational personality and image play a key role in determining the initial beliefs of job seekers about an organization. These initial beliefs are a focal aspect of the recruitment process. Next, a review of the need motivation literature and expectancy beliefs literature will be examined to develop the framework for the research

models that will be tested. We have previously discussed a basic view of how each theory may be applied to the understanding of job seekers' organizational preferences. Finally, the person-organization fit literature will be discussed as the key connection between personality, motivation, and organizational attraction.

Organizational Image \& Organizational Personality

Dutton, Dukerich, and Harquail (1994) describe organizational image in terms of two broad concepts. First is the idea that image is partially determined by what members of the organization believe are "distinctive, central, and enduring (p. 239)" qualities of their organization. Members' views of organizations have become more commonly associated with the constructs of organizational identity or organizational culture (Schein, 1990; O’Reilly, Chatman, \& Caldwell, 1991). Second is the notion that image is partially based on members' views concerning how outsiders think about the company; this conceptualization has evolved over the last several years to place a greater emphasis on outsiders' views of the organization instead of solely focusing on members' opinions (Allen, Mahto, \& Otondo, 2007; Billsberry, 2007; Gioia, Schultz, \& Corley, 2000; Lievens, Van Hoye, \& Anseel, 2007). This research will focus solely on the 
conceptualization of image/personality as a product of outsiders' views of an organization.

Berg (1985) was one of the first to conceptualize organizational image as the public's perception of an organization that is usually linked to a given action or specific event. Berg's definition implies that image may be temporally transient since it is linked to a specific episode or action in a company's history. This definition relates to Fombrun's (1996) definition of reputation as the collective evaluation (by non-members) of an organization's actions and accomplishments. Fombrun's definition of reputation implies a more enduring and widespread appraisal of image. Further, there are related concepts of corporate image (image associated with the name of an organization) and recruitment image (image associated with a recruitment message) (Gatewood, Gowan, \& Lautenschlager, 1993), both of which differ from the two definitions previously mentioned. This inconsistency in the conceptualization of image has been a problem in past research (see Gioia et al., 2000 for a detailed comparison of conceptualizations), but recent research on organizational image has supported the idea that it is a global trait that likely evolves over time in response to an organization's environment (Lievens \& Highhouse, 2003; Lievens et al., 2007).

Lievens (2006) defines organizational image as people's global impression of an organization, which is based on loose structures of knowledge and beliefs about an organization. Further, image is also the product of the net cognitive reactions, and associations of customers, investors, employees, and applicants to an organization's name. An organization's image serves as a heuristic for categorizing, and recalling information that is related to a particular organization. However, no organization has a 
single true "image." Organizational image is largely a product of the various outsider groups that hold differing or similar views of the organization. For instance, stakeholders may pay more attention to economic figures when forming their beliefs concerning an organization while employees and potential employees (the target population of this dissertation) may hold a very different view of the organization. It is also important to note that organizational images are not static. Images may change due to organizational behavior including: information sharing with the public through the media, advertising, and information presented in corporate websites. Recruitment campaigns are very important for organizations because they allow companies to highlight specific attributes that will inform the construction of certain images.

Lievens (2006) identifies two general components of organizational image based on brand equity theory research (Aaker, 1997). First, there are the instrumental attributes which are usually a group of objective attributes that people associate with any organization. These attributes may include factual or historical aspects of the organization, and organization policies. For example, research has shown that applicants to an organization may have knowledge of instrumental attributes such as size, location, level of centralization, pay, and advancement opportunities all of which impact the jobs they choose to apply for (Lievens \& Highhouse, 2003). A second part of image is individuals' symbolic attributes, which are trait-related inferences concerning an organization. Symbolic attributes differ from instrumental attributes in that they are subjective, abstract, and intangible. Research has shown that applicants meaningfully and reliably ascribe symbolic attributes to organizations (Lievens \& Highhouse, 2003; Lievens, Van Hoye, \& Schreurs, 2005). Symbolic attributes also help to convey the 
personalities that people assign to organizations. Attributes allow applicants to refer to potential employers as trendy, prestigious, honest, etc. (Lievens \& Highhouse, 2003, Lievens et al., 2005). Personality attributes play a key role in the overall perception of organizational image, which then influences the types of individuals attracted and selected by that organization.

The instrumental and symbolic attributes that applicants ascribe to organizations may have positive consequences for the organization because they influence how stakeholders respond to the organization (Lievens, 2006). These positive consequences may include competitive leverage in terms of attracting and keeping investors, impacting consumer product choices, serving to attract people to the organization as a place to work, and improving employee attitude and behavior toward the organization (Lievens, 2006). The growing evidence that organizations have personality-like traits (Lievens \& Highhouse, 2003; Lievens et al., 2005) has been useful in leading to the development of the construct of organizational personality.

Slaughter et al. (2004) define organizational personality as the "set of human personality characteristics perceived to be associated with an organization (p. 86)." Like Lievens and Highhouse (2003), they developed the construct of organizational personality based on Aaker's (1997) brand personality theory. Aaker identified five broad dimensions of brand personality: Sincerity, Excitement, Competence, Sophistication, and Ruggedness. Lievens and Highhouse (2003) refined these dimensions as follows: Sincerity, Innovativeness, Competence, Prestige, and Robustness respectively, to represent aspects of symbolic attributes. These two studies provided the framework that would lead to the development of the organizational personality construct. 
Building on this prior research, Slaughter et al. (2004) created and validated an organizational personality measure that identified five general dimensions of organizational personality: Boy Scout, Innovativeness, Dominance, Thrift, and Style. The Boy Scout factor refers to perceptions of an organization's honesty, attentiveness to people, and family orientation, etc. The Innovativeness factor relates to how original, creative, or unique, organizations are. Dominance refers to whether or not an organization would be considered big, successful, or popular. Thrift refers to whether an organization is simple, low-class, or sloppy. Finally, Style involves others' perceptions of the organization as being trendy, up-to-date, or contemporary.

Slaughter et al. (2004, Study 2) further found that organizational personality was significantly related to general applicant attraction, intentions to pursue employment, perceptions of reputation, and the likelihood that applicants would accept job offers. Specifically, Dominance and Innovativeness were positively related to general attraction, intentions to pursue employment, job offer acceptance (only Dominance was significantly related), and perceptions of reputation. Thrift was negatively related to all four attraction variables. Finally, Boy Scout and Style were positively related to reputation. They further validated the organizational personality measure (Study 3) by manipulating organizational personality profiles to emphasize each of the five factors individually. This study showed the same pattern of results. Based on these findings it seems that Dominance and Thrift are the factors most strongly related to attraction variables in general and reputation is the attraction variable that was most strongly related to the organizational personality variables overall. These findings are significant for 
recruitment practices because projecting a certain personality should alter how outsiders view the reputation of the organization.

A key aspect in measuring organizational personality is the understanding that outsiders are able to make an assessment of personality even if they have had limited exposure to the organization (Lievens \& Highhouse, 2003; Slaughter et al., 2004). If so, organizational personality can have a major influence on the ability of organizations to recruit quality applicants. Research has reliably shown that applicants are able to easily ascribe traits to a organization based on limited exposure to advertisement media, corporate web sites, or recruitment materials (Highhouse, Thornbury, \& Little, 2007; Lievens \& Highhouse, 2003; Slaughter et al., 2004). Though it is well established that applicants/outsiders are differentially attracted to various organizational personality profiles (dominance, thrift, boy scout, style, innovativeness), there is no present research that directly addresses the process through which organizational personality profiles affect applicant motivation.

\section{Need Motivation Model}

One possible way to view how organizational personality affects applicant attraction is by considering the concept of need motivation. Murray (1938) was the first to posit the idea of psychogenic or basic needs in personality. These needs are believed to be largely at the unconscious level. After years of research Murray narrowed his list to twenty seven psychogenic needs. Three of Murray's psychogenic needs have been the focus of considerable research: the Need for Achievement ( $n$ Ach), Need for Power ( $n$ Pow), and Need for Affiliation ( $n$ Aff). McClelland dubbed these the trichotomy of needs and believed that based on his research these were the major human motives 
(McClelland, 1961, 1975, 1979, 1985; McClelland, Atkinson, Clark, \& Lowell, 1976; McClelland \& Winter, 1969). McClelland's Theory of Needs has become one of the most popular theories of human motivation (Jex \& Britt, 2008).

For instance, McClelland's Theory of Needs was part of the impetus for the modern socio-analytic theory of personality (Hogan, 1991) that distinguishes between two types of individuals: those seeking to get along with others and those seeking to get ahead of others. This distinction is similar to the need for affiliation and a combination of need for power and need for achievement. Hogan and Holland (2003) conducted a metaanalytic review that demonstrated the broad ranging influence of getting ahead and getting along with individuals' adjustment, ambition, likeability, intellectuality, success in school, and prudence. The getting along and getting ahead motivation patterns have distinct effects on the behavior of individuals in various work environments. The current research posited that McClelland's trichotomy of needs may be used to predict individuals' preferences for certain organizational personalities that may lead to greater perceptions of fit and organizational attraction.

McClelland's early work focused primarily on $n$ Ach, and became popular in the early 1960s because of empirical evidence that demonstrated a correlation between $n$ Ach and levels of achievement as well as progress in cultures (McClelland \& Winter, 1969). Motives in general could be seen as partially determined by the pairing of cues with affect or the conditions that produced affect. In other words, need motives may develop as the result of an individual pairing a particular striving with positive affect based outcomes. For example, striving for academic excellence may lead students to feel a sense of greater pride and accomplishment. However, aspects of $n$ Ach, $n$ Pow, and $n$ Aff, 
are ingrained within individuals. This idea is reinforced by research that has demonstrated a significant relationship between aspects of personality and need motivation (Aitken-Harris, 2004; Winter, John, Stewart, Klohnen, \& Duncan, 1998). The following sections will present brief reviews of the pertinent research concerning each of the three need motivations in order to provide a more comprehensive view of their possible role in the applicant attraction process.

Need for Achievement (nAch). Need for achievement has been conceptualized as the extent to which an individual desires to succeed in areas of behavior that are of interest to him/her (McClelland et al., 1976). $n$ Ach is shown to be positively related to goal setting behavior (Phillips \& Gully, 1997), which in turn is related to performance. Specifically, research has shown that individuals high in $n$ Ach are more likely to set difficult and higher level performance goals. Additionally, Turban and Keon (1993) found that subjects high in $n$ Ach were more attracted to organizations that rewarded performance rather than seniority and organizations that were large or small rather than mid-size. It seems that high $n$ Ach individuals may be less attracted to mid-size organizations because they inferred greater opportunity for promotion and feedback in small organizations and greater challenge in large organizations. Also, the authors believed that high nAch individuals prefer situations in which they are personally responsible for their outcomes, desire personal responsibility, and tend to be more innovative (i.e., they like to try new ways of doing things).

Aitken-Harris (2004) found support for these reflections concerning $n$ Ach. Specifically, she found that $n$ Ach is positively related to personality traits like openness, endurance, innovation, creativity, understanding, and self-discipline. Individuals high in 
$n$ Ach are therefore more likely to (a) persist to completion in difficult tasks, (b) enjoy abstract thinking and figuring out new ways to solve problems, and (c) show better selffocus in getting things done in a timely manner. These findings reaffirm the idea that high $n$ Ach individuals value innovation, challenge, feedback, and opportunity for personal growth.

Need for Power (nPow). Need for power has been defined as a desire to have impact, control, or influence on another person, group, or society in general (Winter et al., 1998). McClelland (1970) has further dichotomized power into two forms: personalized and social power. Personalized power (also known as the negative face of power) is related to behavior that characterizes personal dominance and/or aggression (e.g., fighting, excessive drinking, etc., McClelland, 1970). Social power involves influencing others for the sake of social, group, or organizational goals, and has been found to be a characteristic of effective managers. The focus of the current project will be on the impact of need for the social form of power. As such, the research discussed below refers to need for social power.

High $n$ Pow individuals are concerned with prestige, reputation, and having a strong influence on others. Very little research has been conducted on the influence of $n$ Pow on decision-making as it pertains to organizational preferences. However, Winter et al. (1998) demonstrated that $n$ Pow and extraversion are positively related. This relationship predicted participants' work relationships and career plans over time. High $n$ Pow individuals were typically more extraverted and sought high impact careers over time. 
Interestingly, high $n$ Pow individuals have also been found to react negatively to situations involving assertive others (Fodor, Wick, \& Hartsen, 2006). High $n$ Pow individuals who were asked to rate the affect of a hypothetical individual who was either high or low in assertiveness, reacted more negatively to the assertive individual. An explanation for this reaction is the concept of power stress (McClelland, 1976). It is thought that power motivated individuals derive more satisfaction from situations that allow for the successful exercise of power and/or subordination of others. As such, it is likely that high $n$ Pow individuals would be attracted to organizations that provide opportunity to exercise power.

Additionally, research has shown that high $n$ Pow individuals tend to be trusting, conservative, forthright, and more concerned with people than economic values (Singh, 1986). In particular, Singh (1986) found that power motivation was closely related to conservatism and self-assertion. Based on these findings, it would seem that power motivated individuals would value conservative business practices that include values of honesty.

Need for Affiliation (nAff). A need for affiliation may be thought of as a desire to establish, maintain, or restore friendship or friendly relations among persons or groups. (Winter et al., 1998). A basic belief is that individuals that have high $n$ Aff value the importance of association with others as a goal. As such, we would expect that more outgoing or extraverted individuals should also value affiliation. Winter et al. (1998) found that there is a positive relationship between $n \mathrm{Aff}$ and extraversion. Specifically, high $n$ Aff individuals are more likely to have stable relationships, volunteer their time, and be more satisfied with their careers. 
Research has also identified need for affiliation as an important factor to organizational identification (Wiesenfeld, Raghuram, \& Garud, 2001). High $n$ Aff individuals are able to more easily identify with their organization when faced with virtual work than low $n$ Aff individuals. Additionally, high $n$ Aff individuals are more concerned with organizational social support at work and identify with organizations more readily when they perceive social support to be high. Therefore, these findings suggest that high $n$ Aff individuals will be more attracted to work environments that appear to offer support and concern for others.

Also, based on these prior findings we would expect high $n$ Aff individuals to be more interested in situations that will garner them prestige and social esteem. Prestige and social esteem will make it easier for individuals to form relationships and gain favor with others (Highhouse, Thornbury, \& Little, 2007). However, no prior research has examined how the affiliation motive may influence preferences for particular work environments of organizations. The organization an individual works for plays an important role in helping to determine that person's social identity (Highhouse et al., 2007). As such, understanding how our motivations influence these decisions is a key step to better understanding the relationship between organizational personality and organizational attraction.

It is clear that the needs of individuals play an important part in determining their motivation. But also of consequence in predicting motivation are the outcomes to behavior that individuals expect to occur. Individuals' needs present a limited frame of motivation because needs motivation does not account for whether or not these needs are actually met or whether individuals believe their needs will be met by joining one 
organization over another. It is more likely that as individuals, we have inherent needs that predict the values we hold for certain outcomes and also whether or not membership in a particular organization will allow us to attain these outcomes. Therefore, a better understanding of how expectancy beliefs relates to the processing organizational personality information will improve our ability to predict applicant attraction.

\section{Valence-Instrumentality-Expectancy (VIE) Motivation Model}

Expectancy theory is one of the most popular and widely studied theories of human motivation (Van Eerde \& Thierry, 1996). The basic premise is that individuals will generally direct their efforts toward behaviors or actions when they perceive that there is a high probability that they will be able to perform the behavior, high probability that the behavior will lead to some outcome, and that the outcome will hold value to the individual (Jex \& Britt, 2008). If any of these components is missing then individuals are unlikely to direct their efforts toward this course of action. Vroom $(1964,1995)$ postulated that the belief that one's efforts will allow you to perform a particular behavior is known as expectancy or otherwise denoted as effort-to-performance $(\mathrm{E} \rightarrow \mathrm{P})$. Expectancy is a belief about the future so Vroom proposed that this would be a probability function ranging from 0 to 1 . Therefore, an expectancy of 1 indicates that the individual is certain that if he or she puts forth effort, a given level of performance can be achieved. For instance, job seekers may believe that if they make the effort to attend several job fairs, they will have a greater chance of getting a great job. Expectancy beliefs are based on multiple factors that may include individuals' abilities, constraints in their environments, and training experiences. 
Instrumentality refers to a belief that a specific behavior will lead to a particular outcome and is also denoted as performance-to-outcome $(\mathrm{P} \rightarrow \mathrm{O})$. Instrumentality is also a probability function. For example, a job seeker may perceive that working for a particular organization will offer better career advancement opportunities because incumbents (individuals already working for the organization) report that promotions are typical within the first three years of employment. Instrumentality beliefs are typically based on stated organizational policy or values. Therefore, the information that job seekers are exposed to about an organization should affect how motivated they are to seek employment with that organization (Chapman et al., 2005).

According to Vroom, individuals differentially value the outcomes that can be obtained for different levels of effort. For instance, an individual may place a high value on monetary compensation and therefore be more willing to seek employment with an organization known for paying well rather than an organization that is known for their social morals. The value individuals place on the possible outcomes of their behavior is known as valence. It is important to note that valence can also take negative values because individuals may be unmotivated if they feel a possible outcome is undesirable. For example, a job seeker may place a negative value on organizational simplicity or thriftiness because they believe these characteristics represent a poor, cheap, or unsophisticated workplace with the result that the valence in this case is negative.

Vroom $(1964,1995)$ proposed that expectancy, instrumentality, and valence could be combined to explain an individual's motivation. The basic equation postulates that the level of effort that an individual will direct toward a given behavior (force) is based on a multiplicative relationship between expectancy, instrumentality, and valence $(\mathrm{F}=\mathrm{E}(\Sigma \mathrm{I} \mathrm{x}$ 
V)). All possible combinations of valence multiplied by instrumentality are summed and then multiplied by expectancy. Therefore, effort will be highest when an individual believes that effort will lead to a certain outcome that is valuable to the individual.

Van Eerde and Thierry (1996) conducted a meta-analytic review of 77 studies that tested valence-instrumentality-expectancy (VIE) model predictions. The studies typically measured the correlation of VIE components with work related outcomes such as performance, effort, intention, preference, and choice. The results indicate that the individual components of valence, instrumentality, and expectancy differentially related to outcomes, but multiplying terms did not improve prediction of behavior. Generally, the strongest results were in the prediction of intention, choice, and preference. One reason for multiplicative terms failing to improve prediction may be due to the inappropriateness of multiplying interval level scales (e.g., valence) (Evans, 1991). It was also found that expectancy theory showed stronger results in studies using within-subjects designs. Within-subject design research used expectancy theory to predict individuals' choice among varied courses of action. In contrast, between-subjects designs research used expectancy theory to predict the effort or level of performance of large groups of individuals. The VIE model has been useful in predicting choice behavior of individuals when they are faced with a number of options (Mitchell, 1974; Muchinsky \& Taylor, 1976; Muchinsky, 1977; Wanous, Keon, \& Latack, 1983).

When the VIE model is used to predict preferences, subjects are asked to assign valences to a number of outcomes or goals, and also assign instrumentalities to a series of occupations or organizations. These instrumentalities indicate the degree to which the subjects perceive the occupations or organizations to be instrumental for attaining each of 
the outcomes (Muchinsky \& Taylor, 1976). Therefore, a $\Sigma$ IV (sum of instrumentality and valence) score can be conceptualized as the predictor of preference, while the preference rating assigned to each organization can be viewed as the criterion of organizational preference. Wanous et al. (1983) assessed business students' preference for various graduate schools to test this proposition. Expectancy in this study was evaluated by measuring students' perceptions of their likelihood of being admitted to each school. Instrumentality was measured by having subjects react to a set of 15 items related to various outcomes related to being in a particular graduate program. These included the prestige of the school, quality of teaching, convenience of location, and the chance to gain knowledge. Valence was assessed by asking respondents to indicate the relative importance of each outcome by placing outcomes into groups of 5 based on least importance, moderate importance, and most importance.

Wanous et al. (1983) found that graduate program attractiveness was best predicted by the sum of instrumentalities linked to the outcomes listed among the 5 most important. This finding supported the authors' implicit weighting method for combining valence and instrumentality as opposed to a traditional multiplicative approach. Findings also indicated that effort to join an organization was best predicted by individuals' expectancy weighted by the sum of the instrumentalities for the 5 most important outcomes. The implicit weighting method elicited support for Vroom's entire model (effort was best predicted by both expectancy and attractiveness as compared to a model with either component alone).

The current research will utilize the VIE model to evaluate individuals' preferences for various types of organizational personalities. Individuals will assign 
varying valences to the work related outcomes that they believe each type of organization will be able to provide them. Determining which outcomes are most important to job seekers has been identified as a long-standing issue in prior research (Van Eerde \& Thierry, 1996; Wanous et al., 1983). Wanous et al. (1983) found that prestige, competition, warmth, location, etc. were important outcomes when making decisions about graduate schools. Similarly, Muchinsky and Taylor (1976) found that personal growth and challenge, interesting and stimulating work, sense of accomplishment, opportunity to help people, and chance to use special skills were the five outcomes rated most important by individuals deciding between career paths. Lievens and Highhouse (2003) identified pay, advancement, job security, task demands, benefits, and flexibility as the reasons that most motivated job seeking behavior. Based on these findings, it is evident that there are several outcomes that job seekers value in their decision making. The predictive value of all components of the VIE model has been dubious in prior research (Van Eerde \& Thierry, 1996). The current research will attempt to demonstrate whether Vroom's complete model is useful in predicting the organizational preferences of individuals.

\section{VIE Model Hypotheses}

The VIE model allows for predictions involving an interactive relationship between all three components are well as predictions limited to individual components. The research hypotheses concerning the VIE model will be presented as follows: (a) a general hypothesis involving the original interactive model (Hypothesis 1); (b) five hypotheses involving only the instrumentality portion of the model (Hypotheses 2-6); and 
finally, (c) three hypotheses involving only the valence portion of the model (Hypotheses 7-9).

Hypothesis 1: A weighted model that considers valence ratings, instrumentality ratings, and expectancy ratings $(O A=E(\Sigma I x V))$ will be more predictive of individuals' organizational attractiveness ratings than a partial model (e.g., $O A=\Sigma I, O A=\Sigma I x V$, etc.)

The current research will also attempt to compare the relative importance of work related outcomes and how well individuals feel different types of organizations will allow them to meet these needs. Recall that based on the research of Slaughter et al. (2004), Boy Scout organizations tend to be seen as honest, attentive to people, and family oriented. Innovative organizations are original, creative, or unique. Dominant organizations would be considered big, successful, or popular. Thrifty organizations are simple, low-class, or sloppy. Finally, Stylish organizations are seen as being trendy, upto-date, sophisticated, or contemporary. Therefore we expect:

Hypothesis 2: Boy Scoutishness ratings of organizational personality will be positively related to instrumentality ratings of warmth, ability to help others, good benefits, security, and honesty in business practices outcomes.

Hypothesis 3: Innovativeness ratings of organizational personality will be positively related to instrumentality ratings of flexibility in practices, challenging work, chance to use creative abilities, and intellectual stimulation outcomes.

Hypothesis 4: Dominance ratings of organizational personality will be positively related to instrumentality ratings of prestige, a good salary, and opportunities for advancement outcomes. 
Hypothesis 5: Stylishness ratings of organizational personality will be positively related to instrumentality ratings of prestige, a good salary, and good benefits outcomes.

Hypothesis 6: Thriftiness ratings of organizational personality will be negatively related to instrumentality ratings of prestige, opportunity for advancement, a good salary, and good benefits outcomes.

The attraction of high $n$ Ach, $n$ Pow, and $n$ Aff individuals to specific organizational personalities will be based on the relative value that these individuals assign to traits such as innovativeness, honesty, sophistication, popularity, and simplicity in their decision making processes about work. Based on the aforementioned research findings, we would expect:

Hypothesis 7: $n$ Ach will be positively correlated with valence ratings for challenging work, opportunity for advancement, a good salary, intellectual stimulation, and chance to use creative abilities outcomes.

Hypothesis 8: nPow will be positively correlated with valence ratings for prestige, opportunity for advancement, a good salary, and honesty in business practices outcomes.

Hypothesis 9: nAff will be positively correlated with valence ratings for security, ability to help others, and warmth.

By assessing their relative needs with those of the organization, job seekers are able to determine their subjective perceptions of fit. Person organization fit is a key determinant of individuals' attraction to specific types of jobs and organizations (Chapman et al., 2005). Therefore, it is essential that any discussion of work-related motivation involve fit. 


\section{Defining P-O Fit}

Kristof (1996, p.1) defined P-O fit as the "compatibility between people and the organizations in which they work." Essentially, P-O fit theory posits that there are characteristics of organizations that have the potential to be congruent with characteristics of individuals, and that individuals' attitudes and behaviors will be influenced by the degree of congruence or "fit" between individuals and organizations Despite the general consensus that P-O fit involves the compatibility between individuals and their organizations, the exact nature of this compatibility has resulted in much confusion in defining P-O fit (Kristof, 1996). P-O fit has been defined in a variety of ways including value congruence, goal congruence, needs-supplies fit, and demandsabilities fit (Kristof, 1996; Muchinksy \& Monahan, 1987).

Value congruence, the most frequently assessed dimension of P-O fit, involves the similarity between organizational values and those of the organization's employees (Kristof, 1996). Schneider, Goldstein, and Smith’s (2006) attraction-selection-attrition (ASA) framework also posits goal congruence as an important dimension of P-O fit. According to the ASA framework, individuals will be attracted to organizations whose goals are instrumental in meeting the goals of the individual. Thus, goal congruence involves similarity between the goals of the organization and those of the organization's employees, and it is expected to relate to individual goal attainment such as job performance and individual attitudes such as commitment.

Carless (2005) distinguished between needs-supplies fit and demands-abilities fit. Needs-supplies fit may be defined as the extent to which the organization fulfills the needs of an individual, whereas demands-abilities fit occurs when an individual's 
characteristics fill the needs of the organization. This study focuses on P-O fit as conceptualized as needs-supplies fit.

\section{Measuring $P-O$ fit}

In an integrative review of the P-O fit literature, Kristof (1996) classified differences in the measurement of P-O fit into three categories: objective fit, perceived fit, and subjective fit. The main similarity between these approaches is that all three evaluate the congruence between the characteristics of an individual and the characteristics of the organization. However, the method used to obtain this measure of person-organization congruence may vary widely across the three approaches.

Objective fit measures ask an individual to describe his or her own characteristics, and then ask other organizational members to describe the characteristics of the organization. Typically, agreement across organizational members' perceptions of the environment is then assessed (Kristof, 1996). To the extent that organizational members agree on the nature of the organization's characteristics, organizational members' responses are then combined to form a measure of the organization's climate. Fit is then operationalized as the congruence between an individual's self-description and the aggregate organizational climate.

Perceived fit measures ask individuals to describe themselves, as well as their perceptions of organizational characteristics. The degree of fit is then calculated by assessing the discrepancy between a respondent's self-description and that same respondent's description of the organization. Perceived fit measures are conceptually similar to subjective fit measures in that the degree of fit in both is operationalized as the discrepancy between an individual's self-image and the same individual's perceptions of 
the organization. The primary distinction between perceived and subjective fit measures is that perceived fit measures explicitly ask respondents to describe both their own characteristics and the organization's characteristics via questionnaires; whereas subjective fit measures assess P-O fit by asking respondents how well they fit with their organization using self-report items.

Both perceived and objective fit measures may be contrasted with subjective fit measures, which involve directly asking an individual how well their characteristics fit with their employing organization's characteristics. That is, subjective fit measures do not involve the explicit measurement of either individual or environmental characteristics. Instead, respondents are assumed to have a mental representation of the organizational profile and to cognitively examine the congruence between their personal characteristics and their perception of the organizational profile (Carless, 2005). The current research will examine P-O fit using a subjective fit measure. Importance of Person-Organization Fit (P-O Fit) in Attracting Employees

Several studies have shown that P-O fit is consistently related to attraction to an organization (Cable \& Judge, 1996; Carless, 2005; Chapman et al., 2005; Ehrhart \& Ziegert, 2005), job acceptance intentions (Bretz \& Judge, 1994; Judge \& Bretz, 1992) and hiring recommendations (Cable \& Judge, 1997).

Judge and Cable (1997) conducted a longitudinal assessment of job seekers' objective and subjective perceptions of person-organization fit and their relation to applicant attraction. The findings showed that objective $\mathrm{P}-\mathrm{O}$ fit and subjective $\mathrm{P}-\mathrm{O}$ fit were both significantly related to applicant attraction. However, an important distinction was the finding that subjective fit was more predictive of applicant attraction than 
objective fit. This finding reaffirmed the authors' assertion that a greater understanding of subjective fit, which is an understudied variable, will allow us to gain further insight into applicant attraction because during the initial stages of recruitment our impressions of an organization are all we have to guide our decision making process.

In a similar study, Saks and Ashforth (2002) examined the impact of fit perceptions on job search behavior and career planning. The authors found that subjective P-O fit mediated the relationship between job and organizational attitudes and job search behavior. Job seekers tailor their job search behavior based on their attraction to specific organizations (Barber, 1998). Therefore, job search behavior and career planning can be seen as a proxy for applicant attraction. This finding, taken with the work of Judge and Cable (1997), supports the notion that subjective perceptions-of-fit are predictive of applicant attraction. Additionally, Judge and Cable (1997) assert that this relationship is even more important because of the role that perceptions-of-fit play in influencing job choice decisions through applicant attraction.

Prior research on fit perceptions has shown that subjective assessments of fit whether they be person-job fit or person-organization fit are greatly affected by both the amount and type of information that organizations are willing to reveal to applicants (Breaugh \& Starke, 2000; Cable \& Judge, 1996; Judge \& Cable, 1997; Kristof-Brown, Zimmerman, \& Johnson, 2005). Additionally, the amount of information and type of information that an organization is willing to reveal to applicants will likely impact a company's reputation, as well as the image that is conveyed to the general public.

Chapman et al.'s (2005) meta-analysis on applicant attraction revealed that organizational image was significantly related to both job pursuit intentions, job- 
organization attraction, and job acceptance intentions. Therefore, it is in the best interest of all organizations to invest in the creation of a positive organizational image. A positive organizational image is linked to several characteristics including a reputation of credibility, trustworthiness, honesty, empathy, trendiness, etc. (Breaugh \& Starke, 2000; Lievens \& Highhouse, 2003; Thorsteinson et al., 2004). Consequently, applicants' perceptions of an organization's personality will impact their perceptions-of-fit with that organization.

\section{Importance of P-O Fit to Organizational Performance}

It is important for organizations to understand that $\mathrm{P}-\mathrm{O}$ fit is an important issue because of the role it may play in both new and incumbent employees' success. Aside from the clear influence that $\mathrm{P}-\mathrm{O}$ fit has on employee job seeking behavior, research has also demonstrated the significance of P-O fit to a host of other desirable work related outcomes such as organizational citizenship behaviors, employee commitment, employee turnover, and job satisfaction (Arthur, Bell, Villardo, and Doverspike, 2006; Chen \& Chiu, 2008; Greguras \& Diefendorff, 2009; Resick, Baltes, \& Shantz, 2007).

Arthur et al. (2006) conducted a meta-analytic review of the P-O fit literature to determine the criterion related validity of $\mathrm{P}-\mathrm{O}$ fit as a predictor of both job performance and turnover. They found that P-O fit had a strong positive predictive value for both job performance and turnover. Specifically, across a variety of studies results indicated that individuals who displayed a higher level of fit (whether subjective or objective) performed better and displayed less turnover behavior. Furthermore, P-O fit was also shown to be predictive of work attitudes such as turnover intention, job satisfaction, and organizational commitment. P-O fit positively predicted job satisfaction and 
organizational commitment while negatively predicting turnover intentions. It was noted in that P-O fit's efficacy of a predictor of job performance and turnover may be questionable unless its relationship to work attitudes is taken into account. Hence, the translation of P-O fit's positive influence to the key organizational outcomes of job performance and employee turnover is likely mediated by work attitudes.

Testing the notion that fit may be better suited as a predictor of work attitudes, Resick et al. (2007) explored the relationship between P-O fit and job satisfaction. They found that P-O fit was particularly relevant to job satisfaction when needs-supplies (N-S) fit was low. Individuals who felt that they had a poor N-S fit with the organization were significantly less satisfied than individuals with a progressively greater sense of fit. Additionally, individuals who are high in conscientiousness and perceive a greater sense of fit displayed a significantly higher intent to accept a job offer made by the organization. Conscientiousness is a valued individual difference trait that has been repeatedly associated with positive work related outcomes (Barrick \& Mount, 1997). Instilling a greater sense of fit may have the power to sway quality applicants toward employment when they are initially undecided.

Perceptions of P-O fit have also been linked to other important work related behaviors. Chen and Chiu (2008) tested the theory that P-O fit may be a key mediator in the relationship between supervisory support and organizational citizenship behavior. They were able to show that P-O fit explained an increase in organizational citizenship behaviors (OCB) because it made employees more receptive to supervisory goals related to OCB. If employees have high value congruence with an organization, they are more willing to engage in behavior that will benefit the organization. 
Similarly, Greguras and Diefendorff (2009) tested the notion that P-O fit may influence affective organizational commitment because of its relationship to need satisfaction. They were able to demonstrate that P-O fit was strongly related to both affective organizational commitment and job performance. P-O fit directly affected these outcomes as well as competence, relatedness, and autonomy need satisfaction that were proposed mediators of the relationship. Furthermore, P-O fit was the strongest predictor of both commitment and job performance when compared to demands-abilities fit and person-group fit.

Evaluating the P-O fit of potential employees and incumbent employees can offer organizations great opportunity for professional development and improvement. Information on fit is valuable for both recruitment and selection activities as well as ongoing performance appraisal and development. P-O fit may functionally serve as the glue that binds high quality potential employees to accept jobs and keep incumbent employees satisfied and committed to organizations. As such, P-O fit and the potential impact that organizational personality may have on it is of central interest in the current research.

\section{Linking Organizational Personality and P-O Fit}

Based on the repeated findings that fit perceptions play an important role in applicant attraction (Chapman et al., 2005), and that applicants readily assign symbolic attributes to organizations that are also predictive of applicant attraction (Lievens \& Highhouse, 2003; Slaughter et al., 2002), it seems plausible that organizational personality's relationship to attraction may exist in large part because applicants are able to use personality information to better inform their fit perceptions (Gregory \& 
Viswesvaran, 2009). Fit perceptions are based on an assessment of the congruence between an individual's personality, goals, needs, desires, abilities, and those of the organization (Kristof, 1996). Organizational personality information may act as signals to applicants that allow them to make inferences about the organization (Highhouse et al., 2007). For example, if applicants believe that an organization is thrifty; this may lead applicants to compare the relative importance of thriftiness to their social identity. If thriftiness is something that an individual values and wishes to express to others as a quality that is important to him or her, then the applicant will perceive greater fit with the organization and therefore be more attracted to it. Once again, need motivation will play an important role in determining how applicants evaluate organizational personality information and formulate subjective perceptions of fit.

Need Motivation Model and P-O Fit Hypotheses

The influence of organizational personality on applicants' perceptions of fit will be tempered by their need motivations. For instance, individuals who show high achievement motivation have been found to value innovation, creativity, challenge, and mid-sized organizations (Aitken-Harris, 2004; Phillips \& Gully, 1997; Turban \& Keon, 1993). Research hypotheses concerning the relationship between need motivation and person-organization fit will be presented as follows: (a) four hypotheses on the relationship between need for achievement and person-organization fit or organizational attraction (Hypotheses 10-13); (b) six hypotheses on the relationship between need for power and person-organization fit or organizational attraction (Hypotheses 14-19); (c) six hypotheses on the relationship between need for affiliation and person-organization fit or organizational attraction (Hypotheses 20-25); and finally (d) eight hypotheses on the 
mediating role of person-organization fit in the interaction of $n A c h, n P o w, n A f f$, and ratings of organizational personality in predicting applicant attraction (Hypotheses 2633).

Hypothesis 10: nAch will moderate the relationship between organizational personality and $\mathrm{P}-\mathrm{O}$ fit such that the relationship between innovativeness ratings of organizational personality and P-O fit will be more positive for individuals high in $n A$ ch.

Hypothesis 11: nAch will moderate the relationship between organizational personality and $\mathrm{P}-\mathrm{O}$ fit such that the relationship between dominance ratings of organizational personality and $P$-O fit will be more negative for individuals high in $n$ Ach.

Hypothesis 12: nAch will moderate the relationship between innovativeness ratings of organizational personality and organizational attractiveness such that the relationship between innovativeness ratings of organizational personality and organizational attractiveness will be more positive for individuals high in $n$ Ach.

Hypothesis 13: nAch will moderate the relationship between dominance ratings of organizational personality and organizational attractiveness such that the relationship between dominance ratings of organizational personality and organizational attractiveness will be more negative for individuals high in $n$ Ach.

Research has also demonstrated that high $n$ Pow individuals value prestige, the ability to exercise power, honesty, conservatism, and assertiveness (Fodor et al., 2006; Singh, 1986; Winter et al., 1998). Hence:

Hypothesis 14: nPow will moderate the relationship between dominance ratings of organizational personality and $\mathrm{P}-\mathrm{O}$ fit such that the relationship between dominance 
ratings of organizational personality and $\mathrm{P}-\mathrm{O}$ fit will be more positive for individuals high in nPow.

Hypothesis 15: nPow will moderate the relationship between stylishness ratings of organizational personality and $\mathrm{P}-\mathrm{O}$ fit such that the relationship between stylishness ratings of organizational personality and $P-O$ fit will be more positive for individuals high in nPow.

Hypothesis 16: nPow will moderate the relationship between thriftiness ratings of organizational personality and $P-O$ fit such that the relationship between thriftiness ratings of organizational personality and $\mathrm{P}-\mathrm{O}$ fit will be more negative for individuals high in nPow.

Hypothesis 17: nPow will moderate the relationship between dominance ratings of organizational personality and organizational attractiveness such that the relationship between dominance ratings of organizational personality and organizational attractiveness will be more positive for individuals high in nPow.

Hypothesis 18: nPow will moderate the relationship between stylishness ratings of organizational personality and organizational attractiveness such that the relationship between stylishness ratings of organizational personality and organizational attractiveness will be more positive for individuals high in nPow.

Hypothesis 19: nPow will moderate the relationship between thriftiness ratings of organizational personality and organizational attractiveness such that the relationship between thriftiness ratings of organizational personality and organizational attractiveness will be more negative for individuals high in nPow. 
Additionally, the need for affiliation has been found to be an important motivation in decision making and determining values (Harrell \& Stahl, 1981). High $n$ Aff individuals value social esteem, prestige, social concern, and supportiveness (Wiesenfeld et al., 2001; Winter et al., 1998). Hence:

Hypothesis 20: nAff will moderate the relationship between boy scoutishness ratings of organizational personality and $\mathrm{P}-\mathrm{O}$ fit such that the relationship between boy scoutishness ratings of organizational personality and $P$-O fit will be more positive for individuals high in $n$ Aff.

Hypothesis 21: nAff will moderate the relationship between stylishness ratings of organizational personality and P-O fit such that the relationship between stylishness ratings of organizational personality and $\mathrm{P}-\mathrm{O}$ fit will be more positive for individuals high in nAff.

Hypothesis 22: nAff will moderate the relationship between thriftiness ratings of organizational personality and P-O fit such that the relationship between thriftiness ratings of organizational personality and $P$-O fit will be more negative for individuals high in nAff.

Hypothesis 23: nAff will moderate the relationship between boy scoutishness ratings of organizational personality and organizational attractiveness such that the relationship between boy scoutishness ratings of organizational personality and organizational attractiveness will be more positive for individuals high in nAff.

Hypothesis 24: nAff will moderate the relationship between stylishness ratings of organizational personality and organizational attractiveness such that the relationship 
between stylishness ratings of organizational personality and organizational attractiveness will be more positive for individuals high in nAff.

Hypothesis 25: nAff will moderate the relationship between thriftiness ratings of organizational personality and organizational attractiveness such that the relationship between thriftiness ratings of organizational personality and organizational attractiveness will be more negative for individuals high in nAff.

Chapman et al. (2005) demonstrated the importance of P-O fit perceptions to applicant attraction for organizations. P-O fit is predicated on the ability of individuals to compare their traits, values, and goals with those of the organization. Therefore, information that describes the personality of an organization will influence applicant attraction because it allows individuals to make more accurate assessments of their P-O fit. Hence:

Hypothesis 26: P-O fit will mediate the relationship between the interaction of innovativeness ratings of organizational personality and nAch in predicting applicant attraction.

Hypothesis 27: P-O fit will mediate the relationship between the interaction of dominance ratings of organizational personality and $n$ Ach in predicting applicant attraction.

Hypothesis 28: P-O fit will mediate the relationship between the interaction of dominance ratings of organizational personality and nPow in predicting applicant attraction. 
Hypothesis 29: P-O fit will mediate the relationship between the interaction of stylishness ratings of organizational personality and nPow in predicting applicant attraction.

Hypothesis 30: P-O fit will mediate the relationship between the interaction of thriftiness ratings of organizational personality and nPow in predicting applicant attraction.

Hypothesis 31: P-O fit will mediate the relationship between the interaction of boy scoutishness ratings of organizational personality and nAff in predicting applicant attraction.

Hypothesis 32: P-O fit will mediate the relationship between the interaction of stylishness ratings of organizational personality and nAff in predicting applicant attraction.

Hypothesis 33: P-O fit will mediate the relationship between the interaction of thriftiness ratings of organizational personality and nAff in predicting applicant attraction.

The present research was motivated by a need for greater understanding of the mechanisms underlying individuals' reactions to organizational personality as communicated through organizational recruitment activities. The relevance of both need motivation and valence, instrumentality, and expectancy beliefs to the processing of organizational personality information was examined as a predictor of individuals' subjective perceptions of fit and organizational attraction. Additionally, a model of organizational attraction that is based solely on valence, instrumentality, expectancy 
beliefs driven by organizational personality perceptions is also evaluated. 
Figure 1. Need Motivation Research Model

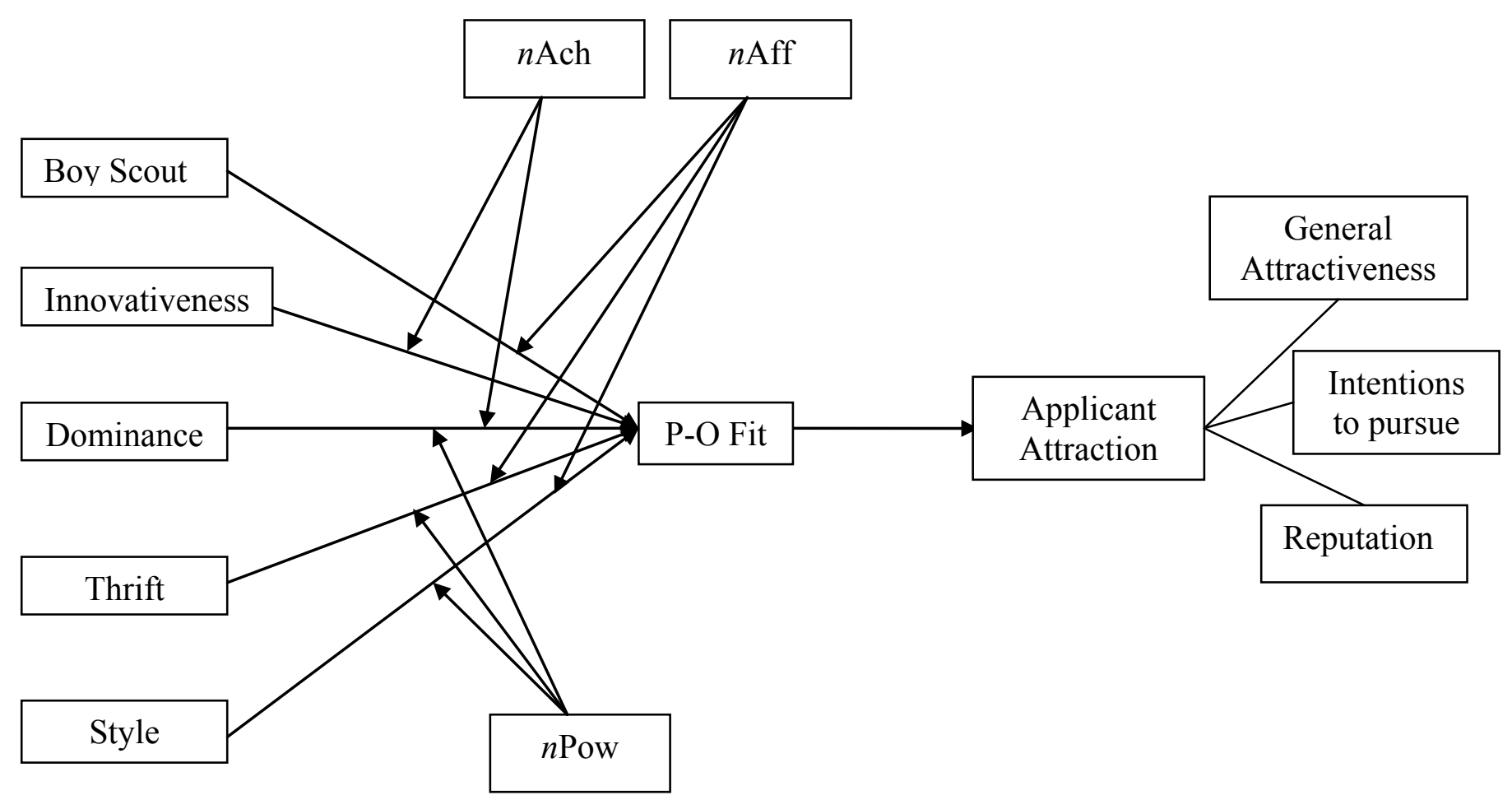




\section{Chapter III: Method}

\section{Participants}

Participants included two hundred undergraduate psychology students from a large southeastern university and two hundred working adults. Undergraduate students participated as part of an online psychology research pool. Among students, the average age was $20, \mathrm{SD}=3.84$. The majority of student participants were female (68\%), Latino (70\%), and unemployed job seekers (44\%) or working part-time (42\%). In return for their participation, student participants received course research credit.

Working adults were sampled using a snowball convenience sampling approach using social media such as Facebook.com, online newsletters, and email requests through business and personal contacts. All participants in the working adult sample had to be currently working full-time, part-time, or actively seeking employment. Among working adults, the average age was $37, \mathrm{SD}=11.82$. The majority of working adults were female $(59 \%)$, Caucasian (65\%), and working full time (80\%). Working adults volunteered to participate in the study and received no compensation other than the researcher's gratitude.

\section{Procedure}

The study was conducted online. Participants were asked to participate in a study that involved a simulation of the job hunt/choice process. All subjects were randomly assigned to one of five experimental conditions (typically Boy Scout organization profile, Dominance organization profile, Innovativeness organization profile, Style organization profile, and Thrift organization profile). All participants were told to consider the type of organization that they would like to work for ideally regardless of their current work 
status. The participants were then informed that they would be presented with an organization's profile describing the organization's mission statement and ideology. Participants were asked to read the description carefully and then answer the questions that follow concerning their impressions of the organization (organizational personality scale), the type of factors that they believe affect their personal job choice decisions (need motivation scale), their expectations about working with the organization (expectancy, instrumentality, and valence measures), whether they believed they would fit in working at the organization they read about (P-O fit scale) and how interested they would be in seeking employment with the organization that was described (applicant attraction scales).

Organizational Personality Profiles. The organizational personality profiles were developed during pre-study pilot testing. Pilot subjects $(\mathrm{N}=91)$ were presented with a list of Fortune magazine's 2008 top 100 list plus 1 fictitious organization ("Dandy Toys") and asked to indicate for each organization whether they recognized the name of the organization (check yes or no) and to rate their familiarity with the organization $(1=$ very unfamiliar to $5=$ very familiar). Organizations were then retained for organizational profile development if there was $90 \%$ recognition, mean familiarity ratings of greater than 4.25 (out of possible 5) and nationwide presence (Slaughter et al., 2004). These selection criteria produced thirty organizations (See Appendix 1) to be considered for profile development organizations.

The thirty organizations that remained were then presented to a second group of pilot subjects $(\mathrm{N}=301)$ who were asked to complete Slaughter et al.'s (2004) organizational personality scale $(\mathrm{n}=33$ items). Participants in the second pilot were 
randomly assigned to rate one of the remaining organizations on traits related to Boy Scout $(\alpha=.89)$, Dominance $(\alpha=.76)$, Innovativeness $(\alpha=.86)$, Thrift $(\alpha=.78)$, and Style $(\alpha=.88)$. Each organization was rated by an average of ten $(\mathrm{N}=10.03)$ raters with a minimum of six and maximum of fifteen raters. Based on the results of this study, the organizations were ranked in each organizational personality factor to determine which organizations to select as a prototypical Boy Scout organization, Dominance organization, Innovativeness organization, Thrift organization, and Style organization. Organizations were selected as the prototype for a particular personality dimension if their score on that dimension was in the top five averages for that dimension and no other dimension. For instance, even though Apple was rated as the most stylish organization by the pilot group, it was also in the top five for boy scoutishness, innovativeness, and dominance. Therefore, Apple was not retained for profile development. Instead, Verizon was selected as the prototype for stylishness because it was the second highest rated organization in terms of style and did not rank in the top five on any other personality dimension (See Appendix 2). The goal of this procedure was to ensure that organizations were selected that would allow for variability in the organizational personality ratings of the final study samples. In order to develop the organizational profiles for each of the prototype organizations, the corporate websites of each of the five prototype organizations were visited to find information on (a) the company's mission statement, (b) corporate goals, and (c) business philosophy. From this search, a single page profile was developed for using information that was taken from each organization's site verbatim (See Appendix 3-7). 
Participants in the final samples were randomly assigned to one of the five organizational personality profiles. Each profile was labeled with the name of the organization and presented the same information about the organization as was presented in the final pilot. Participants' ratings of organizational personality for the final student and adult samples were also used as a manipulation check to ensure that organizational personality ratings varied freely across profiles. Also, no a priori hypotheses were made concerning expected differences between student and working adult participants.

\section{Measures}

Demographics. All participants provided background information at the conclusion of the study. Demographic information included participants' age, gender, ethnicity, marital status, employment status, educational level, and when applicable GPA, and class year (Appendix 8).

Person-Organization (P-O) Fit. Subjective perceptions of person-organization fit were assessed using a 4 -item scale ( $\alpha=.85$ for students and $\alpha=.86$ for working adults) developed by Saks and Ashforth (2002). Participants responded using a 5-point Likerttype scale with anchors from $1=$ strongly disagree to $5=$ strongly agree. The scale includes items such as "To what extent are the values of the organization similar to your own values" and "To what extent does your personality match the personality or image of the organization.” (Appendix 9)

Organizational Personality. Organizational personality was measured using Slaughter et al.'s (2004) 33-item organizational personality scale. Participants rated the extent to which each of 33 trait adjectives described the organization in the profile that 
they were assigned to read on a 5 -point scale of agreement $(1=$ Strongly Disagree to $5=$ Strongly Agree). Items included, "Cooperative, Friendly, Low class, etc. " (Appendix 10) Applicant Attraction (OA). Applicant attraction was measured using three scales adapted from a validity study by Highhouse, Lievens, \& Sinar (2003). Participants rated the organization they were randomly assigned to with respect to their attraction to the company as a place to work (five-item scale) (e.g., "This company is attractive to me as a place for employment," $\alpha=.90$ for students and $\alpha=.93$ for working adults), their future intentions toward the company (five-item scale) (e.g., "I would exert a great deal of effort to work for this company," $\alpha=.87$ for students and $\alpha=.82$ for working adults), and their perceptions of the organization's reputation as a place to work (five-item scale) (e.g., "This is a reputable company to work for," $\alpha=.86$ for students and $\alpha=.86$ for working adults). All responses were made using a 5-point Likert-type scale of agreement $(1=$ Strongly Disagree to 5 = Strongly Agree) (Appendix 11).

Expectancy (E) Beliefs. Participants' expectancies about joining the organization were measured using a three item scale ( $\alpha=.87$ for students and $\alpha=.95$ for working adults) developed for this project by the author. Participants were asked to indicate the likelihood that they would be offered a job if they apply with the organization presented in their profile. Participants were also asked to indicate the likelihood that they would be offered a job by the organization if they decided it was a place they would like to work. Finally, participants were asked to indicate the likelihood that they would obtain employment with the organization if they made an effort to gain employment with the organization. All responses were made using a scale of 1 to $7(1=$ no chance at all, and 7 = extremely good chance) (Appendix 12). 
Instrumentality (I) Beliefs. The instrumentality of outcomes associated with each organization was measured using a twelve item scale $(\alpha=.91$ for students and $\alpha=.87$ for working adults) developed by the author. Participants indicated whether they felt the following work related outcomes would be characteristic of working for the organization that they read about: (1) prestige, (2) opportunities for advancement, (3) flexibility in practices, (4) challenging work, (5) a good salary, (6) job security, (7) chance to use creative abilities, (8) intellectual stimulation, (9) ability to help others, (10) warmth, (11) good benefits, and (12) honesty in business practices. Responses were made on a six point Likert-type scale $(1=$ very uncharacteristic to $6=$ very characteristic $)($ Appendix $13)$.

Valence (V) Beliefs. The valence of outcomes associated with each organization was measured using twelve items. Participants were asked to indicate how important they feel being able to attain each of the following work related outcomes are in deciding if they would work for an organization: (1) prestige, (2) opportunities for advancement, (3) flexibility in practices, (4) challenging work, (5) a good salary, (6) job security, (7) chance to use creative abilities, (8) intellectual stimulation, (9) ability to help others, (10) warmth, (11) good benefits, and (12) honesty in business practices. Participants made a forced ranking of the twelve work related outcomes importance to their job decisions $(1=$ most important to 12 = least important) (Appendix 14). Reliability was not assessed for these items since forced rankings allowed for zero variance in the scale scores. Valence was assessed for each outcome based on the averaged ranking of that outcome across individuals. 
Need Motivation. $n$ Ach, $n$ Pow, and $n$ Aff were measured using the achievement ( $\alpha=.59$ for students and $\alpha=.56$ for working adults), dominance ( $\alpha=.79$ for students and $\alpha=.84$ for working adults), and affiliation ( $\alpha=.70$ for students and $\alpha=.83$ for working adults) portions of the Personality Research Form (PRF). The PRF is a highly reliable and extensively validated measure that has been used as measure of explicit need motives in several prior studies (Mayer, Faber, \& Xu, 2007; McClelland, Koestner, \& Weinberger, 1989; Turban \& Keon, 1993; Wiesenfeld et al., 2001). Each scale consisted of 16 items ( 8 positively related to need motive and 8 negatively related to the need motive) that participants responded to by indicating whether they felt each statement was true or false in regards to their own behavior. For instance, "I seldom set standards which are difficult for me to reach." Positive items are scored if a participant indicates true while negative items are scored if a participant indicates false. This allows for a maximum score of sixteen on each scale where higher scores indicate a greater need for each motive (Jackson, 1974; these items could not be included in appendices due to copyright restrictions).

Statistical Power and Sample Size Considerations. To determine an appropriate sample size, a power analysis was conducted prior to the study using GPOWER software (Erdfelder, Faul, \& Buchner, 1996). Using an estimated medium effect size of $r=.10, d=$ .20 (Cohen, 1988) for all paths (organizational personality dimensions, need motivation dimensions, and applicant fit perceptions) on our dependent measure (applicant attraction), with 5 experimental conditions, an alpha level of .05, and target power of .90 the appropriate number of participants to include in analyses was approximately four hundred (two hundred students and two hundred working adults). 
Missing Data. The final data set was checked for respondents with missing data. There were a total of 4 participants ( 2 students, 2 working adults) that were removed from consideration in the final analyses because they completed less than $50 \%$ of the survey scales. All other participants completed $100 \%$ of the survey scales. This left a final sample size of $\mathrm{N}=198$ students and $\mathrm{N}=198$ working adults. 


\section{Chapter IV: Results}

Prior to testing research hypotheses, five 2 (rater type - students vs. working adults) x 5 (organization - American Express, Chevron, Coca Cola, Home Depot, and Verizon) univariate analyses of variance (ANOVA) were conducted to determine whether students and working adults differed in their perceptions of organizational personality across the organizations. The five dependent variables assessed were individuals' ratings of the boy scoutishness, dominance, innovativeness, stylishness, and thriftiness of each organization. It would be expected that only the organization that individuals received should affect their organizational personality ratings. Differences between students and working adults would indicate systematic differences in the way each group reacted to the organizational profile and therefore warrant separate hypothesis testing.

As expected, there was a main effect for organization on perceptions of organizational personality (See Tables 1-5). Individuals consistently perceived differences in the organizational personality of each organization. This finding supports the validity of the manipulation of organizational personality in the organizational profiles. Unexpectedly, students and working adults significantly differed in their perceptions of boy scoutishness $(\mathrm{F}(1,4)=25.43, \mathrm{p}<.01)$ (See Table 1$)$, thriftiness $(\mathrm{F}(1$, $4)=8.41, p<.01)($ See Table 4$)$, and stylishness $(F(1,4)=12.88, p<.01)($ See Table 5$)$. Post hoc mean comparisons revealed that students perceived Chevron, Coca Cola, and Verizon as being more boy scoutish than adults did. Also, students' ratings of thriftiness were consistently higher than those of working adults. Finally, students rated Chevron, Coca Cola, and Verizon as significantly more stylish than did working adults. Because of 
these observed differences in organizational personality perceptions, all further analyses were conducted separately for students and working adults.

It should be noted that for all further analyses involving attraction ratings, the general attraction scale was used as the criterion measure. This scale was selected because the intercorrelations of the reputation, intentions to pursue employment, and general attraction scales were very high ( $\mathrm{r}$ 's $>.60$ in most cases for both students and working adults). Therefore, it seemed redundant to conduct analyses separately for each scale. A correlation matrix is presented in Appendix 15 that displays the Pearson correlations between the three attraction measures and all 12 of the work related outcomes of the instrumentality measure as evidence of the similarity and interchangeability of the three attraction measures.

Additionally, applicant quality was assessed as a possible covariate in preliminary analyses by using GPA and SAT scores as proxies of applicant quality in the student sample. There was no significant relationship between GPA and valence rankings for desirable workplace outcomes with the exception of (job security and chance to use creative abilities) (Appendix 16). The highest quality students $(\mathrm{GPA}>3.5, \mathrm{~N}=60)$ had a significantly higher average value rank for security than either mid-quality (GPA 3.0$3.49, \mathrm{~N}-82$ ) or lowest-quality (GPA $<2.99, \mathrm{~N}=55)$ students indicating that the highestquality students were less concerned with job security. Conversely, the lowest-quality students had a significantly higher value ranking for chance to use creative abilities than the highest-quality students indicating that the highest-quality students valued chances to use their creative abilities more than the lowest-quality students. In general, these findings provide limited evidence for a systematic difference in the values of high quality 
applicants. Also, there were no significant correlations between valence ratings of desirable work related outcomes and SAT score of students (Appendix 17). Taken together these findings indicate that students valued work related outcomes similarly regardless of their quality as an applicant. 
Table 1.

Univariate Analysis of Variance Comparing Students and Working Adults Mean Ratings of Boy Scoutishness.

\begin{tabular}{|c|c|c|c|c|c|c|c|c|c|c|c|c|c|}
\hline \multirow[t]{2}{*}{ Factor } & \multirow[t]{2}{*}{$\mathbf{F}$} & \multirow[t]{2}{*}{ df } & \multirow[t]{2}{*}{$\mathbf{p}$} & \multirow[t]{2}{*}{ Organization } & \multicolumn{3}{|c|}{ Students } & \multicolumn{3}{|c|}{ Adults } & \multicolumn{3}{|c|}{ Total } \\
\hline & & & & & $\mathrm{N}$ & $\mathrm{M}$ & SD & $\mathrm{N}$ & $\mathrm{M}$ & $\mathrm{SD}$ & $\mathrm{N}$ & $\mathrm{M}$ & SD \\
\hline Rater Type & 25.43 & 1 & $<.01$ & Amex & 30 & 33.10 & 7.32 & 40 & 31.38 & 5.67 & 70 & 32.11 & 6.44 \\
\hline Organization & 10.24 & 4 & $<.01$ & Chevron & 41 & 30.68 & 7.54 & 40 & 26.73 & 7.98 & 81 & 28.73 & 7.97 \\
\hline \multirow[t]{4}{*}{ Interaction } & 4.50 & 4 & $<.01$ & Coca Cola & 38 & 34.16 & 5.75 & 40 & 27.05 & 5.72 & 78 & 30.51 & 6.73 \\
\hline & & & & Home Depot & 49 & 34.12 & 6.30 & 38 & 35.11 & 5.00 & 87 & 34.55 & 5.75 \\
\hline & & & & Verizon & 40 & 36.05 & 5.16 & 40 & 30.95 & 8.81 & 80 & 33.50 & 7.62 \\
\hline & & & & Total & 198 & 33.65 & 6.62 & 198 & 30.19 & 7.42 & 396 & 31.92 & 7.23 \\
\hline
\end{tabular}

Table 2.

Univariate Analysis of Variance Comparing Students and Working Adults Mean Ratings of Innovativeness.

\begin{tabular}{|c|c|c|c|c|c|c|c|c|c|c|c|c|c|}
\hline \multirow[t]{2}{*}{ Factor } & \multirow[t]{2}{*}{$\mathbf{F}$} & \multirow[t]{2}{*}{ df } & \multirow[t]{2}{*}{$\mathbf{p}$} & \multirow[t]{2}{*}{ Organization } & \multicolumn{3}{|c|}{ Students } & \multicolumn{3}{|c|}{ Adults } & \multicolumn{3}{|c|}{ Total } \\
\hline & & & & & $\mathrm{N}$ & $\mathrm{M}$ & SD & $\mathrm{N}$ & $\mathrm{M}$ & SD & $\mathrm{N}$ & $\mathrm{M}$ & $\mathrm{SD}$ \\
\hline Rater Type & 2.91 & 1 & .09 & Amex & 30 & 23.00 & 5.28 & 40 & 23.23 & 5.26 & 70 & 23.13 & 5.24 \\
\hline Organization & 12.10 & 4 & $<.01$ & Chevron & 41 & 22.46 & 5.80 & 40 & 20.35 & 6.06 & 81 & 21.42 & 5.99 \\
\hline \multirow[t]{4}{*}{ Interaction } & .83 & 4 & .51 & Coca Cola & 38 & 27.53 & 4.16 & 40 & 25.85 & 5.54 & 78 & 26.67 & 4.96 \\
\hline & & & & Home Depot & 49 & 22.73 & 3.97 & 38 & 22.79 & 4.03 & 87 & 22.76 & 3.97 \\
\hline & & & & Verizon & 40 & 24.05 & 4.36 & 40 & 23.25 & 5.09 & 80 & 23.65 & 4.73 \\
\hline & & & & Total & 198 & 23.90 & 5.02 & 198 & 23.10 & 5.49 & 396 & 23.50 & 5.27 \\
\hline
\end{tabular}


Table 3.

Univariate Analysis of Variance Comparing Students and Working Adults Mean Ratings of Dominance.

\begin{tabular}{|c|c|c|c|c|c|c|c|c|c|c|c|c|c|}
\hline \multirow[t]{2}{*}{ Factor } & \multirow[t]{2}{*}{$\mathbf{F}$} & \multirow[t]{2}{*}{ df } & \multirow[t]{2}{*}{$\mathbf{p}$} & \multirow[t]{2}{*}{ Organization } & \multicolumn{3}{|c|}{ Students } & \multicolumn{3}{|c|}{ Adults } & \multicolumn{3}{|c|}{ Total } \\
\hline & & & & & $\mathrm{N}$ & $\mathrm{M}$ & SD & $\mathrm{N}$ & $\mathrm{M}$ & SD & $\mathrm{N}$ & $\mathrm{M}$ & SD \\
\hline Rater Type & .679 & 1 & .41 & Amex & 30 & 20.23 & 3.63 & 30 & 19.13 & 2.93 & 30 & 19.60 & 3.27 \\
\hline Organization & 10.68 & 4 & $<.01$ & Chevron & 41 & 18.44 & 3.17 & 41 & 17.15 & 3.34 & 41 & 17.80 & 3.30 \\
\hline \multirow[t]{4}{*}{ Interaction } & 1.41 & 4 & .239 & Coca Cola & 38 & 20.55 & 3.05 & 38 & 20.75 & 3.61 & 38 & 20.65 & 3.33 \\
\hline & & & & Home Depot & 49 & 17.88 & 3.43 & 49 & 18.37 & 2.76 & 49 & 18.09 & 3.15 \\
\hline & & & & Verizon & 40 & 19.23 & 2.66 & 40 & 19.60 & 3.32 & 40 & 19.41 & 3.00 \\
\hline & & & & Total & 198 & 19.14 & 3.33 & 198 & 19.01 & 3.40 & 198 & 19.07 & 3.36 \\
\hline
\end{tabular}

Table 4.

Univariate Analysis of Variance Comparing Students and Working Adults Mean Ratings of Thriftiness.

\begin{tabular}{|c|c|c|c|c|c|c|c|c|c|c|c|c|c|}
\hline \multirow[t]{2}{*}{ Factor } & \multirow[t]{2}{*}{$\mathbf{F}$} & \multirow[t]{2}{*}{ df } & \multirow[t]{2}{*}{$\mathbf{p}$} & \multirow[t]{2}{*}{ Organization } & \multicolumn{3}{|c|}{ Students } & \multicolumn{3}{|c|}{ Adults } & \multicolumn{3}{|c|}{ Total } \\
\hline & & & & & $\mathrm{N}$ & $\mathrm{M}$ & SD & $\mathrm{N}$ & $\mathrm{M}$ & SD & $\mathrm{N}$ & $\mathrm{M}$ & $\mathrm{SD}$ \\
\hline Rater Type & 8.41 & 1 & $<.01$ & Amex & 30 & 14.00 & 5.28 & 30 & 11.20 & 4.70 & 30 & 12.40 & 5.11 \\
\hline Organization & 4.81 & 4 & $<.01$ & Chevron & 41 & 15.44 & 5.42 & 41 & 15.73 & 5.98 & 41 & 15.58 & 5.67 \\
\hline \multirow[t]{4}{*}{ Interaction } & 1.42 & 4 & .23 & Coca Cola & 38 & 14.71 & 4.82 & 38 & 13.20 & 6.83 & 38 & 13.94 & 5.95 \\
\hline & & & & Home Depot & 49 & 16.39 & 6.16 & 49 & 15.68 & 3.40 & 49 & 16.08 & 5.13 \\
\hline & & & & Verizon & 40 & 16.65 & 5.68 & 40 & 13.40 & 5.05 & 40 & 15.03 & 5.58 \\
\hline & & & & Total & 198 & 15.56 & 5.57 & 198 & 13.82 & 5.55 & 198 & 14.69 & 5.62 \\
\hline
\end{tabular}


Table 5.

Univariate Analysis of Variance Comparing Students and Working Adults Mean Ratings of Stylishness.

\begin{tabular}{|c|c|c|c|c|c|c|c|c|c|c|c|c|c|}
\hline \multirow[t]{2}{*}{ Factor } & \multirow[t]{2}{*}{$\mathbf{F}$} & \multirow[t]{2}{*}{ df } & \multirow[t]{2}{*}{$\mathbf{p}$} & \multirow[t]{2}{*}{ Organization } & \multicolumn{3}{|c|}{ Students } & \multicolumn{3}{|c|}{ Adults } & \multicolumn{3}{|c|}{ Total } \\
\hline & & & & & $\mathrm{N}$ & $\mathrm{M}$ & SD & $\mathrm{N}$ & $\mathrm{M}$ & SD & $\mathrm{N}$ & $\mathrm{M}$ & SD \\
\hline Rater Type & 12.88 & 1 & $<.01$ & Amex & 30 & 11.30 & 3.69 & 30 & 11.63 & 3.85 & 30 & 11.49 & 3.76 \\
\hline Organization & 33.07 & 4 & $<.01$ & Chevron & 41 & 9.56 & 3.29 & 41 & 7.80 & 3.24 & 41 & 8.69 & 3.36 \\
\hline Interaction & 2.82 & 4 & .03 & Coca Cola & 38 & 15.18 & 2.76 & 38 & 12.65 & 3.75 & 38 & 13.88 & 3.52 \\
\hline & & & & Home Depot & 49 & 9.06 & 4.06 & 49 & 9.05 & 2.80 & 49 & 9.06 & 3.55 \\
\hline & & & & Verizon & 40 & 13.58 & 3.81 & 40 & 11.25 & 3.07 & 40 & 12.41 & 3.63 \\
\hline & & & & Total & 198 & 11.59 & 4.27 & 198 & 10.49 & 3.78 & 198 & 11.04 & 4.07 \\
\hline
\end{tabular}




\section{Comparison of Motivation Models}

Hypothesis 1 was tested by comparing the changes in variance explained $\left(\Delta R^{2}\right)$ between several regression models for several alternatives of the valence-instrumentalityexpectancy (VIE) model. The most predictive model was expected to be the model that accounted for the greatest percent of variance explained in organizational attractiveness (OA) ratings. Three models were compared: $\mathrm{OA}=\mathrm{E}(\Sigma \mathrm{IV}), \mathrm{OA}=\Sigma \mathrm{I}$ and $\mathrm{OA}=\Sigma \mathrm{IV}$.

Among students, hypothesis 1 was not supported. A weighted model that considers valence ratings, instrumentality ratings, and expectancy ratings $(\mathrm{OA}=\mathrm{E}(\Sigma$ IV)) was not more predictive of individuals' organizational attractiveness ratings than a partial model (e.g., OA $=\Sigma \mathrm{I}, \mathrm{OA}=\Sigma \mathrm{IV})($ See Table 6). For students, the model that best predicted organizational attractiveness ratings was the partial model $\mathrm{OA}=\Sigma \mathrm{I}$. This model accounted for $25 \%$ of the variance in students' attractiveness ratings compared to only $14 \%$ in a weighted model $(\mathrm{OA}=\mathrm{E}(\Sigma \mathrm{IV})$ and $23 \%$ in the partial model $\mathrm{OA}=(\Sigma \mathrm{IV})$.

Among working adults, hypothesis 1 was partially supported. A weighted model that considers valence ratings, instrumentality ratings, and expectancy ratings $(\mathrm{OA}=\mathrm{E}(\Sigma$ IV)) was more predictive of individuals' organizational attractiveness ratings than a partial model (e.g., $\mathrm{OA}=\Sigma \mathrm{I}, \mathrm{OA}=\Sigma \mathrm{IV})$. The weighted model OA $=\mathrm{E}(\Sigma \mathrm{IV})$ accounted for $30 \%$ of variance explained among working adults' ratings. However, the partial model $\mathrm{OA}=\Sigma \mathrm{I}$ also accounted for $30 \%$ of the variance explained among working adults' attractiveness ratings while the model $\mathrm{OA}=(\Sigma \mathrm{IV})$ accounted for only $22 \%$ of the variance explained. 
Table 6.

Comparison of the Predictive Strength of Valence-Instrumentality-Expectancy Regression Models for Students and Working Adults

\begin{tabular}{llccccc}
\hline Model & Predictor & M & SD & Beta & p & $\mathbf{R}^{\mathbf{2}}$ \\
\hline Students & & & & & & \\
$\mathrm{OA}=\mathrm{E}(\Sigma \mathrm{IV})$ & $\mathrm{E}(\Sigma \mathrm{IV})$ & 4318.14 & 1862.66 & .001 & $<.01$ & .14 \\
$\mathrm{OA}=\Sigma \mathrm{I}$ & $\Sigma \mathrm{I}$ & 49.52 & 11.21 & .24 & $<.01$ & .25 \\
$\mathrm{OA}=\Sigma \mathrm{IV}$ & $\Sigma \mathrm{IV}$ & 316.57 & 72.87 & .04 & $<.01$ & .23 \\
& & & & & & \\
\hline Working Adults & & & & & & \\
$\mathrm{OA}=\mathrm{E}(\Sigma \mathrm{IV})$ & $\mathrm{E}(\Sigma \mathrm{IV})$ & 4174.62 & 1853.64 & .002 & $<.01$ & .30 \\
$\mathrm{OA}=\Sigma \mathrm{I}$ & $\Sigma \mathrm{I}$ & 45.57 & 10.19 & .29 & $<.01$ & .30 \\
$\mathrm{OA}=\Sigma \mathrm{IV}$ & $\Sigma \mathrm{IV}$ & 289.68 & 64.67 & .04 & $<.01$ & .22 \\
& & & & & & \\
\hline
\end{tabular}

Incremental Variance of VIE Models

The incremental variance of VIE models was also tested to determine the significance of each predictor mentioned above. To test for incremental variance, the change in $\mathrm{R}^{2}\left(\Delta \mathrm{R}^{2}\right)$ was calculated for regression models for both students and working adults that included just $\Sigma \mathrm{I}, \Sigma \mathrm{IV}, \mathrm{E}(\Sigma \mathrm{IV})$, or a combination of two of those predictors, or all three predictors (e.g., $\mathrm{OA}=\Sigma \mathrm{I}$ vs. $\mathrm{OA}=\Sigma \mathrm{I}+\Sigma \mathrm{IV}$, or $\mathrm{OA}=\Sigma \mathrm{I}+\Sigma \mathrm{IV}+\mathrm{E}(\Sigma \mathrm{IV})$ ). The results of these analyses are presented in Tables 7 and 8. Among students, there was no incremental variance in the prediction of organizational attraction beyond a model with only the sum of instrumentalities $(\Sigma \mathrm{I})$. Additionally, $\Sigma \mathrm{I}$ was the only significant predictor in each regression model tested. Therefore, students, instrumentality beliefs best accounted for differences in their organizational attraction, compared to a model including valence or expectancy beliefs. 
Table 7.

Comparison of the Incremental Variance Explained by Competing VIE Regression Models for Students

\begin{tabular}{lccccc}
\hline Model & Predictor & Beta & $\mathbf{p}$ & $\mathbf{R}^{\mathbf{2}}$ & $\Delta \mathbf{R}^{\mathbf{2}}$ \\
\hline 1. $\mathrm{OA}=\Sigma \mathrm{I}$ & Constant & 4.40 & $<.01$ & .251 & -- \\
& $\Sigma \mathrm{I}$ & .237 & $<.01$ & & \\
\hline 2. $\mathrm{OA}=\Sigma \mathrm{I}+\Sigma \mathrm{IV}$ & Constant & 4.43 & $<.01$ & .253 & $.002^{\text {ns }}$ \\
& $\Sigma \mathrm{I}$ & .34 & .02 & & \\
& $\Sigma \mathrm{IV}$ & -.02 & $.45^{\text {ns }}$ & & \\
\hline 3. $\mathrm{OA}=\Sigma \mathrm{I}+\Sigma \mathrm{IV}+\mathrm{E}(\Sigma \mathrm{IV})$ & Constant & 4.74 & $<.01$ & .258 & $.005^{\text {ns }}$ \\
& $\Sigma \mathrm{I}$ & .33 & .02 & & \\
& $\Sigma \mathrm{IV}$ & -.02 & $.38^{\text {ns }}$ & & \\
& $\mathrm{E}(\Sigma \mathrm{IV})$ & $<.01$ & $.27^{\mathrm{ns}}$ & & \\
\hline
\end{tabular}

Conversely, working adults' organizational attraction was best predicted by a model that included their valence, instrumentality, and expectancy beliefs. There was significant incremental variance observed when instrumentality beliefs were coupled with valence, and then valence and expectancy beliefs. This finding supports traditional expectancy theory and demonstrates that working adults' may better incorporate their valence and expectancy beliefs into determining their organizational preferences and job choice behavior.

Table 8.

Comparison of the Incremental Variance Explained by Competing VIE Regression Models for Working Adults

\begin{tabular}{lccccc}
\hline Model & Predictor & Beta & $\mathbf{p}$ & $\mathbf{R}^{\mathbf{2}}$ & $\Delta \mathbf{R}^{\mathbf{2}}$ \\
\hline $1 . \quad \mathrm{OA}=\Sigma \mathrm{I}$ & Constant & 3.35 & .02 & .300 & -- \\
& $\Sigma \mathrm{I}$ & .29 & $<.01$ & & \\
\hline 2. $\mathrm{OA}=\Sigma \mathrm{I}+\Sigma \mathrm{IV}$ & Constant & 4.11 & $<.01$ & .356 & $.055^{* *}$ \\
& $\Sigma \mathrm{I}$ & .76 & $<.01$ & & \\
& $\Sigma \mathrm{IV}$ & -.08 & $<.01$ & & \\
\hline
\end{tabular}




\begin{tabular}{cccccc}
\hline 3. $\mathrm{OA}=\Sigma \mathrm{I}+\Sigma \mathrm{IV}+\mathrm{E}(\Sigma \mathrm{IV})$ & Constant & 5.94 & $<.01$ & .427 & $.071^{* *}$ \\
& $\Sigma \mathrm{I}$ & .71 & $<.01$ & & \\
& $\Sigma \mathrm{IV}$ & -.09 & $<.01$ & & \\
& $\mathrm{E}(\Sigma \mathrm{IV})$ & $<.01$ & $<.01$ & & \\
& & & & & \\
\hline
\end{tabular}

**Significant at $\mathrm{p}<.01$ level

Bivariate Hypothesized Relationships

Hypotheses 2-9 were assessed using bivariate correlations and simple linear regression.

Hypothesis 2. Among student participants, hypothesis 2 was partially supported. Students' ratings of boy scoutishness were significantly positively correlated to instrumentality ratings of warmth, ability to help others, good benefits, security, and honesty in business practices outcomes (See Table 9). Additionally, students' boy scoutishness ratings were significantly correlated to instrumentality ratings for all other desirable work correlated outcomes. However, when all instrumentality beliefs were included in a regression to predict boy scoutishness ratings, only ability to help others and honesty in business practices were significant predictors (See Table 10).

Among working adults, hypothesis 2 was partially supported. Working adults' boy scoutishness ratings of organizational personality were significantly positively correlated to instrumentality ratings of warmth, ability to help others, good benefits, security, and honesty in business practices outcomes (See Table 11). Unlike students, working adults' boy scoutishness ratings were only correlated to two additional desirable work outcomes: flexibility in practices and opportunity for advancement. Working adults ratings of boy scoutishness were not correlated to instrumentality ratings for prestige, a good salary, or intellectual stimulation. However, when all instrumentality beliefs were included in a regression to predict boy scoutishness ratings, opportunities for 
advancement, ability to help others, warmth, intellectual stimulation and honesty in business practices were all significant predictors (See Table 12).

Hypothesis 3. Among students, hypothesis 3 was partially supported. Students' innovativeness ratings of organizational personality were significantly positively correlated to instrumentality ratings of flexibility in practices, challenging work, chance to use creative abilities, and intellectual stimulation outcomes. Additionally, students' innovativeness ratings were significantly correlated to instrumentality ratings for all other desirable work related outcomes. However, when all instrumentality beliefs were included in a regression to predict innovativeness ratings, prestige, opportunities for advancement, challenging work, job security, and chance to use creative abilities were significant predictors.

Among working adults, hypothesis 3 was partially supported. Working adults' innovativeness ratings of organizational personality were significantly positively correlated to instrumentality ratings of flexibility in practices, challenging work, chance to use creative abilities, and intellectual stimulation outcomes. Additionally, Working adults' innovativeness ratings were significantly correlated to instrumentality ratings for all other desirable work related outcomes. However, when all instrumentality beliefs were included in a regression to predict innovativeness ratings, prestige, challenging work, a good salary, and warmth were significant predictors.

Hypothesis 4. Among students, hypothesis 4 was partially supported. Students' dominance ratings of organizational personality were significantly positively correlated to instrumentality ratings of prestige, a good salary, and opportunities for advancement outcomes. Additionally, students' ratings of dominance were significantly correlated to 
instrumentality ratings for flexibility in practices, and good benefits. However, when all instrumentality beliefs were included in a regression to predict dominance ratings, prestige and opportunities for advancement were the only significant predictors.

Among working adults, hypothesis 4 was partially supported. Working adults dominance ratings of organizational personality were significantly positively correlated to instrumentality ratings of prestige, a good salary, and opportunities for advancement outcomes. Additionally, working adults' ratings of dominance were significantly correlated to instrumentality ratings for challenging work and good benefits. However, when all instrumentality beliefs were included in a regression to predict dominance ratings, prestige, flexibility in practices, a good salary, and warmth were the only significant predictors.

Hypothesis 5. Among students, hypothesis 5 was partially supported. Students' stylishness ratings of organizational personality were significantly positively correlated to instrumentality ratings of prestige, a good salary, and good benefits outcomes.

Additionally, students' stylishness ratings were significantly correlated to instrumentality ratings for all other desirable work related outcomes except an ability to help others. However, when all instrumentality beliefs were included in a regression to predict stylishness ratings, prestige, ability to help others, warmth, and chance to use creative abilities were the only significant predictors.

Among working adults, hypothesis 5 was partially supported. Working adults' stylishness ratings of organizational personality were significantly positively correlated to instrumentality ratings of prestige, and a good salary, but were not related to good benefits. Additionally, working adults' stylishness ratings were significantly positively 
correlated to instrumentality ratings for opportunities for advancement, flexibility in practices, challenging work, and chance to use creative abilities. However, when all instrumentality beliefs were included in a regression to predict stylishness ratings, prestige and chance to use creative abilities were the only significant predictors.

Hypothesis 6. Among students, hypothesis 6 was partially supported. Students' thriftiness ratings of organizational personality were significantly negatively related to instrumentality ratings of opportunity for advancement, but did not reach significance for prestige, a good salary, and good benefits outcomes. Additionally, students' thriftiness ratings were significantly positively related to instrumentality ratings of warmth. However, when all instrumentality beliefs were included in a regression to predict thriftiness ratings, opportunities for advancement and warmth were the only significant predictors.

Among working adults, hypothesis 6 was partially supported. Working adults' thriftiness ratings of organizational personality were significantly negatively related to instrumentality ratings of prestige, opportunity for advancement, a good salary, and good benefits outcomes. Additionally, working adults' thriftiness ratings were significantly negatively related to instrumentality ratings for challenging work, ability to help others, security, intellectual stimulation, and honesty in business practices. However, when all instrumentality beliefs were included in a regression to predict thriftiness ratings, prestige, flexibility in practices, and honesty in business practices were the only significant predictors. 
Table 9.

Intercorrelations of Organizational Personality Ratings and Instrumentality of Work Related Outcomes for Student Participants.

\begin{tabular}{|c|c|c|c|c|c|c|c|c|c|c|c|c|c|c|c|c|}
\hline Variables & 1 & 2 & 3 & 4 & 5 & 6 & 7 & 8 & 9 & 10 & 11 & 12 & 13 & 14 & 15 & 16 \\
\hline 1. Boy Scout & -- & & & & & & & & & & & & & & & \\
\hline 2. Innovativeness & 0.61 & -- & & & & & & & & & & & & & & \\
\hline 3. Dominance & 0.43 & 0.40 & -- & & & & & & & & & & & & & \\
\hline 4. Thrift & -0.19 & -0.25 & -0.35 & -- & & & & & & & & & & & & \\
\hline 5. Style & 0.30 & 0.46 & 0.27 & 0.21 & -- & & & & & & & & & & & \\
\hline 6. Prestige & 0.30 & 0.38 & 0.40 & -0.11 & 0.32 & -- & & & & & & & & & & \\
\hline $\begin{array}{l}\text { 7. Opportunities for } \\
\text { Advancement }\end{array}$ & 0.34 & 0.42 & 0.30 & -0.25 & 0.22 & 0.40 & -- & & & & & & & & & \\
\hline 8. Flexibility in Practices & 0.42 & 0.45 & 0.19 & 0.00 & 0.24 & 0.43 & 0.54 & -- & & & & & & & & \\
\hline 9. Challenging Work & 0.30 & 0.45 & 0.12 & -0.08 & 0.26 & 0.36 & 0.39 & 0.56 & -- & & & & & & & \\
\hline 10. A Good Salary & 0.31 & 0.42 & 0.16 & -0.09 & 0.36 & 0.35 & 0.55 & 0.55 & 0.57 & -- & & & & & & \\
\hline 11. Ability to Help Others & 0.48 & 0.28 & 0.07 & 0.05 & 0.12 & 0.23 & 0.23 & 0.52 & 0.39 & 0.35 & -- & & & & & \\
\hline 12. Job Security & 0.34 & 0.25 & 0.11 & -0.02 & 0.27 & 0.37 & 0.43 & 0.54 & 0.47 & 0.58 & 0.55 & -- & & & & \\
\hline 13. Warmth & 0.46 & 0.33 & 0.06 & 0.15 & 0.38 & 0.33 & 0.29 & 0.49 & 0.39 & 0.46 & 0.69 & 0.61 & -- & & & \\
\hline $\begin{array}{l}\text { 14. Chance to use Creative } \\
\text { Abilities }\end{array}$ & 0.29 & 0.45 & 0.06 & 0.11 & 0.39 & 0.30 & 0.33 & 0.49 & 0.50 & 0.51 & 0.41 & 0.40 & 0.53 & -- & & \\
\hline 15. Good Benefits & 0.33 & 0.33 & 0.15 & -0.12 & 0.32 & 0.32 & 0.52 & 0.46 & 0.48 & 0.69 & 0.36 & 0.59 & 0.41 & 0.49 & -- & \\
\hline 16. Intellectual Stimulation & 0.34 & 0.39 & 0.07 & 0.06 & 0.36 & 0.36 & 0.48 & 0.51 & 0.54 & 0.60 & 0.42 & 0.51 & 0.51 & 0.66 & 0.64 & -- \\
\hline $\begin{array}{l}\text { 17. Honesty in Business } \\
\text { Practices }\end{array}$ & 0.50 & 0.36 & 0.13 & 0.00 & 0.18 & 0.27 & 0.39 & 0.44 & 0.38 & 0.42 & 0.57 & 0.43 & 0.53 & 0.32 & 0.50 & 0.41 \\
\hline
\end{tabular}

Correlations greater than .18 are significant at the 0.01 level (2-tailed).

Correlations between .14 and .18 are significant at the 0.05 level (2-tailed).

Correlations less than .14 are non-significant 
Table 10.

Predicting Organizational Personality Perceptions by Instrumentality Beliefs of Work Related Outcomes in Students

\begin{tabular}{|c|c|c|c|c|c|c|c|c|c|c|}
\hline \multirow[b]{3}{*}{ Predictor } & \multicolumn{10}{|c|}{ Organizational Personality Ratings } \\
\hline & \multicolumn{2}{|c|}{ Boy Scoutishness } & \multicolumn{2}{|c|}{$\underline{\text { Innovativeness }}$} & \multicolumn{2}{|c|}{ Dominance } & \multicolumn{2}{|c|}{ Thriftiness } & \multicolumn{2}{|c|}{$\underline{\text { Stylishness }}$} \\
\hline & Beta & $\mathbf{p}$ & Beta & $\mathbf{p}$ & Beta & $\mathbf{p}$ & Beta & $\mathbf{p}$ & Beta & $\mathbf{p}$ \\
\hline Constant & 17.64 & $<.01$ & 11.84 & $<.01$ & 14.43 & $<.01$ & 20.42 & $<.01$ & 5.08 & $<.01$ \\
\hline 1. Prestige & 0.42 & 0.18 & 0.54 & $0.02 * *$ & 0.88 & $<.01 * *$ & -0.37 & 0.21 & 0.52 & $0.02 *$ \\
\hline 2. Opportunities for Advancement & 0.64 & 0.15 & 0.69 & $0.04 *$ & 0.61 & $0.02 * *$ & -1.57 & $<.01 * *$ & -0.15 & 0.61 \\
\hline 3. Flexibility in Practices & 0.57 & 0.25 & 0.41 & 0.27 & $<.01$ & 1.00 & 0.74 & 0.11 & -0.13 & 0.69 \\
\hline 4. Challenging Work & -0.01 & 0.98 & 0.75 & $0.03 *$ & -0.07 & 0.79 & -0.64 & 0.13 & -0.03 & 0.93 \\
\hline 5. A Good Salary & -0.21 & 0.69 & 0.45 & 0.23 & 0.10 & 0.73 & -0.13 & 0.78 & 0.46 & 0.18 \\
\hline 6. Ability to Help Others & 0.89 & $0.03 *$ & -0.04 & 0.89 & 0.15 & 0.52 & -0.55 & 0.16 & -0.78 & $0.01 * *$ \\
\hline 7. Job Security & -0.49 & 0.32 & -0.74 & $0.04^{*}$ & -0.17 & 0.54 & 0.09 & 0.85 & -0.10 & 0.76 \\
\hline 8. Warmth & 0.76 & 0.10 & 0.09 & 0.80 & -0.20 & 0.43 & 0.87 & $0.05^{*}$ & 1.10 & $<.01 * *$ \\
\hline 9. Chance to use Creative Abilities & -0.17 & 0.64 & 0.75 & $0.01 *$ & -0.03 & 0.90 & 0.47 & 0.18 & 0.49 & $0.05^{*}$ \\
\hline 10. Good Benefits & 0.22 & 0.68 & -0.34 & 0.40 & 0.13 & 0.66 & -0.86 & 0.09 & 0.25 & 0.49 \\
\hline 11. Intellectual Stimulation & 0.06 & 0.90 & -0.10 & 0.77 & -0.41 & 0.11 & 0.82 & 0.06 & 0.15 & 0.63 \\
\hline 12. Honesty in Business Practices & 1.12 & $0.01 * *$ & 0.56 & 0.06 & 0.05 & 0.83 & 0.33 & 0.39 & -0.06 & 0.83 \\
\hline
\end{tabular}

$* *$ Significant at $\mathrm{p}<.01$ level

$*$ Significant at $\mathrm{p}<.05$ level 
Table 11.

Intercorrelations of Organizational Personality Ratings and Instrumentality of Work Related Outcomes for Working Adult Participants.

\begin{tabular}{|c|c|c|c|c|c|c|c|c|c|c|c|c|c|c|c|c|}
\hline Variables & 1 & 2 & 3 & 4 & 5 & 6 & 7 & 8 & 9 & 10 & 11 & 12 & 13 & 14 & 15 & 16 \\
\hline 1. Boy Scout & -- & & & & & & & & & & & & & & & \\
\hline 2. Innovativeness & 0.48 & -- & & & & & & & & & & & & & & \\
\hline 3. Dominance & 0.22 & 0.54 & -- & & & & & & & & & & & & & \\
\hline 4. Thrift & -0.29 & -0.38 & -0.43 & -- & & & & & & & & & & & & \\
\hline 5. Style & 0.21 & 0.59 & 0.45 & -0.14 & -- & & & & & & & & & & & \\
\hline 6. Prestige & 0.05 & 0.33 & 0.36 & -0.34 & 0.29 & -- & & & & & & & & & & \\
\hline $\begin{array}{l}\text { 7. Opportunities for } \\
\text { Advancement }\end{array}$ & 0.27 & 0.37 & 0.35 & -0.29 & 0.19 & 0.52 & -- & & & & & & & & & \\
\hline 8. Flexibility in Practices & 0.37 & 0.32 & 0.09 & -0.10 & 0.15 & 0.34 & 0.44 & -- & & & & & & & & \\
\hline 9. Challenging Work & 0.13 & 0.38 & 0.29 & -0.21 & 0.20 & 0.37 & 0.61 & 0.52 & -- & & & & & & & \\
\hline 10. A Good Salary & 0.07 & 0.17 & 0.15 & -0.31 & 0.17 & 0.47 & 0.59 & 0.33 & 0.60 & -- & & & & & & \\
\hline 11. Ability to Help Others & 0.60 & 0.24 & 0.07 & -0.20 & 0.12 & 0.01 & 0.27 & 0.46 & 0.21 & 0.17 & -- & & & & & \\
\hline 12. Security & 0.46 & 0.24 & 0.12 & -0.23 & 0.10 & 0.10 & 0.42 & 0.31 & 0.23 & 0.29 & 0.43 & -- & & & & \\
\hline 13. Warmth & 0.65 & 0.36 & 0.07 & -0.10 & 0.11 & -.05 & 0.24 & 0.49 & 0.22 & 0.08 & 0.55 & 0.55 & -- & & & \\
\hline $\begin{array}{l}\text { 14. Chance to use Creative } \\
\text { Abilities }\end{array}$ & 0.34 & 0.33 & 0.09 & -0.03 & 0.24 & 0.14 & 0.27 & 0.56 & 0.46 & 0.31 & 0.39 & 0.32 & 0.50 & -- & & \\
\hline 15. Good Benefits & 0.17 & 0.21 & 0.22 & -0.16 & 0.02 & 0.16 & 0.52 & 0.28 & 0.43 & 0.47 & 0.18 & 0.57 & 0.32 & 0.31 & -- & \\
\hline 16. Intellectual Stimulation & 0.09 & 0.29 & 0.10 & -0.16 & 0.12 & 0.24 & 0.44 & 0.40 & 0.74 & 0.58 & 0.19 & 0.35 & 0.23 & 0.60 & 0.53 & -- \\
\hline $\begin{array}{l}\text { 17. Honesty in Business } \\
\text { Practices }\end{array}$ & 0.68 & 0.38 & 0.07 & -0.28 & 0.08 & 0.11 & 0.29 & 0.49 & 0.34 & 0.23 & 0.56 & 0.53 & 0.65 & 0.48 & 0.36 & 0.38 \\
\hline
\end{tabular}

Correlations greater than .18 are significant at the 0.01 level (2-tailed).

Correlations between .14 and .18 are significant at the 0.05 level (2-tailed).

Correlations less than .14 are non-significant 
Table 12.

Predicting Organizational Personality Perceptions by Instrumentality Beliefs of Work Related Outcomes in Working Adults

\begin{tabular}{|c|c|c|c|c|c|c|c|c|c|c|}
\hline \multirow[b]{3}{*}{ Predictor } & \multicolumn{10}{|c|}{ Organizational Personality Ratings } \\
\hline & \multicolumn{2}{|c|}{ Boy Scoutishness } & \multicolumn{2}{|c|}{$\underline{\text { Innovativeness }}$} & \multicolumn{2}{|c|}{ Dominance } & \multicolumn{2}{|c|}{ Thriftiness } & \multicolumn{2}{|c|}{$\underline{\text { Stylishness }}$} \\
\hline & Beta & $\mathbf{p}$ & Beta & $\mathbf{p}$ & Beta & $\mathbf{p}$ & Beta & $\mathbf{p}$ & Beta & $\mathbf{p}$ \\
\hline Constant & 14.26 & $<.01$ & 10.75 & $<.01$ & 12.83 & $<.01$ & 24.34 & $<.01$ & 6.29 & $<.01$ \\
\hline 1. Prestige & 0.17 & 0.59 & 1.17 & $<.01 * *$ & 0.89 & $<.01 * *$ & -1.17 & $<.01 * *$ & 0.82 & $<.01 * *$ \\
\hline 2. Opportunities for Advancement & 1.20 & $0.01 * *$ & 0.75 & 0.12 & 0.43 & 0.16 & -0.09 & 0.86 & -0.08 & 0.82 \\
\hline 3. Flexibility in Practices & -0.48 & 0.22 & -0.60 & 0.12 & -0.79 & $<.01 * *$ & 0.86 & $0.04 *$ & -0.51 & 0.09 \\
\hline 4. Challenging Work & -0.21 & 0.68 & 1.15 & $0.02 *$ & 1.27 & $<.01 * *$ & -0.30 & 0.58 & 0.73 & 0.06 \\
\hline 5. A Good Salary & -0.27 & 0.49 & -0.99 & $0.01 * *$ & -0.63 & $0.01 * *$ & -0.72 & 0.08 & 0.09 & 0.76 \\
\hline 6. Ability to Help Others & 1.03 & $<.01 * *$ & 0.07 & 0.80 & 0.19 & 0.31 & -0.53 & 0.09 & 0.15 & 0.50 \\
\hline 7. Job Security & 0.39 & 0.32 & -0.20 & 0.61 & 0.02 & 0.95 & -0.41 & 0.32 & 0.31 & 0.30 \\
\hline 8. Warmth & 1.54 & $<.01 * *$ & 0.95 & $0.02 *$ & 0.15 & 0.56 & 0.06 & 0.88 & 0.24 & 0.42 \\
\hline 9. Chance to use Creative Abilities & 0.23 & 0.51 & 0.36 & 0.30 & 0.31 & 0.16 & 0.67 & 0.07 & 0.77 & $<.01 * *$ \\
\hline 10. Good Benefits & -0.75 & 0.07 & -0.13 & 0.76 & 0.59 & $0.03 *$ & 0.31 & 0.48 & -0.40 & 0.20 \\
\hline 11. Intellectual Stimulation & -1.03 & $0.04^{*}$ & 0.04 & 0.94 & -0.87 & $0.01 * *$ & $<.01$ & 1.00 & -0.62 & 0.11 \\
\hline 12. Honesty in Business Practices & 2.36 & $<.01 * *$ & 0.64 & 0.08 & -0.19 & 0.41 & -1.10 & $0.01 * *$ & -0.31 & 0.27 \\
\hline
\end{tabular}

$* *$ Significant at $\mathrm{p}<.01$ level

$*$ Significant at $\mathrm{p}<.05$ level 
Hypothesis 7. Among students, hypothesis 7 was not supported. Students' $n$ Ach scores were not significantly related to valence ratings for challenging work, opportunity for advancement, a good salary, intellectual stimulation, and chance to use creative abilities outcomes (See Table 13). Unexpectedly, students' $n$ Ach scores were not significantly related to valence ratings for any work related outcomes.

Among working adults, hypothesis 7 was partially supported. Working adults' $n$ Ach scores were significantly related to valence ratings for chance to use creative abilities, but were not significantly related to challenging work, opportunity for advancement, a good salary, and intellectual stimulation valence ratings (See Table 14).

Hypothesis 8 . Among students, hypothesis 8 was partially supported. Students' nPow scores were significantly positively correlated with valence ratings for prestige, but were not significantly related to opportunity for advancement, a good salary, and honesty in business practices valence ratings. Additionally, students' nPow scores were significantly negatively related to valence ratings for flexibility in practices.

Among working adults, hypothesis 8 was partially supported. Working adults' nPow scores were significantly positively correlated with valence ratings for prestige, and opportunity for advancement, but were not significantly related to good salary, and honesty in business practices valence ratings. Additionally, working adults' nPow scores were significantly negatively related to valence ratings for ability to help others and warmth, but positively related to valence ratings for chance to use creative abilities.

Hypothesis 9. Among students, hypothesis 9 was partially supported. Students' nAff scores were significantly positively correlated with valence ratings for ability to help others, but were not significantly related to valence ratings for warmth and security. 
Additionally, students' nAff scores were significantly negatively related to valence ratings for flexibility in practices, but positively related to valence ratings for honesty in business practices.

Among working adults, hypothesis 9 was not supported. Working adults' nAff scores were not significantly positively correlated with valence ratings for warmth, ability to help other, or security. However, relationships were in the predicted direction.

Additionally, working adults' nAff scores were significantly negatively related to valence ratings for challenging work. 
Table 13.

Intercorrelations of Need Motivation Scores and Valence of Work Related Outcomes for Student Participants.

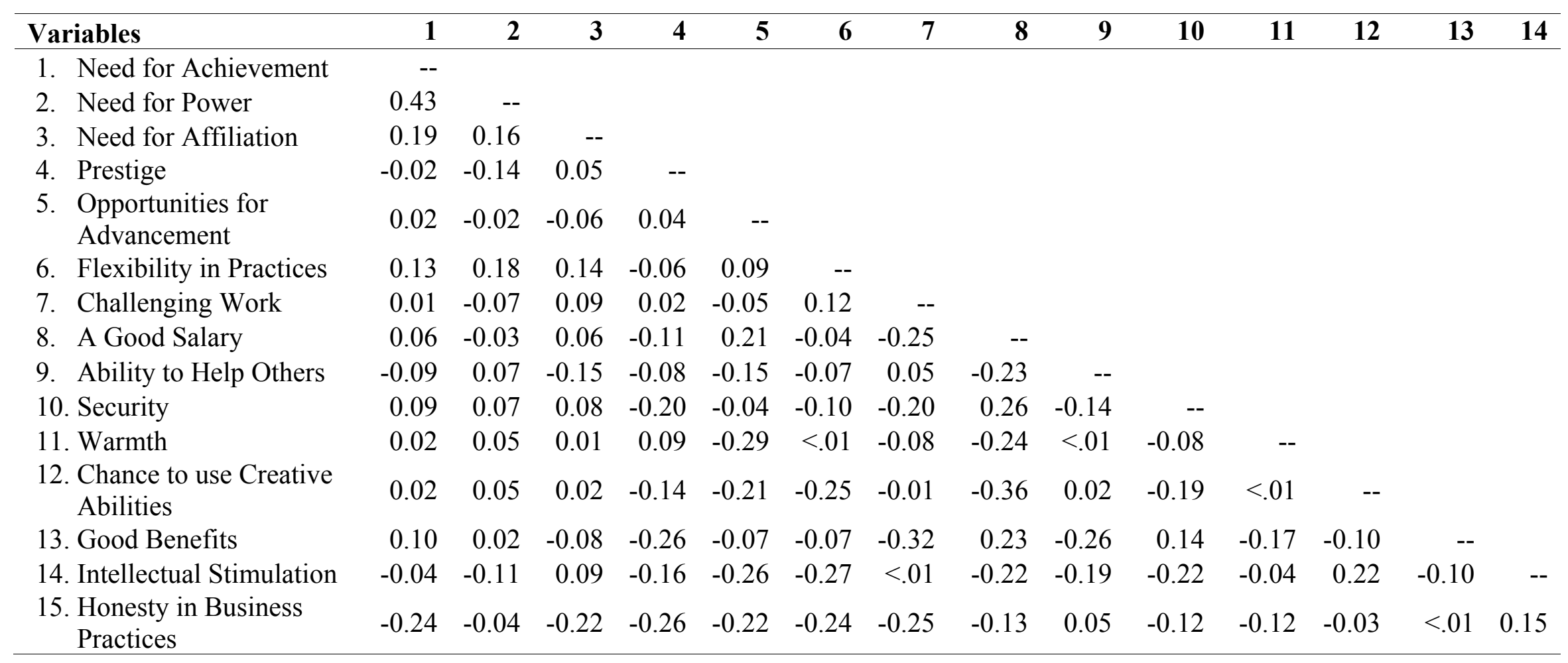

Correlations greater than .18 are significant at the 0.01 level (2-tailed).

Correlations between .14 and .18 are significant at the 0.05 level (2-tailed).

Correlations less than .14 are non-significant 
Table 14.

Intercorrelations of Need Motivation Scores and Valence of Work Related Outcomes for Working Adult Participants.

\begin{tabular}{|c|c|c|c|c|c|c|c|c|c|c|c|c|c|c|}
\hline Variables & 1 & 2 & 3 & 4 & 5 & 6 & 7 & 8 & 9 & 10 & 11 & 12 & 13 & 14 \\
\hline 1. Need for Achievement & -- & & & & & & & & & & & & & \\
\hline 2. Need for Power & 0.42 & -- & & & & & & & & & & & & \\
\hline 3. Need for Affiliation & 0.20 & 0.17 & -- & & & & & & & & & & & \\
\hline 4. Prestige & 0.03 & -0.23 & -0.07 & -- & & & & & & & & & & \\
\hline $\begin{array}{l}\text { 5. Opportunities for } \\
\text { Advancement }\end{array}$ & 0.10 & -0.16 & 0.05 & 0.20 & -- & & & & & & & & & \\
\hline 6. Flexibility in Practices & 0.03 & 0.07 & 0.06 & -0.03 & 0.01 & -- & & & & & & & & \\
\hline 7. Challenging Work & -0.09 & -0.01 & 0.18 & 0.05 & -0.05 & 0.02 & -- & & & & & & & \\
\hline 8. A Good Salary & 0.11 & $<.01$ & 0.02 & 0.08 & 0.05 & -0.09 & -0.10 & -- & & & & & & \\
\hline 9. Ability to Help Others & 0.01 & 0.16 & -0.12 & -0.21 & -0.35 & -0.26 & -0.13 & -0.29 & -- & & & & & \\
\hline 10. Security & 0.03 & 0.03 & -0.01 & -0.35 & -0.06 & 0.03 & -0.24 & 0.06 & 0.02 & -- & & & & \\
\hline 11. Warmth & 0.04 & 0.19 & -0.12 & -0.18 & -0.34 & -0.11 & -0.38 & -0.13 & 0.25 & 0.19 & -- & & & \\
\hline $\begin{array}{l}\text { 12. Chance to use Creative } \\
\text { Abilities }\end{array}$ & -0.15 & -0.17 & 0.10 & -0.06 & -0.30 & -0.10 & 0.12 & -0.16 & 0.05 & -0.36 & -0.03 & -- & & \\
\hline 13. Good Benefits & 0.10 & 0.05 & -0.07 & -0.25 & 0.06 & -0.19 & -0.33 & 0.12 & -0.20 & 0.17 & 0.02 & -0.20 & -- & \\
\hline 14. Intellectual Stimulation & -0.08 & 0.05 & 0.12 & -0.11 & -0.03 & -0.15 & 0.23 & -0.16 & -0.17 & -0.23 & -0.37 & 0.06 & -0.10 & -- \\
\hline $\begin{array}{l}\text { 15. Honesty in Business } \\
\text { Practices }\end{array}$ & -0.11 & 0.07 & -0.12 & -0.17 & -0.29 & -0.12 & -0.17 & -0.18 & 0.17 & -0.15 & 0.08 & -0.13 & $<.01$ & -0.05 \\
\hline
\end{tabular}

Correlations greater than .18 are significant at the 0.01 level (2-tailed).

Correlations between .14 and .18 are significant at the 0.05 level (2-tailed).

Correlations less than .14 are non-significant 


\section{Moderated Regression Hypothesized Relationships}

Hypotheses 10-25 were tested using a moderated regression approach. Because continuous moderator variables were used in the current research, it was necessary to include a product term in the regression equation and then to compare the change in variance explained from an equation that does not model the interaction. For example, person-organization fit was regressed on each organizational personality dimension and accompanying need motivation moderator variable. Then a second regression of personorganization fit on those variables including the multiplicative term of each interaction:

For example, $P-O$ Fit $=B S+n A f f+e(1), P-O F i t=B S+n A f f+B S^{*} n A f f+e(2)$. An interaction is indicated if $\Delta \mathrm{R}^{2}(2)-(1)$ is significant at $\mathrm{p}<.05$ alpha level. The tables below present the beta weights, significance values, and variance explained by regression equations when the moderator is present. The line below each predictor displays the results for that predictor in a regression model that does not contain the moderator.

Hypothesis 10. Among students and working adults, hypothesis 10 was not supported. $n$ Ach scores did not moderate the relationship between organizational personality and $\mathrm{P}-\mathrm{O}$ fit such that the relationship between innovativeness ratings of organizational personality and P-O fit would be more positive for individuals high in $n$ Ach (See Table 15).

Hypothesis 11. Among students and working adults, hypothesis 11 was not supported. $n$ Ach scores did not moderate the relationship between organizational personality and P-O fit such that the relationship between dominance ratings of organizational personality and P-O fit would be more negative for individuals high in $n$ Ach. 
Table 15.

P-O Fit Moderated Regression Analyses by nAch Scores for Students and Working Adults

\begin{tabular}{|c|c|c|c|c|c|}
\hline Model & Predictor & Beta & $\mathbf{p}$ & $\mathbf{R}^{2}$ & $\Delta \mathbf{R}^{2}$ \\
\hline $\mathrm{P}-\mathrm{O}$ Fit $=\mathrm{INV}+\mathrm{nAch}+\mathrm{nAch} * \mathrm{INV}$ & (Constant) & 15.51 & $<.01$ & .11 & .01 \\
\hline \multirow[t]{7}{*}{$\mathrm{P}-\mathrm{O}$ Fit $=\mathrm{INV}+\mathrm{nAch}$} & & 8.97 & $<.01$ & .10 & \\
\hline & Innovativeness & -.09 & .60 & & \\
\hline & & .18 & $<.01$ & & \\
\hline & Need for Achievement & -.49 & .21 & & \\
\hline & & .12 & .13 & & \\
\hline & Interaction & .03 & .10 & & \\
\hline & & -- & -- & & \\
\hline \multirow[t]{7}{*}{ Working Adults } & (Constant) & 11.12 & .01 & .15 & 0 \\
\hline & & 8.42 & $<.01$ & .15 & \\
\hline & Innovativeness & .09 & .64 & & \\
\hline & & .22 & $<.01$ & & \\
\hline & Need for Achievement & -.10 & .77 & & \\
\hline & & .12 & .19 & & \\
\hline & Interaction & .01 & .52 & & \\
\hline
\end{tabular}

\begin{tabular}{llcccc}
\hline Model & Predictor & Beta & $\mathbf{p}$ & $\mathbf{R}^{\mathbf{2}}$ & $\Delta \mathbf{R}^{\mathbf{2}}$ \\
\hline P-O Fit = DOM+nAch+nAch*DOM & (Constant) & 14.30 & .01 & .08 & 0 \\
P-O Fit = DOM+nAch & & 8.86 & $<.01$ & .08 & \\
& Dominance & -.06 & .85 & & \\
& & .22 & $<.01$ & & \\
& & Need for Achievement & -.39 & .47 & \\
& & .14 & .09 & \\
Working Adults & Interaction & .03 & .32 & \\
& & -- & -- & & \\
& (Constant) & 21.41 & .01 & .05 & .01 \\
& & 10.39 & $<.01$ & .04 & \\
& Dominance & -.47 & .22 & & \\
& & .07 & .29 & & \\
& Need for Achievement & -.67 & .30 & & \\
& & .26 & .01 & & \\
& Interaction & .05 & .15 & & \\
& & -- & -- & &
\end{tabular}


Hypothesis 12. Among students and working adults, hypothesis 12 was not supported. $n$ Ach scores did not moderate the relationship between innovativeness ratings of organizational personality and organizational attractiveness such that the relationship between innovativeness ratings of organizational personality and organizational attractiveness would be more positive for individuals high in $n$ Ach (See Table 16).

Hypothesis 13. Among students and working adults, hypothesis 13 was not supported. $n$ Ach scores did not moderate the relationship between dominance ratings of organizational personality and organizational attractiveness such that the relationship between dominance ratings of organizational personality and organizational attractiveness would be more negative for individuals high in $n$ Ach.

Hypothesis 14. Among students and working adults, hypothesis14 was not supported. $n$ Pow scores did not moderate the relationship between dominance ratings of organizational personality and $\mathrm{P}-\mathrm{O}$ fit such that the relationship between dominance ratings of organizational personality and $\mathrm{P}-\mathrm{O}$ fit would be more positive for individuals high in $n$ Pow (See Table 17).

Hypothesis 15. Among working adults, hypothesis 15 was supported. $n$ Pow scores moderated the relationship between stylishness ratings of organizational personality and P-O fit such that the relationship between stylishness ratings of organizational personality and P-O fit was more positive for individuals high in $n$ Pow. Among students, hypothesis 15 was not supported. 
Table 16.

Attraction Moderated Regression Analyses by nAch Scores for Students and Working Adults

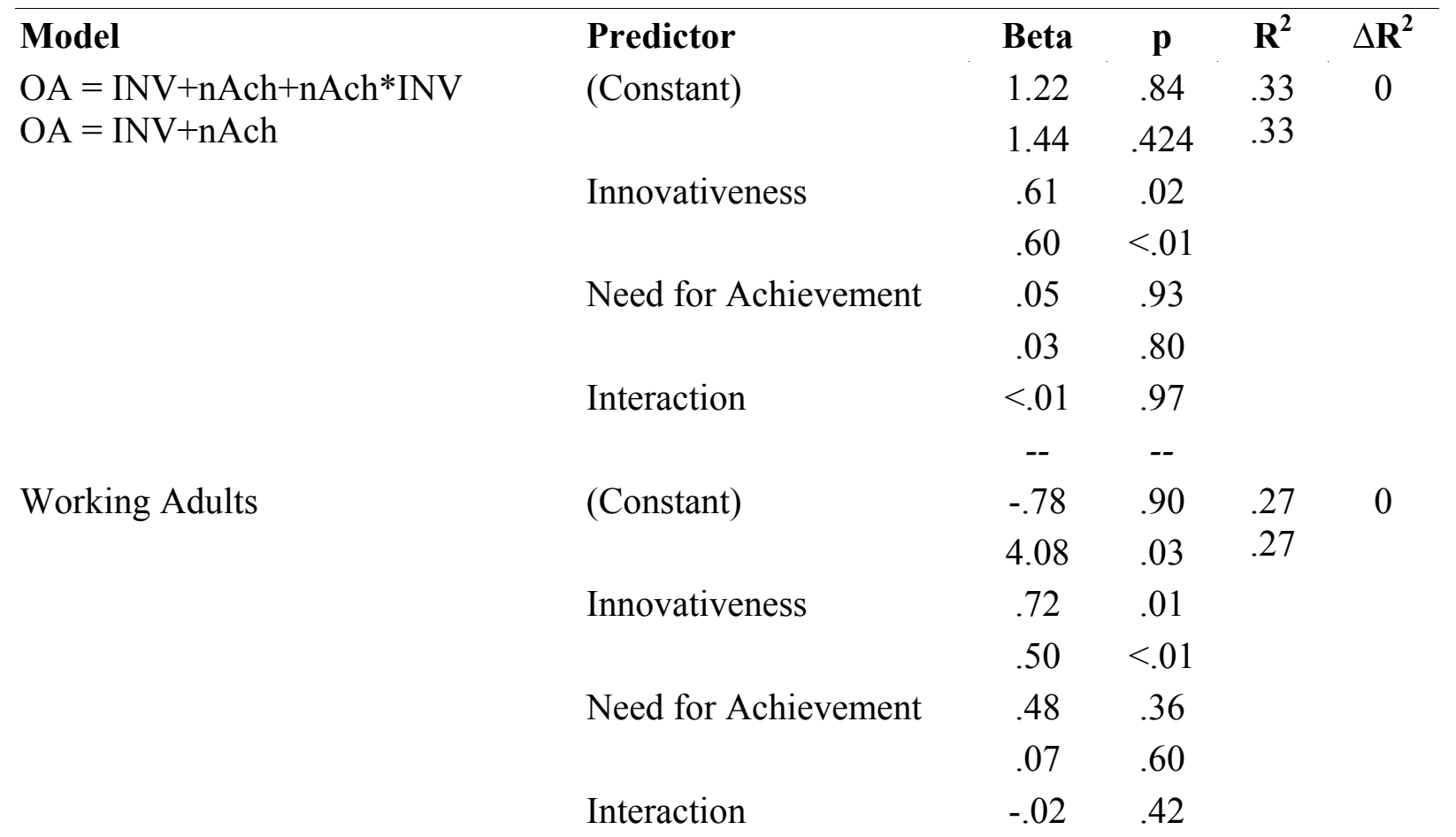

\begin{tabular}{|c|c|c|c|c|c|}
\hline & & & -1 & & \\
\hline Model & Predictor & Beta & $\mathbf{p}$ & $\mathbf{R}^{2}$ & $\Delta \mathbf{R}^{2}$ \\
\hline $\mathrm{OA}=\mathrm{DOM}+\mathrm{nAch}+\mathrm{nAch} * \mathrm{DOM}$ & (Constant) & 3.24 & .72 & .14 & 0 \\
\hline $\mathrm{OA}=\mathrm{DOM}+\mathrm{nAch}$ & & 3.96 & .09 & .14 & \\
\hline & Dominance & .61 & .19 & & \\
\hline & & .57 & $<.01$ & & \\
\hline & Need for Achievement & .18 & .83 & & \\
\hline & & .11 & .39 & & \\
\hline & Interaction & $<-.01$ & .94 & & \\
\hline & & -- & -- & & \\
\hline Working Adults & (Constant) & -3.39 & .78 & .07 & .01 \\
\hline & & 6.06 & .03 & .06 & \\
\hline & Dominance & .77 & .19 & & \\
\hline & & .30 & $<.01$ & & \\
\hline & Need for Achievement & 1.19 & .24 & & \\
\hline & & .40 & $<.01$ & & \\
\hline & Interaction & -.04 & .42 & & \\
\hline & & -- & -- & & \\
\hline
\end{tabular}


Table 17.

P-O Fit Moderated Regression Analyses by nPow Scores for Students and Working Adults

\begin{tabular}{llcccc} 
Model & Predictor & Beta & $\mathbf{p}$ & $\mathbf{R}^{\mathbf{2}}$ & $\Delta \mathbf{R}^{\mathbf{2}}$ \\
\hline P-O Fit = DOM+nPow+nPow*DOM & (Constant) & 4.28 & .02 & .08 & 0 \\
P-O Fit = DOM+nPow & & 1.36 & $<.01$ & .08 & \\
& Dominance & .22 & .48 & & \\
& & .07 & $<.01$ & & \\
& Need for Power & .40 & .99 & & \\
& & .06 & .08 & \\
Interaction & & .02 & .77 & \\
Working Adults & & -- & -- & & \\
& (Constant) & 7.53 & .09 & .03 & .01 \\
& & 12.56 & $<.01$ & .02 & \\
& Dominance & .32 & .16 & & \\
& & .06 & .41 & & \\
& Need for Power & .62 & .13 & &
\end{tabular}

\begin{tabular}{llcccc}
\hline Model & Predictor & Beta & $\mathbf{p}$ & $\mathbf{R}^{\mathbf{2}}$ & $\Delta \mathbf{R}^{\mathbf{2}}$ \\
\hline P-O Fit = STY+nPow+nPow*STY & (Constant) & 12.62 & $<.01$ & .04 & 0 \\
P-O Fit = STY+nPow & & 12.24 & $<.01$ & .04 & \\
& Stylishness & .05 & .76 & & \\
& & .09 & .11 & & \\
& & Need for Power & .10 & .56 & \\
& & .14 & .03 & \\
Working Adults & Interaction & $<.01$ & .82 & & \\
& & -- & -- & & \\
& (Constant) & 7.79 & $<.01$ & .07 & $.04 * *$ \\
& & 12.94 & $<.01$ & .03 & \\
& Stylishness & .60 & $<.01$ & & \\
& & .08 & .22 & & \\
& Need for Power & .62 & .01 & & \\
& & .11 & .08 & & \\
& Interaction & .05 & $<.01$ & & \\
& & -- & -- & &
\end{tabular}




\begin{tabular}{|c|c|c|c|c|c|}
\hline Model & Predictor & Beta & $\mathbf{p}$ & $\mathbf{R}^{2}$ & $\Delta \mathbf{R}^{2}$ \\
\hline P-O Fit $=$ THR + nPow + nPow $*$ THR & (Constant) & 18.84 & $<.01$ & .09 & $.02 *$ \\
\hline \multirow[t]{7}{*}{$\mathrm{P}-\mathrm{O}$ Fit $=\mathrm{THR}+\mathrm{nPow}$} & & 15.27 & $<.01$ & .07 & \\
\hline & Thriftiness & -.36 & $<.01$ & & \\
\hline & & -.13 & $<.01$ & & \\
\hline & Need for Power & -.22 & .23 & & \\
\hline & & .13 & .04 & & \\
\hline & Interaction & .02 & .05 & & \\
\hline & & -- & -- & & \\
\hline \multirow[t]{8}{*}{ Working Adults } & (Constant) & 13.40 & $<.01$ & .08 & .01 \\
\hline & & 15.63 & $<.01$ & .07 & \\
\hline & Thriftiness & .03 & .82 & & \\
\hline & & -.14 & $<.01$ & & \\
\hline & Need for Power & .33 & .03 & & \\
\hline & & .12 & .05 & & \\
\hline & Interaction & -.02 & .14 & & \\
\hline & & -- & -- & & \\
\hline
\end{tabular}

Hypothesis 16. Among students hypothesis 16 was supported. $n$ Pow scores moderated the relationship between thriftiness ratings of organizational personality and $\mathrm{P}-\mathrm{O}$ fit such that the relationship between thriftiness ratings of organizational personality and P-O fit was more negative for individuals high in $n$ Pow. Among working adults, hypothesis 16 was not supported.

Hypothesis 17. Among students and working adults, hypothesis 17 was not supported. $n$ Pow scores did not moderate the relationship between dominance ratings of organizational personality and organizational attractiveness such that the relationship between dominance ratings of organizational personality and organizational attractiveness would be more positive for individuals high in $n$ Pow (See Table 18). 
Table 18 .

Attraction Moderated Regression Analyses by nPow Scores for Students and Working Adults

\begin{tabular}{|c|c|c|c|c|c|}
\hline Model & Predictor & Beta & $\mathbf{p}$ & $\mathbf{R}^{2}$ & $\Delta \mathbf{R}^{2}$ \\
\hline \multirow{8}{*}{$\begin{array}{l}\mathrm{OA}=\mathrm{DOM}+\mathrm{nPow}+\mathrm{nPow} * \mathrm{DOM} \\
\mathrm{OA}=\mathrm{DOM}+\mathrm{nPow}\end{array}$} & (Constant) & 5.28 & .43 & .16 & 0 \\
\hline & & 3.38 & .11 & .16 & \\
\hline & Dominance & .45 & .20 & & \\
\hline & & .54 & $<.01$ & & \\
\hline & Need for Power & .04 & .94 & & \\
\hline & & .23 & .02 & & \\
\hline & Interaction & $<.01$ & .77 & & \\
\hline & & -- & -- & & \\
\hline \multirow[t]{8}{*}{ Working Adults } & (Constant) & -1.26 & .85 & .05 & .01 \\
\hline & & 10.18 & $<.01$ & .04 & \\
\hline & Dominance & .87 & $<.01$ & & \\
\hline & & .27 & $<.01$ & & \\
\hline & Need for Power & 1.23 & .06 & & \\
\hline & & .11 & .27 & & \\
\hline & Interaction & -.06 & .08 & & \\
\hline & & -- & -- & & \\
\hline Model & Predictor & Beta & $\mathbf{p}$ & $\mathbf{R}^{2}$ & $\Delta \mathbf{R}^{2}$ \\
\hline \multirow{8}{*}{$\begin{array}{l}\mathrm{OA}=\mathrm{STY}+\text { nPow }+ \text { nPow } * \mathrm{STY} \\
\mathrm{OA}=\mathrm{STY}+\text { nPow }\end{array}$} & (Constant) & 6.61 & .02 & .21 & 0 \\
\hline & & 7.63 & $<.01$ & .21 & \\
\hline & Stylishness & .60 & .02 & & \\
\hline & & .50 & $<.01$ & & \\
\hline & Need for Power & .36 & .16 & & \\
\hline & & .26 & $<.01$ & & \\
\hline & Interaction & $<-.01$ & .68 & & \\
\hline & & -- & -- & & \\
\hline \multirow[t]{8}{*}{ Working Adults } & (Constant) & 9.15 & $<.01$ & .31 & .01 \\
\hline & & 11.71 & $<.01$ & .30 & \\
\hline & Stylishness & .67 & .03 & & \\
\hline & & .41 & $<.01$ & & \\
\hline & Need for Power & .29 & .33 & & \\
\hline & & .03 & .71 & & \\
\hline & Interaction & -.03 & .36 & & \\
\hline & & -- & -- & & \\
\hline
\end{tabular}




\begin{tabular}{|c|c|c|c|c|c|}
\hline Model & Predictor & Beta & $\mathbf{p}$ & $\mathbf{R}^{2}$ & $\Delta \mathbf{R}^{2}$ \\
\hline \multirow{8}{*}{$\begin{array}{l}\mathrm{OA}=\mathrm{THR}+\text { nPow }+ \text { nPow } * \text { THR } \\
\mathrm{OA}=\mathrm{THR}+\text { nPow }\end{array}$} & \multirow[t]{2}{*}{ (Constant) } & 13.98 & .01 & \multirow{4}{*}{$\begin{array}{l}.05 \\
.05\end{array}$} & \multirow[t]{8}{*}{0} \\
\hline & & 14.54 & .01 & & \\
\hline & \multirow[t]{2}{*}{ Thriftiness } & -.06 & .78 & & \\
\hline & & -.09 & .16 & & \\
\hline & \multirow[t]{2}{*}{ Need for Power } & .35 & .26 & & \\
\hline & & .30 & $<.01$ & & \\
\hline & \multirow[t]{2}{*}{ Interaction } & $<-.01$ & .85 & & \\
\hline & & -- & -- & & \\
\hline \multirow[t]{8}{*}{ Working Adults } & \multirow[t]{2}{*}{ (Constant) } & 20.10 & $<.01$ & .14 & \multirow[t]{8}{*}{0} \\
\hline & & 20.30 & $<.01$ & .14 & \\
\hline & \multirow[t]{2}{*}{ Thriftiness } & -.33 & .07 & & \\
\hline & & -.35 & $<.01$ & & \\
\hline & \multirow[t]{2}{*}{ Need for Power } & .11 & .63 & & \\
\hline & & .09 & .30 & & \\
\hline & \multirow[t]{2}{*}{ Interaction } & $<-.01$ & .93 & & \\
\hline & & -- & -- & & \\
\hline
\end{tabular}

Hypothesis 18. Among students and working adults, hypothesis 18 was not supported. $n$ Pow scores did not moderate the relationship between stylishness ratings of organizational personality and organizational attractiveness such that the relationship between stylishness ratings of organizational personality and organizational attractiveness would be more positive for individuals high in $n$ Pow.

Hypothesis 19. Among students and working adults, hypothesis 19 was not supported. $n$ Pow scores did not moderate the relationship between thriftiness ratings of organizational personality and organizational attractiveness such that the relationship between thriftiness ratings of organizational personality and organizational attractiveness would be more negative for individuals high in $n$ Pow. 
Hypothesis 20. Among students and working adults, hypothesis 20 was not supported. $n$ Aff scores did not moderate the relationship between boy scoutishness ratings of organizational personality and $\mathrm{P}-\mathrm{O}$ fit such that the relationship between boy scoutishness ratings of organizational personality and P-O fit would be more positive for individuals high in $n$ Aff (See Table 19).

Hypothesis 21. Among students and working adults, hypothesis 21 was not supported. $n$ Aff scores did not moderate the relationship between stylishness ratings of organizational personality and P-O fit such that the relationship between stylishness ratings of organizational personality and $\mathrm{P}-\mathrm{O}$ fit would be more positive for individuals high in $n$ Aff.

Hypothesis 22. Among students and working adults, hypothesis 22 was not supported. $n$ Aff scores did not moderate the relationship between thriftiness ratings of organizational personality and P-O fit such that the relationship between thriftiness ratings of organizational personality and $\mathrm{P}-\mathrm{O}$ fit would be more negative for individuals high in $n$ Aff.

Hypothesis 23. Among students and working adults, hypothesis 23 was not supported. $n$ Aff scores did not moderate the relationship between boy scoutishness ratings of organizational personality and organizational attractiveness such that the relationship between boy scoutishness ratings of organizational personality and organizational attractiveness would be more positive for individuals high in $n$ Aff (See Table 20). 
Table 19.

P-O Fit Moderated Regression Analyses by Aff Scores for Students and Working Adults

\begin{tabular}{|c|c|c|c|c|c|}
\hline Model & Predictor & Beta & $\mathbf{p}$ & $\mathbf{R}^{2}$ & $\Delta \mathbf{R}^{2}$ \\
\hline \multirow{8}{*}{$\begin{array}{l}\text { P-O Fit }=B S+n A f f+n A f{ }^{*} B S \\
\text { P-O Fit }=B S+n A f f\end{array}$} & (Constant) & 7.14 & .03 & .14 & 0 \\
\hline & & 7.76 & $<.01$ & .14 & \\
\hline & Boy Scoutishness & .18 & .06 & & \\
\hline & & .16 & $<.01$ & & \\
\hline & Need for Affiliation & .20 & .52 & & \\
\hline & & .13 & .05 & & \\
\hline & Interaction & $<-.01$ & .83 & & \\
\hline & & -- & -- & & \\
\hline \multirow[t]{8}{*}{ Working Adults } & (Constant) & 8.92 & $<.01$ & .20 & 0 \\
\hline & & 8.47 & $<.01$ & .20 & \\
\hline & Boy Scoutishness & .18 & .03 & & \\
\hline & & .20 & $<.01$ & & \\
\hline & Need for Affiliation & -.01 & .95 & & \\
\hline & & .03 & .57 & & \\
\hline & Interaction & $<.01$ & .83 & & \\
\hline & & -- & -- & & \\
\hline Model & Predictor & Beta & $\mathbf{p}$ & $\mathbf{R}^{2}$ & $\Delta \mathbf{R}^{2}$ \\
\hline \multirow{8}{*}{$\begin{array}{l}\text { P-O Fit }=\text { STY }+ \text { nAff }+ \text { nAff } * \text { STY } \\
\text { P-O Fit }=S T Y+n A f f\end{array}$} & (Constant) & 11.89 & $<.01$ & .04 & 0 \\
\hline & & 11.82 & $<.01$ & .04 & \\
\hline & Stylishness & .09 & .63 & & \\
\hline & & .10 & .07 & & \\
\hline & Need for Affiliation & .16 & .40 & & \\
\hline & & .17 & .02 & & \\
\hline & Interaction & $<.01$ & .97 & & \\
\hline & & -- & -- & & \\
\hline \multirow[t]{8}{*}{ Working Adults } & (Constant) & 11.61 & $<.01$ & .03 & 0 \\
\hline & & 12.64 & $<.01$ & .03 & \\
\hline & Stylishness & .21 & .25 & & \\
\hline & & .12 & .04 & & \\
\hline & Need for Affiliation & .20 & .32 & & \\
\hline & & .10 & .11 & & \\
\hline & Interaction & $<-.01$ & .59 & & \\
\hline & & -- & -- & & \\
\hline
\end{tabular}




\begin{tabular}{|c|c|c|c|c|c|}
\hline Model & Predictor & Beta & $\mathbf{p}$ & $\mathbf{R}^{2}$ & $\Delta \mathbf{R}^{2}$ \\
\hline \multirow{8}{*}{$\begin{array}{l}\text { P-O Fit }=\text { THR }+ \text { nAff }+ \text { nAff } * \text { THR } \\
\text { P-O Fit }=T H R+\text { Aff }\end{array}$} & \multirow[t]{2}{*}{ (Constant) } & 18.23 & $<.01$ & \multirow{4}{*}{$\begin{array}{l}.08 \\
.07\end{array}$} & \multirow[t]{8}{*}{.01} \\
\hline & & 15.12 & $<.01$ & & \\
\hline & \multirow[t]{2}{*}{ Thriftiness } & -.33 & .03 & & \\
\hline & & -.12 & $<.01$ & & \\
\hline & \multirow[t]{2}{*}{ Need for Affiliation } & -.18 & .43 & & \\
\hline & & .13 & .06 & & \\
\hline & \multirow[t]{2}{*}{ Interaction } & .02 & .15 & & \\
\hline & & -- & -- & & \\
\hline \multirow[t]{8}{*}{ Working Adults } & \multirow[t]{2}{*}{ (Constant) } & 14.13 & $<.01$ & .08 & \multirow[t]{8}{*}{.01} \\
\hline & & 15.91 & $<.01$ & .07 & \\
\hline & \multirow[t]{2}{*}{ Thriftiness } & -.01 & .93 & & \\
\hline & & -.15 & $<.01$ & & \\
\hline & \multirow[t]{2}{*}{ Need for Affiliation } & .27 & .12 & & \\
\hline & & .11 & .07 & & \\
\hline & \multirow[t]{2}{*}{ Interaction } & -.01 & .33 & & \\
\hline & & -- & -- & & \\
\hline
\end{tabular}


Table 20 .

Attraction Moderated Regression Analyses by nAff Scores for Students and Working Adults

\begin{tabular}{|c|c|c|c|c|c|}
\hline Model & Predictor & Beta & $\mathbf{p}$ & $\mathbf{R}^{2}$ & $\Delta \mathbf{R}^{2}$ \\
\hline \multirow{8}{*}{$\begin{array}{l}\mathrm{OA}=\mathrm{BS}+\mathrm{nAff}+\mathrm{nAff} * \mathrm{BS} \\
\mathrm{OA}=\mathrm{BS}+\mathrm{nAff}\end{array}$} & (Constant) & 2.39 & .64 & .19 & 0 \\
\hline & & 4.02 & .04 & .19 & \\
\hline & Boy Scoutishness & .40 & $<.01$ & & \\
\hline & & .35 & $<.01$ & & \\
\hline & Need for Affiliation & .21 & .67 & & \\
\hline & & .04 & .68 & & \\
\hline & Interaction & -.01 & .73 & & \\
\hline & & -- & -- & & \\
\hline \multirow[t]{8}{*}{ Working Adults } & (Constant) & 5.68 & .13 & .17 & 0 \\
\hline & & 7.78 & $<.01$ & .17 & \\
\hline & Boy Scoutishness & .37 & $<.01$ & & \\
\hline & & .30 & $<.01$ & & \\
\hline & Need for Affiliation & .16 & .64 & & \\
\hline & & -.04 & .63 & & \\
\hline & Interaction & -.01 & .54 & & \\
\hline & & -- & -- & & \\
\hline Model & Predictor & Beta & $\mathbf{p}$ & $\mathbf{R}^{2}$ & $\Delta \mathbf{R}^{2}$ \\
\hline \multirow{8}{*}{$\begin{array}{l}\mathrm{OA}=\mathrm{STY}+\mathrm{nAff}+\mathrm{nAff} * \mathrm{STY} \\
\mathrm{OA}=\mathrm{STY}+\mathrm{nAff}\end{array}$} & (Constant) & 8.67 & $<.01$ & .18 & 0 \\
\hline & & 8.89 & $<.01$ & .18 & \\
\hline & Stylishness & .54 & .05 & & \\
\hline & & .53 & $<.01$ & & \\
\hline & Need for Affiliation & .14 & .64 & & \\
\hline & & .12 & .28 & & \\
\hline & Interaction & $<-.01$ & .94 & & \\
\hline & & -- & -- & & \\
\hline \multirow[t]{8}{*}{ Working Adults } & (Constant) & 9.32 & $<.01$ & .10 & 0 \\
\hline & & 10.78 & $<.01$ & .10 & \\
\hline & Stylishness & .57 & .04 & & \\
\hline & & .44 & $<.01$ & & \\
\hline & Need for Affiliation & .25 & .42 & & \\
\hline & & .10 & .27 & & \\
\hline & Interaction & -.01 & .62 & & \\
\hline & & -- & -- & & \\
\hline
\end{tabular}




\begin{tabular}{|c|c|c|c|c|c|}
\hline Model & Predictor & Beta & p & $\mathbf{R}^{2}$ & $\Delta \mathbf{R}^{2}$ \\
\hline \multirow{8}{*}{$\begin{array}{l}\mathrm{OA}=\mathrm{THR}+\mathrm{nAff}+\mathrm{nAff} * \mathrm{THR} \\
\mathrm{OA}=\mathrm{THR}+\mathrm{nAff}\end{array}$} & (Constant) & 12.61 & .01 & .02 & 0 \\
\hline & & 16.78 & .01 & .02 & \\
\hline & Thriftiness & .18 & .48 & & \\
\hline & & -.10 & .14 & & \\
\hline & Need for Affiliation & .52 & .19 & & \\
\hline & & .09 & .45 & & \\
\hline & Interaction & -.03 & .28 & & \\
\hline & & -- & -- & & \\
\hline \multirow[t]{8}{*}{ Working Adults } & (Constant) & 19.82 & .01 & .14 & 0 \\
\hline & & 20.38 & .01 & .14 & \\
\hline & Thriftiness & -.32 & .17 & & \\
\hline & & -.36 & .01 & & \\
\hline & Need for Affiliation & .16 & .56 & & \\
\hline & & .10 & .25 & & \\
\hline & Interaction & $<-.01$ & .84 & & \\
\hline & & -- & -- & & \\
\hline
\end{tabular}

Hypothesis 24. Among students and working adults, hypothesis 24 was not supported. $n$ Aff scores did not moderate the relationship between stylishness ratings of organizational personality and organizational attractiveness such that the relationship between stylishness ratings of organizational personality and organizational attractiveness would be more positive for individuals high in $n$ Aff.

Hypothesis 25. Among students and working adults, hypothesis 25 was not supported. $n$ Aff scores did not moderate the relationship between thriftiness ratings of organizational personality and organizational attractiveness such that the relationship between thriftiness ratings of organizational personality and organizational attractiveness would be more negative for individuals high in $n$ Aff. 
Despite the null findings for the moderated regression analyses, it should be noted that there are significant relationships between the interactive terms for organizational personality ratings and need motivation with perceptions of fit and organizational attraction (See Table 21 and 22).

Table 21.

Intercorrelations of Interactive Terms (Need Motivation by Organizational Personality), Perceptions of Fit, and Organizational Attraction for Student Participants.

\begin{tabular}{lcccc}
\hline Variables & P-O Fit & $\begin{array}{c}\text { General } \\
\text { Attractiveness }\end{array}$ & $\begin{array}{c}\text { Intentions } \\
\text { to Pursue }\end{array}$ & Reputation \\
\hline Innovativeness x nAch & $0.30^{* *}$ & $0.41^{* *}$ & $0.39^{* *}$ & $0.40^{* *}$ \\
Dominance x nAch & $0.25^{* *}$ & $0.27^{* *}$ & $0.29^{* *}$ & $0.36^{* *}$ \\
Dominance x nPow & $0.24^{* *}$ & $0.33^{* *}$ & $0.33^{* *}$ & $0.35^{* *}$ \\
Stylishness x nPow & $0.19^{* *}$ & $0.42^{* *}$ & $0.42^{* *}$ & $0.37^{* *}$ \\
Thriftiness x nPow & $-0.02^{\mathrm{ns}}$ & $0.06^{\mathrm{ns}}$ & $0.10^{\mathrm{ns}}$ & $0.02^{\mathrm{ns}}$ \\
Boy Scoutishness x nAff & $0.31^{* *}$ & $0.27^{* *}$ & $0.30^{* *}$ & $0.38^{* *}$ \\
Stylishness x nAff & $0.20^{* *}$ & $0.37^{* *}$ & $0.38^{* *}$ & $0.38^{* *}$ \\
Thriftiness x nAff & $-0.05^{\mathrm{ns}}$ & $-0.06^{\mathrm{ns}}$ & $<.01^{\mathrm{ns}}$ & $-0.01^{\mathrm{ns}}$ \\
\hline
\end{tabular}

**Correlations greater than .18 are significant at the 0.01 level (2-tailed).

*Correlations between .14 and .18 are significant at the 0.05 level (2-tailed).

${ }^{\mathrm{ns}}$ Correlations less than .14 are non-significant

Table 22.

Intercorrelations of Interactive Terms (Need Motivation by Organizational Personality), Perceptions of Fit, and Organizational Attraction for Working Adult Participants.

\begin{tabular}{lcccc}
\hline Variables & P-O Fit & $\begin{array}{c}\text { General } \\
\text { Attractiveness }\end{array}$ & $\begin{array}{c}\text { Intentions } \\
\text { to Pursue }\end{array}$ & Reputation \\
\hline Innovativeness x nAch & $0.36^{* *}$ & $0.44^{* *}$ & $0.48^{* *}$ & $0.41^{* *}$ \\
Dominance x nAch & $0.20^{* *}$ & $0.24^{* *}$ & $0.31^{* *}$ & $0.32^{* *}$ \\
Dominance x nPow & $0.14^{*}$ & $0.13^{\mathrm{ns}}$ & $0.27^{* *}$ & $0.30^{* *}$ \\
Stylishness x nPow & $0.12^{\mathrm{ns}}$ & $0.23^{* *}$ & $0.36^{* *}$ & $0.31^{* *}$ \\
Thriftiness x nPow & $-0.10^{\mathrm{ns}}$ & $-0.21^{* *}$ & $-0.17^{*}$ & $-0.30^{* *}$ \\
Boy Scoutishness x nAff & $0.31^{* *}$ & $0.23^{* *}$ & $0.20^{* *}$ & $0.25^{* *}$ \\
Stylishness x nAff & $0.14^{\mathrm{ns}}$ & $0.22^{* *}$ & $0.25^{* *}$ & $0.20^{* *}$ \\
Thriftiness x nAff & $-0.13^{\mathrm{ns}}$ & $-0.25^{* *}$ & $-0.24^{* *}$ & $-0.39^{* *}$ \\
\hline
\end{tabular}

**Correlations greater than .18 are significant at the 0.01 level (2-tailed).

*Correlations between .14 and .18 are significant at the 0.05 level (2-tailed).

${ }^{\text {ns }}$ Correlations less than .14 are non-significant 
Among students all interactive terms (with the exception of thriftiness $\mathrm{x}$ nPow and thriftiness $\mathrm{x}$ nAff) were significantly correlated with perceptions of fit, general attraction to the organization, intentions to pursue employment with the organization, and perceptions of a positive reputation. The pattern of positive correlations between the interactive terms and the outcomes measures are consistent with the notion that an increase in organizational personality traits that are complementary to certain need motives increase individuals' perceptions of fit and organizational attraction. For instance, as individuals' need for achievement increase the perceptions of greater innovativeness in an organization will lead to a positive increase in perceptions of fit and organizational attraction.

Unlike students, working adults displayed a less consistent pattern of correlation between interactive terms, perceptions of fit and organizational attraction. Surprisingly, dominance $\mathrm{x}$ nPow did not positively correlate with general attraction ratings. Also, several interactive terms including: stylishness $\mathrm{x}$ nPow, thriftiness $\mathrm{x}$ nPow, stylishness $\mathrm{x}$ nAff and thriftiness $\mathrm{x}$ nAff did not significantly correlate with perceptions of fit even though they were positively correlated with all attraction ratings. It is possible that stylishness and thriftiness are not as relevant to working adults when forming opinions of fit as they are to students.

\section{Mediated Regression Hypothesized Relationships}

Hypotheses 26-33 were tested using a mediated regression approach. To test the mediated relationships, the steps developed by Baron and Kenny (1986) to evaluate mediation were used. Baron and Kenny (1986) outline four conditions that must be met in order to infer the presence of mediation between variables. First, the predictor variable 
(x) must be significantly correlated with outcome variable (y). Second, $x$ must be correlated with the mediator variable (m). Third, m must significantly predict $y$ in the presence of $\mathrm{x}$. Finally, the relationship between $\mathrm{x}$ and $\mathrm{y}$ should be reduced or become non-existent in the presence of $\mathrm{m}$. For the current project, the model proposed moderated mediation. Therefore, the analyses were conducted as follows: For each mediated relationship, four equations were tested to establish mediation, for example: $P$-O Fit $=B S$ ratings $x n A f f+e(1)(\beta$ for $\mathrm{BS} \times n$ Aff must significantly predict $\mathrm{P}-\mathrm{O}$ fit). $O A=P-O$ Fit + $e$ (2) ( $\beta$ for $\mathrm{P}-\mathrm{O}$ fit must significantly predict $\mathrm{OA}) . O A=B S x n A f f+e(3)(\beta$ for $\mathrm{BS} \mathrm{x}$ $n$ Aff must significantly predict $\mathrm{OA}) . O A=B$ S ratings $x n A f f+P-O f i t+e(4)(\beta$ for $\mathrm{BS} \mathrm{x}$ $n$ Aff must be reduced or become zero when predicting OA in the presence of $\mathrm{P}-\mathrm{O}$ fit).

The tables below present a three step test of mediation with the first section presenting the regression weights and variance explained for each interactive term in the prediction of $\mathrm{P}-\mathrm{O}$ fit. This is followed by the regression weights and variance explained by each interactive term and $\mathrm{P}-\mathrm{O}$ fit perceptions in the prediction of organizational attraction. Finally, the third section of the table presents the mediated model where P-O fit is added to each interactive term to predict organizational attraction. Following Baron and Kenny's (1986) steps for testing mediation, the mediated model regressions are only presented when the first two sections of the tables identified the interactive term as a significant predictor of both P-O fit and organizational attraction.

Hypothesis 26. Among students, hypothesis 26 was supported. P-O partially mediated the relationship between the interaction of innovativeness ratings of organizational personality and $n$ Ach in predicting attraction ratings (See Table 23 ). The influence of the interaction of ratings of innovativeness with need for achievement on 
attraction ratings was reduced $(\beta=.406$ to $\beta=.290)$ when $\mathrm{P}-\mathrm{O}$ fit was added to the model predicting attraction ratings.

Among working adults, hypothesis 26 was supported. P-O partially mediated the relationship between the interaction of innovativeness ratings of organizational personality and $n$ Ach in predicting attraction ratings (See Table 24). The influence of the interaction of ratings of innovativeness with need for achievement on attraction ratings was reduced $(\beta=.442$ to $\beta=.319)$ when $\mathrm{P}-\mathrm{O}$ fit was added to the model predicting attraction ratings.

Table 23.

Mediating Effect of P-O Fit on Attraction Ratings of Students

\begin{tabular}{|c|c|c|c|c|}
\hline Outcome & Predictor & Beta & $\mathbf{p}$ & $\mathbf{R}^{2}$ \\
\hline \multirow[t]{8}{*}{ P-O Fit $=$ Predictor $+\mathrm{e}$} & a) INV*nAch & .297 & $<.01$ & .09 \\
\hline & b) $\mathrm{DOM}^{*} \mathrm{nAch}$ & .250 & $<.01$ & .06 \\
\hline & c) $\mathrm{DOM}^{*}$ nPow & .239 & $<.01$ & .06 \\
\hline & d) $\mathrm{STY}^{*}$ nPow & .192 & $<.01$ & .04 \\
\hline & e) $\mathrm{THR}^{*}$ nPow & -.021 & $.76^{\mathrm{ns}}$ & $<.01$ \\
\hline & f) $\mathrm{BS} * \mathrm{nAff}$ & .306 & $<.01$ & .09 \\
\hline & g) STY*nAff & .198 & $<.01$ & .04 \\
\hline & h) THR*nAff & -.047 & $.51^{\mathrm{ns}}$ & $<.01$ \\
\hline \multirow[t]{9}{*}{$\mathrm{OA}=$ Predictor $+\mathrm{e}$} & P-O Fit & .474 & $<.01$ & .23 \\
\hline & a) $\mathrm{INV}^{*} \mathrm{nAch}$ & .406 & $<.01$ & .16 \\
\hline & b) $\mathrm{DOM}^{*} \mathrm{nAch}$ & .266 & $<.01$ & .07 \\
\hline & c) $\mathrm{DOM}^{*}$ nPow & .331 & $<.01$ & .11 \\
\hline & d) $\mathrm{STY}^{*}$ nPow & .422 & $<.01$ & .18 \\
\hline & e) $\mathrm{THR}^{*}$ nPow & .062 & $.39^{\mathrm{ns}}$ & $<.01$ \\
\hline & f) $\mathrm{BS}^{*} \mathrm{nAff}$ & .270 & $<.01$ & .07 \\
\hline & g) $\mathrm{STY}^{*} \mathrm{nAff}$ & .367 & $<.01$ & .14 \\
\hline & h) THR*nAff & -.061 & $.40^{\mathrm{ns}}$ & $<.01$ \\
\hline \multirow[t]{3}{*}{$\mathrm{OA}=\mathrm{P}-\mathrm{O}$ Fit + Predictor $+\mathrm{e}$} & a) INV*nAch & .290 & $<.01$ & .30 \\
\hline & b) $\mathrm{DOM}^{*} \mathrm{nAch}$ & .157 & .02 & .25 \\
\hline & c) $\mathrm{DOM}^{*}$ nPow & .231 & $<.01$ & .28 \\
\hline
\end{tabular}



d) $\mathrm{STY}^{*} \mathrm{nPow}$
$\begin{array}{lll}.343 & <.01 & .34\end{array}$
f) BS*nAff
$\begin{array}{lll}.138 & .04 & .24\end{array}$
g) STY*nAff
$\begin{array}{lll}.284 & <.01 \quad .30\end{array}$

Table 24.

Mediating Effect of P-O Fit on Attraction Ratings of Working Adults

\begin{tabular}{|c|c|c|c|c|}
\hline Outcome & Predictor & Beta & $\mathbf{p}$ & $\mathbf{R}^{2}$ \\
\hline \multirow[t]{8}{*}{$\mathrm{P}-\mathrm{O}$ Fit $=$ Predictor $+\mathrm{e}$} & a) INV*nAch & .363 & $<.01$ & .13 \\
\hline & b) $\mathrm{DOM}^{*}$ nAch & .197 & $<.01$ & .04 \\
\hline & c) $\mathrm{DOM}^{*} \mathrm{nPow}$ & .143 & $<.05$ & .02 \\
\hline & d) $\mathrm{STY}^{*}$ nPow & .122 & $.09^{\mathrm{ns}}$ & .02 \\
\hline & e) THR*nPow & -.103 & $.15^{\mathrm{ns}}$ & .01 \\
\hline & f) $\mathrm{BS} * \mathrm{nAff}$ & .309 & $<.01$ & .10 \\
\hline & g) STY*nAff & .141 & $<.05$ & .02 \\
\hline & h) THR*nAff & -.127 & $.08^{\mathrm{ns}}$ & .02 \\
\hline \multirow[t]{9}{*}{$\mathrm{OA}=$ Predictor $+\mathrm{e}$} & P-O Fit & .454 & $<.01$ & .21 \\
\hline & a) INV*nAch & .442 & $<.01$ & .19 \\
\hline & b) $\mathrm{DOM}^{*} \mathrm{nAch}$ & .242 & $<.01$ & .06 \\
\hline & c) $\mathrm{DOM}^{*}$ nPow & .128 & $.07^{\mathrm{ns}}$ & .02 \\
\hline & d) STY*nPow & .226 & $<.01$ & .05 \\
\hline & e) THR*nPow & .214 & $<.01$ & .05 \\
\hline & f) $\mathrm{BS} * \mathrm{nAff}$ & .226 & $<.01$ & .05 \\
\hline & g) STY*nAff & .215 & $<.01$ & .05 \\
\hline & h) THR*nAff & -.248 & $<.01$ & .06 \\
\hline \multirow[t]{4}{*}{$\mathrm{OA}=\mathrm{P}-\mathrm{O}$ Fit + Predictor $+\mathrm{e}$} & a) INV*nAch & .319 & $<.01$ & .29 \\
\hline & b) $\mathrm{DOM}^{*} \mathrm{nAch}$ & .157 & .02 & .25 \\
\hline & f) $\mathrm{BS}^{*} \mathrm{nAff}$ & .095 & .16 & .21 \\
\hline & g) STY*nAff & .154 & .02 & .23 \\
\hline
\end{tabular}

Hypothesis 27. Among students, hypothesis 27 was supported. P-O fit partially mediated the relationship between the interaction of dominance ratings of organizational personality and $n$ Ach in predicting attraction ratings. The influence of the interaction of 
ratings of dominance with need for achievement on attraction ratings was reduced ( $\beta=$ .266 to $\beta=.157$ ) when $\mathrm{P}-\mathrm{O}$ fit was added to the model predicting attraction ratings.

Among working adults, hypothesis 27 was supported. P-O partially mediated the relationship between the interaction of dominance ratings of organizational personality and $n$ Ach in predicting attraction ratings. The influence of the interaction of ratings of innovativeness with need for achievement on attraction ratings was reduced ( $\beta=.242$ to $\beta$ $=.157)$ when $\mathrm{P}-\mathrm{O}$ fit was added to the model predicting attraction ratings.

Hypothesis 28 . Among students, hypothesis 28 was supported. P-O fit partially mediated the relationship between the interaction of dominance ratings of organizational personality and $n$ Pow in predicting applicant attraction. The influence of the interaction of ratings of dominance with need for power on attraction ratings was reduced $(\beta=.331$ to $\beta=.231$ ) when $\mathrm{P}-\mathrm{O}$ fit was added to the model predicting attraction ratings.

Among working adults, hypothesis 28 was not supported. The interaction of dominance ratings and need for power did not significantly predict attraction ratings, therefore a test of mediation was inappropriate.

Hypothesis 29. Among students, hypothesis 29 was supported. P-O fit partially mediated the relationship between the interaction of stylishness ratings of organizational personality and $n$ Pow in predicting applicant attraction. The influence of the interaction of ratings of style with need for power on attraction ratings was reduced $(\beta=.422$ to $\beta=$ .343) when P-O fit was added to the model predicting attraction ratings.

Among working adults, hypothesis 29 was not supported. The interaction of stylishness ratings and need for power did not significantly predict P-O fit, therefore a test of mediation was inappropriate. 
Hypothesis 30. Among students, hypothesis 30 was not supported. The interaction of thriftiness ratings and need for power did not significantly predict $\mathrm{P}-\mathrm{O}$ fit or attraction ratings, therefore a test of mediation was inappropriate.

Among working adults, hypothesis 30 was not supported. The interaction of thriftiness ratings and need for power did not significantly predict P-O fit, therefore a test of mediation was inappropriate.

Hypothesis 31 . Among students, hypothesis 31 was supported. P-O fit partially mediated the relationship between the interaction of boy scoutishness ratings of organizational personality and $n \mathrm{Aff}$ in predicting applicant attraction. The influence of the interaction of ratings of boy scout with need for affiliation on attraction ratings was reduced $(\beta=.270$ to $\beta=.138)$ when $\mathrm{P}-\mathrm{O}$ fit was added to the model predicting attraction ratings.

Among working adults, hypothesis 31 was supported. P-O fit fully mediated the relationship between the interaction of boy scoutishness ratings of organizational personality and $n \mathrm{Aff}$ in predicting applicant attraction. The influence of the interaction of ratings of boy scout with need for affiliation on attraction ratings was reduced $(\beta=.309$ to $\beta=.095$ ) and became non-significant when $\mathrm{P}-\mathrm{O}$ fit was added to the model predicting attraction ratings.

Hypothesis 32 . Among students, hypothesis 32 was supported. P-O fit partially mediated the relationship between the interaction of stylishness ratings of organizational personality and $n$ Aff in predicting applicant attraction. The influence of the interaction of ratings of style with need for affiliation on attraction ratings was reduced $(\beta=.367$ to $\beta=$ .284) when P-O fit was added to the model predicting attraction ratings. 
Among working adults, hypothesis 32 was supported. P-O fit partially mediated the relationship between the interaction of stylishness ratings of organizational personality and $n$ Aff in predicting applicant attraction. The influence of the interaction of ratings of style with need for affiliation on attraction ratings was reduced $(\beta=.215$ to $\beta=$ .154) when P-O fit was added to the model predicting attraction ratings.

Hypothesis 33. Among students, hypothesis 33 was not supported. The interaction of thriftiness ratings and need for affiliation did not significantly predict $\mathrm{P}-\mathrm{O}$ fit or attraction ratings, therefore a test of mediation was inappropriate.

Among working adults, hypothesis 33 was not supported. The interaction of thriftiness ratings and need for affiliation did not significantly predict P-O fit, therefore a test of mediation was inappropriate. 


\section{Chapter V: Discussion}

This dissertation was designed to examine the processes that may underlie the relationship between person-organization fit and applicant attraction. Specifically, the goal of this project was to determine whether individuals' perceptions of organizational personality may affect their subjective perceptions of fit and subsequent attraction to an organization through underlying mechanisms involving motivation. Two models of human motivation related to need motivation and expectancy beliefs were tested to evaluate their influence on the aforementioned relationships. Findings from the working adult sample support the assertion that individuals' valence, instrumentality, and expectancy of work related outcomes are significantly related to organizational personality perceptions and attraction to an organization. Also, the interaction of organizational personality perceptions and need motivation significantly affects individuals' perceptions of person-organization fit and subsequent attraction to an organization. Additionally, these relationships were inconsistent in several instances for student and working adult participants. This inconsistency draws into question the utility of using students as proxies for working adults when conducting research on applicant attraction.

It should be noted that a possible cause of the difference in working adults' and students' impressions of organizational personality and valence for certain work related outcomes may be due to generational effects. Prior research has demonstrated that generational differences (for e.g., Gen-X, Baby-Boomers, and Millennials) may exist in psychological traits (Macky, Gardner, \& Forsyth, 2008; Twenge \& Campbell, 2008) and work values (Cennamo \& Gardner, 2008) that may affect the career choices of 
individuals. However, the impact of generational differences in the current research may have been minimal since prior research has also shown that individuals from different generations do not typically differ in terms of personality traits or motivational drivers (Wong, Gardiner, Lang, \& Coulon, 2008). Future research will need to address generational differences in organizational personality preferences.

\section{Valence-Instrumentality-Expectancy Beliefs Model Findings}

The findings of the current project extend prior research on the valenceinstrumentality-expectancy (VIE) model of motivation for predicting behavior and also adds to the literature on VIE model by establishing support for a relationship between organizational personality perceptions and instrumentality ratings of desirable work related outcomes. Specifically, among students there was strong support for a predictive model of attraction based on the sum of instrumentality ratings for desirable outcomes $(\mathrm{OA}=\Sigma \mathrm{I})$. Students used organizational personality information to help them determine the extent to which they believed working for an organization would provide them with desired outcomes like prestige, a good salary, and job security. This finding supports similar results by Wanous et al. (1983). Unexpectedly, a weighted model of motivation $(\mathrm{OA}=\mathrm{E}(\Sigma \mathrm{IV}))$ including expectancy, instrumentality and valence ratings did not predict attraction better than all other models among students. However, the weighted model showed utility in predicting attraction for working adults. Working adult's attraction to an organization was predicted equally well by the weighted model $(\mathrm{OA}=\mathrm{E}(\Sigma \mathrm{IV}))$ as by the sum of instrumentality model $(\mathrm{OA}=\Sigma \mathrm{I})$. It is possible that working adults are better able to consider the differential value of desirable outcomes and their expectations about how likely it is they would be able to work with an organization when forming their feelings 
of attraction. Taken together these findings support the idea that organizational personality information may affect applicant attraction most strongly due to motivation caused by the instrumentality of desired work outcomes.

The strong support for hypotheses 5 through 9 indicate that both students' and working adults' perceptions of organizational personality significantly affected their opinions concerning the instrumentality of work related outcomes. As hypothesized, both students and working adults believed that boy scoutish organizations would be warmer, more secure, more honest, and provide better benefits and greater chance to help others. Interestingly, students seemed to prefer boy scoutish organizations more than working adults. Students' instrumentality ratings for all desired work outcomes were significantly positively related to boy scoutishness ratings, but working adults did not believe that boy scoutishness was an important indicator of being able to gain prestige, a good salary, or intellectual stimulation.

Both students and working adults believed that innovativeness was a desirable organizational personality trait that would lead to greater likelihood of flexibility in practices, challenging work, chance to use creative abilities, and intellectual stimulation. Additionally, more innovative organizations were seen as providing a greater likelihood to obtain prestige, opportunities for advancement, a good salary, ability to help others, job security, warmth, good benefits, and honesty in business practices. Innovativeness seems to be a highly desired organizational personality trait for both students and working adults. If individuals seek out traits in organizations that they deem valuable for their own identity, then creativity, originality, and uniqueness may be the most important market signals for organizations. 
As expected, dominance ratings were related to instrumentality for prestige, a good salary, and opportunities for advancement. Both students and working adults felt that dominant organizations would offer good benefits. Additionally, students saw flexibility in practices as a possible outcome of dominance while working adults believed dominance may lead to challenging work. Unlike the other organizational personality traits, dominance ratings were not related to instrumentality of many outcomes beyond those hypothesized. It is possible that students and working adults' shared understanding of dominance as a trait was more consistent than with the other organizational personality traits.

Stylishness ratings produced similar results as boy scoutishness and innovativeness ratings. Students seem to make more globally positive inferences concerning instrumentality of work outcomes than working adults. Once again, students' stylishness ratings were significantly related to all positive work related outcomes except an ability to help others. Conversely, working adults felt that stylishness would be associated with a chance to gain prestige, a good salary, opportunities for advancement, flexibility in practices, challenging work, and a chance to use creative abilities. Working adults seem to be better able to distinguish the differential impact of organizational personality traits on the instrumentality of desirable work outcomes. Working adults in this research were predominantly full time workers and therefore likely had much more experience than students in evaluating information about organizational values, policies, and goals.

Thriftiness signaled different instrumentality for students and working adults. Students felt that thriftiness would lead to less opportunity for advancement and greater 
opportunity for warmth in the workplace. Conversely, working adults felt that thriftiness would be detrimental to being able to gain prestige, opportunity for advancement, a good salary, good benefits, challenging work, ability to help others, job security, intellectual stimulation, and honesty in business practices. Working adults' clearly believed that thriftiness was not a good trait for organizations to hold. This has implication for how organizations known for thriftiness should target their recruitment practices. Students will likely be less dissuaded by thriftiness than working adults, but this may be a problem for thrifty organizations when recruiting for high level positions. Being able to gauge thriftiness could be critical to individuals' decisions concerning fit and attraction because of its polarizing effect.

In summary, all five organizational personality traits are important to informing individuals' beliefs about being able to obtain desirable work outcomes from an organization. However, students and working adults appear to use organizational personality information differently to inform fit decisions. No a priori hypotheses were made about how each organizational personality trait might influence personorganization fit, but the instrumentality findings demonstrate that students and working adults do not always agree in their observations. To test this idea, organizational personality trait ratings were regressed on person-organization fit scores (See Table 25). Among students, organizational personality trait ratings significantly predicted about $14 \%$ of the variance in P-O fit scores. However, when all traits were included in the regression model only boy scoutishness and thriftiness ratings were significant. This is likely because students did not see much difference in their ability to obtain desired outcomes between boy scoutish, innovative, dominant, and stylish organizations. Unlike 
students, working adults' organizational personality trait ratings accounted for a much more $(27 \%)$ variance in $\mathrm{P}-\mathrm{O}$ fit scores. Also unlike students, working adults' $\mathrm{P}-\mathrm{O}$ fit scores were being significantly affected by boy scoutishness, innovativeness, and dominance ratings when all traits were included in the regression model. These results indicate that the ability of individuals to use organizational personality information to inform their fit perceptions could differ greatly based on their work experience and the type of trait information organizations focus on in their recruitment.

Table 25 .

Predicting P-O Fit through Organizational Personality Ratings

\begin{tabular}{llccc} 
Group & Predictor & Beta & p & $\mathbf{R}^{\mathbf{2}}$ \\
\hline \multirow{6}{*}{ Students } & Constant & 9.658 & $<.01$ & .16 \\
& Boy Scoutishness & .119 & $<.01$ & \\
& Innovativeness & .048 & .43 & .56 \\
& Dominance & .045 & $<.05$ & .27 \\
& Thrift & -.091 & .62 & \\
& Style & .031 & $<.01$ & \\
Working Adults & 11.294 & $<.01$ & \\
& Constant & .142 & $<.01$ & .01 \\
& Boy Scoutishness & .206 & .11 & .34 \\
& Dominance & .202 & & \\
& Thrift & -.070 & -.068 & \\
& Style & &
\end{tabular}

\section{Need Motivation Model Findings}

The utility of the need motivation model in predicting individuals' perceptions of fit and attraction to organizations was mixed. As expected, $\mathrm{P}-\mathrm{O}$ fit scores mediated the relationships between attraction ratings and interactions between organizational personality ratings with need motivation. Generally, this finding supports prior research 
that has demonstrated the important role that P-O fit often plays as a mediator for many desirable organizational outcomes. Clearly, organizations should not ignore the importance of P-O fit to employees' future success. Organizational personality information that allows individuals to make inferences about organizational traits such as boy scoutishness, innovativeness, dominance, stylishness, and thriftiness is useful for recruitment strategies because it influences $\mathrm{P}-\mathrm{O}$ fit. The current research demonstrated that organizational personality information may affect P-O fit because of its interaction with individuals need motivations (need for achievement, need for power, and need for affiliation.

Among students and working adults the interaction of need for achievement scores with both innovativeness and dominance ratings predicted P-O fit scores and subsequent attraction. P-O fit scores partially mediated the relationship of these interactions to attraction because these interactions help to inform perceptions of $\mathrm{P}-\mathrm{O}$ fit. For instance, higher need for achievement coupled with greater perceptions of innovativeness was predictive of a greater sense of fit that lead to greater attraction to an organization for both students and working adults. Also, higher need for achievement coupled with greater perceptions of dominance were predictive of a greater sense of fit and attraction to an organization. These findings support the notion that individuals may compare their requisite needs for achievement to aspects of the organization that are associated with achievement (i.e. dominance and innovativeness) to help them form opinions about their fit. These fit perceptions are then become the driving force behind attraction to the organization. 
Similarly, the interaction of need for power scores with both dominance and stylishness ratings predicted P-O fit and subsequent attraction in students. As before, P-O fit scores mediated the relationship between these interactions and attraction. Individuals with a higher need for power who perceived greater dominance or stylishness in an organization had a greater sense of fit that lead to greater attraction. Dominance and stylishness in organizations are both related to organizations being powerful, influential, trendy, and prestigious. High nPow individuals are should feel more at home organizations that strive to be dominant and stylish because those types of organizations are more likely to meet their needs. Contrary to students, working adults need for power did not interact with dominance and stylishness ratings to predict P-O fit. Working adults may not value social power in a job search context the same way that students do. Working adults preferred dominance as an organizational personality trait regardless of their need for power. Dominance ratings positively predicted perceptions of fit (Table 16) across all individuals.

The interactions of need for affiliation scores with both boy scoutishness ratings and stylishness ratings were predictive of $\mathrm{P}-\mathrm{O}$ fit and subsequent attraction. Both students and working adults' perceptions of fit increased if those high in need for affiliation perceived more organizational boy scoutishness or stylishness. As expected, need for affiliation seems to be satisfied by traits like concern for others, honesty, prestige, and impressiveness that are all associated with organizations striving for boy scoutishness and/or style. Once again, these perceptions of fit then predicted attraction ratings. These findings strengthen prior research findings that need for affiliation is related to values for social esteem, prestige, social concern, and supportiveness (Wiesenfeld et al., 2001; 
Winter et al., 1998). The current research also extends the need theory of motivation by identifying organizational personality traits as relevant sources of information for individuals to assess possible need fulfillment.

Contrary to expectations, P-O fit did not mediate the interaction of thriftiness ratings and need motivation to predict attraction. For both students and working adults the findings related to thriftiness ratings were mixed. For instance the interaction of thriftiness ratings and need for power scores significantly predicted organizational attraction in working adults, but did not predict working adults' perceptions of fit. A possible explanation for this is that thriftiness was seen as a negative organizational trait in general by both students and working adults. Increased thriftiness was negatively related to both organizational attraction and fit perceptions overall in both students and working adults. Need motivation may have become irrelevant in the case of thriftiness because all individuals felt it was undesirable.

\section{Crossing Need Motivation and Expectancy Beliefs}

It was believed that individuals need for achievement, power, and affiliation would influence their valence for various desirable work related outcomes that organizations may be able to offer through employment. These outcomes included: prestige, opportunities for advancement, flexibility in practices, challenging work, a good salary, ability to help others, job security, warmth, chance to use creative abilities, good benefits, intellectual stimulation, and honesty in business practices. Students' nAch scores were not significantly related to any valence ratings. However, there was support for the assertion that working adults with higher nAch scores would place a high value on opportunities to use the creative abilities. In general, it seems that need for achievement 
was of little consequence to individuals in the current research in determining the value they placed on desired work outcomes. This may be because the work related outcomes that participants rated were all positive in nature and would likely be strongly desired by all individuals regardless of need for achievement. In addition, participants were asked to rank each of the twelve work outcomes in terms of how important they felt each was to a job decision. The averaged rankings showed a clear preference by students and for working adults for a good salary followed by opportunities for advancement. Valence ratings may not have varied sufficiently to test the influence of nAch scores.

Need for power (nPow) scores were significantly related to valence ratings of prestige for both students and working adults and opportunity for advancement for working adults only. nPow is partly synonymous with a desire for social power. Value for prestige was expected since prestige is often a tool for helping individuals exercise social influence. Similarly, opportunities for advancement would allow an individual a greater likelihood of supervising others. Unexpectedly, honesty in business practices and a good salary were not valued more highly by high nPow individuals. A good salary is something that individuals valued highly regardless of nPow. A good salary was ranked as the most valued work outcome for both students and working adults. High nPow individuals tend to be trusting and conservative (Singh, 1986), but honesty in business practices may not be as relevant to these individuals. Perhaps coworker honesty would be of greater issue to high nPow individuals. Honesty in business practices also may seem ambiguous to individuals and represent a variety of possible outcomes (i.e. honesty in hiring procedures, honesty with business partners, etc.) that do not necessarily relate to social power. 
Need for affiliation (nAff) scores were significantly related to valence ratings of ability to help others for students, but did not affect the valence ratings of working adults. High nAff individuals are focused on relationships with others and would logically value being able to help others in the workplace. Unexpectedly, nAff scores of students and working adults were not related to valence ratings for warmth or job security. It is possible that valence ratings for warmth and job security did not vary sufficiently to test for the relationship to nAff scores. Both warmth and job security were middle of the pack in terms of the overall averaged valence rankings provided by students and working adults. Once again, since these work outcomes were all very positive in nature, individuals high in nAff may have felt that warmth and job security were important enough to rank above other outcomes like a good salary, good benefits, or opportunities for advancement. However, students' nAff scores were positively related to valence for honesty in business practices while working adults' scores were negatively related to valence for challenging work. High nAff students who are likely new to the workplace may feel honesty in business practices is more important to them compared to other outcomes because of the impact it will have on forging work relationships. Conversely, high nAff working adults' may be less interested in challenging work because they may see it as a hindrance to being able to socialize with coworkers or family and friends. Implications on Organizational Personality in Recruitment

One of the primary goals of this research was to evaluate how organizational personality information will affect job seekers' behavior. Though the current findings strengthen the utility of organizational personality measures, they also draw into question the construct validity of these measures. The effective measurement of organizational 
personality may be hindered by the current five factor conceptualization posited by Slaughter et al. (2004). For instance, the present study found that working adults' ratings of stylishness and innovativeness were very highly correlated $(\mathrm{r}=.59)$ as well as dominance and innovativeness ratings $(\mathrm{r}=.54)$. Similar high correlations were observed between several of the five dimensions of organizational personality amongst students' ratings. One issue with these findings is that there may be a positive manifold effect (see Viswesvaran \& Sanchez, 1997) across the correlations of the five dimensions of organizational personality whereby it may be more suitable to reduce the number of factors. Conversely, it is possible that the current conceptualization of organizational personality is too limited in scope and overlooks the likelihood of sub-facets, or additional dimensions of personality. This issue is akin to the appropriate measurement of individual personality that has been heavily researched over the past several decades and produced numerous conceptualizations of personality including the five factor model (FFM) and the sixteen personality trait (16PF) model. In most research involving personality it is difficult to prevent the bandwidth fidelity dilemma (Ones \& Viswesvaran, 1996). For instance, in the current research, would it have been better to focus on superordinate dimensions of organizational personality or more narrowly focused facets be analyzed in relation to processes like job seeker decision making. Perhaps more narrow facets of organizational personality would have borne more meaningful relationships between need motivation and fit perceptions or attraction. For example, it is possible that high nAff individuals' perceptions of fit would be more impacted by believing an organization highly values attentiveness to people rather than 
simply looking at the overall boy scoutishness of that organization since boy scoutishness encompasses several other traits (e.g., honesty, family orientation, and fair practice).

Additionally, perceptions of organizational personality for specific organizational profiles in the current study were not consistent between working adults and students and did not have consistent effects on job seeker decision making behavior. These findings create major implications to organizations in terms of their recruitment strategies. For instance, organizations pursuing recently graduated students for entry level positions may be better served by focusing on the boy scoutishness or innovativeness of the organization since both these personality dimensions were significantly positively correlated with instrumentality ratings for all positive work related outcomes in students' ratings in the current study. Conversely, recruiters that are seeking experienced workers may want to focus on selling the dominance of the organization and stylishness of the organization. Also, it is likely that sub-facets of these organizational personality traits may also play an important role in the differential preference of students and adults for certain superordinate organizational personality traits. Therefore, organizations also need to determine whether it is advantageous to create different profiles of themselves for different audiences. Further research is needed to determine if this type of recruitment strategy is possible and also how differential profiles may be created by organizations that still capture the core values of the organizations. As McCrae and Sutin (2007) have suggested, researchers need to explore the “...consequences of aggregate personality traits in dyads, organizations, and nations..." (p. 423) to garner a greater understanding of how these types of personality influence individuals and to further develop theories for of aggregate personality. 


\section{Non-Findings}

There were non-significant findings for several hypotheses of moderated relationships involving need motivation scores, organizational personality ratings, perceptions of fit and organizational attraction. For instance, it was expected that need for achievement scores would moderate the relationship between organizational innovativeness ratings and perceptions of fit such that individuals high in nAch would indicate greater perceptions of fit when innovativeness ratings were high. Even though this expectation was supported by the mediated regression model involving the interaction term for $\mathrm{nAch}$ and innovativeness ratings, the moderated regression model did not obtain significant slope differences for the interaction term (Table 15). However, both regression models in the test for moderation were significantly predictive of perceptions of fit with significant differences in the intercept and slope (beta) for innovativeness. Additionally, regression models where P-O fit was predicted by innovativeness ratings solely or nAch scores solely were significant. Therefore, innovativeness ratings had were significantly predictive of $\mathrm{P}-\mathrm{O}$ fit, nAch scores were predictive of $\mathrm{P}-\mathrm{O}$ fit, and the interaction term was predictive of $\mathrm{P}-\mathrm{O}$ fit. However, a regression model containing all three predictor models did not yield significant slopes for all three predictors, but the overall model fit the data. This pattern of results was found consistently across all the hypothesized moderated regression relationships. The non-findings for these hypotheses are unexpected, but the regression models did fit the data. Also, as mentioned earlier there was support for the predictive value of several multiplicative interaction terms (organizational personality traits with need motivation) for perceptions of fit and organizational attraction. 
Additionally, the prediction of P-O fit and attraction by combinations of a single need motivation and organizational personality trait rating may be insufficient to calculate meaningful slopes. P-O fit and attraction are based on several considerations and in this research individuals were exposed to organizational personality information for five separate traits and completed measures pertaining to three different need motives. Each individual therefore had fifteen possible need motivation score to organizational personality trait rating combinations. Therefore, there is no way to realistically evaluate how individuals may differ in terms of perceptions of fit because of these competing need motives and competing perceptions of organizational personality traits. For instance, an individual who has a high nAch score may also have a high nAff score and a high nPow score. It is unlikely that all individuals with this need motivation profile will value organizational innovativeness the same when assessing their subjective perceptions of fit.

\section{Limitations and Future Research}

The current study contained two primary limitations. First, the work related outcomes that participants completed valence ratings for may have been too positive in nature and therefore created a ceiling effect. As mentioned earlier, outcomes like a good salary and good benefits are going to be highly valued by any sensible working individual. Therefore, it may have been difficult for individuals to rank some work outcomes unequivocally. For instance, a good salary and good benefits were ranked very high in terms of importance for both working adults and students, but several of the other work outcomes like warmth, intellectual stimulation, job security, etc. were similarly ranked. Ideally, all outcomes should have had similar averaged rankings in order to test for differences in ranking due to need motivation or any other predictors. This would 
have meant that each outcome would statistically have had the same probability of being ranked 1 through 12 by any given individual. Future research may be able to address this issue in a few different ways. A more diverse set of work related outcomes could be used for valence ratings. It would probably be best to avoid inclusion of outcomes like a good salary and good benefits that are going to be very highly ranked by all individuals. The response format for valence ratings could also be changed to a Likert-type continuous measure instead of a forced ranking. This would allow individuals to rate the importance of each outcome separately instead of in relation to one another. Therefore, greater consistency would likely be seen among individuals that share similarities on an individual difference predictor like need motivation. A ranking scheme has been used in prior research (Wanous et al., 1983) on valence, but that study did not attempt to predict valence for various outcomes by individual difference variables. Future research should be conducted to evaluate the influence of valence ratings for work related outcomes using a continuous scale response format to compare differences to a ranking approach.

A second limitation of this research is that organizational personality profiles did not discuss any job related features to participants. In retrospect, participants' perceptions of fit and organizational attraction may have been affected by their preconceptions concerning the organization. For instance, working individuals who are pursuing careers in education may not have been able to imagine fitting in at American Express because it is known as a financial corporation. They would therefore report lower perceptions of fit and attraction even if their need motives may have been satisfied by American Express based on its organizational personality traits. It would have been better to specify in organizational profiles that the participants imagine that they are considering a position in 
their career path at the organization they were assigned. Job seekers are not going to consider organizations for employment if they do not offer opportunities within their career interests. Fortunately, the current research had enough statistical power to overcome any such issues with the organizational profiles. This is evidenced by the significant findings for the prediction of P-O fit and organizational attraction. However, future research should be conducted that addresses this issue.

Two other issues that should be addressed in future research is the significance of organizational reputation and job market conditions to job seeker decision making. Reputation was measured in the current research, but the reputations of the organizations included in this project were all very positive. Future research could address how individuals may deal with the moral issues of working for powerful organizations with questionable reputations (e.g., Phillip Morris, BP). These types of organizations also bring into question the generalizability of the current organizational personality framework for categorizing companies. Many individuals may argue that these largely successful organizations that have negative reputations may be some sort of other personality like the maverick or rebel. Additionally, job market conditions could also have a major role in job seekers' behavior. In the current economic downturn for the United States it is arguable that most individuals would accept just about any job since the rate of unemployment is at a record high. This situation could have a detrimental effect on measuring the effectiveness of recruitment activities since all job seekers could potentially be interested in a position simply because it is one of few available. The current research was unable to address this issue since the participants would have had to be restricted to individuals actively seeking jobs. 


\section{Concluding Remarks}

The purpose of this research was to investigate possible mechanisms underlying the influence of organizational personality on applicants' perceptions of fit and organizational attraction. Based on the current research findings it is evident that individuals place a great deal of importance on the outcomes that they expect to receive after joining an organization when making their ob choice decisions. Further, these instrumentality beliefs are shaped by our perceptions of organization personality that we form from gathering information about an organization from media like company advertisements, seeing commercials, job postings, popular press, and first hand interaction with current employees. Also, instrumentality beliefs about desirable work related outcomes seem to be more important to individuals' organizational attraction decisions than their need motives. However, need motives seem to interact with individuals' perceptions of organizational personality in consistent and logical patterns to predict perceptions of fit and organization attraction. For instance, individuals who are high in need for achievement are able to recognize how innovativeness or dominance in an organization may represent a greater likelihood for meeting identity relevant needs or goals. As expected, a greater congruence between need motives and organizational personality will lead to greater perceptions of fit and organizational attraction. Once again, the significance of subjective perceptions of person-organization fit is highlighted as a means through which our beliefs concerning organizational personality affect our attraction to an organization.

Interestingly, this relationship was not consistent across our samples. Organizations need to be aware that students seem to be motivated in their job choice 
behavior mostly by what they believe the organization will be able to provide them while working adults are better able to balance their instrumentality beliefs along with their preexisting values, and their expectations concerning the viability of possible employment with the organization. The recruitment activities for each of these populations must therefore be tailored to maximize the power of a selection system involving positions for either group. Further research must be conducted to evaluate the importance of organizational personality to job choice behavior, but the current research has demonstrated that organizational personality is a dynamic construct that may greatly affect the recruitment viability of organizations. 


\section{REFERENCES}

Aaker, J.L. (1997). Dimensions of brand personality. Journal of Marketing Research, 34, 347-356.

Aitken-Harris, J. (2004). Measured intelligence, achievement, openness to experience, and creativity. Personality and Individual Differences, 36, 913-929.

Allen, D.G., Mahto, R.V., \& Otondo, R.F. (2007). Web-based recruitment: Effects of information, organizational brand, and attitudes toward a Web site on applicant attraction. Journal of Applied Psychology, 92, 1696-1708.

Anderson, N. (2003). Applicant and Recruiter Reactions to New Technology in Selection: A Critical Review and Agenda for Future Research. International Journal of Selection and Assessment, 11, 121-136.

Arthur, W., Jr., Bell, S. T., Villado, A. J., \& Doverspike, D. (2006). The use of personorganization fit in employment decision making: An assessment of its criterionrelated validity. Journal of Applied Psychology, 91, 786-801.

Barber, A.E. (1998). Recruiting Employees: Individual and organizational perspectives. Thousand Oaks, CA: Sage Publications.

Baron, R.M. \& Kenny, D.A. (1986). The moderator-mediator variable distinction in social psychological research: Conceptual, strategic, and statistical considerations. Journal of Personality and Social Psychology, 51, 1173-1182.

Berg, P.O. (1985). Organization change as a symbolic transformation process. In P. Frost, L. Moore, M. R. Louis, C. Lundberg, \& J. Martin (Eds.), Reframing Organizational Culture, pp. 281-300. Beverly Hills, CA: Sage.

Billsberry, J. (2007). Attracting for values: An empirical study of ASA's attraction proposition. Journal of Managerial Psychology, 22, 132-149.

Breaugh, J. A. (1992). Employee Recruitment: Theory and Practice. Boston: PWS-Kent Publishing.

Breaugh, J.A. \& Starke, M. (2000). Research on employee recruitment: So many studies, so many remaining questions. Journal of Management, 26, 405-434.

Bretz, R.D., \& Judge, T.A. (1994). The role of human resource systems in job applicant decision processes. Journal of Management, 20, 531-551.

Bright, W.E. (1976). How one company manages its human resources. Harvard Business Review, 54, 81-93. 
Cable, D.M., \& Judge, T.A. (1996). Person-organization fit, job choice decisions, and organizational entry. Organizational Behavior and Human Decision Processes, $67,294-311$.

Cable, D. M., \& Judge, T.A. (1997). Interviewer's perceptions of person-organization fit and organizational selection decisions. Journal of Applied Psychology, 82, 546-561.

Cable, D. M., \& Turban, D. B. (2003). The value of organizational reputation in the recruitment context: A brand equity perspective. Journal of Applied Social Psychology, 33, 2244-2266.

Cappelli, P. (2001). Making the most of on-line recruiting. Harvard Business Review, 79, $139-146$.

Carless, S.A. (2005). Person-job fit versus person-organization fit as predictors of organizational attraction and job acceptance intentions: A longitudinal study. Journal of Occupational and Organizational Psychology, 78, 411-429.

Cascio. W.F. \& Aguinis, H.E. (2005). Applied Psychology in Human Resource Management. (6 ${ }^{\text {th }}$ Edition). New York, NY: Prentice-Hall.

Cennamo, L. \& Gardner, D, (2008). Generational differences in work values, outcomes and person-organisation values fit. Journal of Managerial Psychology, 23, 891906.

Chapman, D.S., Uggerslev, K.L., Carroll, S.A., Piasentin, K.A. \& Jones, D.A. (2005). Applicant attraction to organizations and job choice: A meta-analytic review of the correlates of recruiting outcomes. Journal of Applied Psychology, 90, 928944.

Cober, R. T., Brown, D. J., Keeping, L. M., \& Levy, P. E. (2004). Recruitment on the net: How do organizational web site characteristics influence applicant attraction? Journal of Management, 30, 623-646.

Cober, R. T., Brown, D. J., Levy, P. E., Cober, A. B., \& Keeping, L. M. (2003). Organizational web sites: Web site content and style as determinants of organizational attraction. International Journal of Selection and Assessment, 11, 158-169.

Cohen, J. (1988). Statistical power analysis for the behavioral sciences. Matwah, NJ: Erlbaum.

Cooper, D., Robertson, I.T., \& Tinline, G. (2003). Recruitment and Selection: A framework for success. London: England, Thompson. 
Dutton, J. E., Dukerich, J. M., \& Harquail, C. V. (1994). Organizational images and member identification. Administrative Science Quarterly, 39, 239-263.

Ehrhart, K.H., \& Ziegert, J.C. (2005). Why are individuals attracted to organizations? Journal of Management, 31, 901-919.

Erdfelder, E., Faul, F., \& Buchner, A. (1996). GPOWER: A general power analysis program. Behavior Research Methods, Instruments, \& Computers, 28, 1-11.

Evans, M. G. (1991). The problem of analyzing multiplicative composites. Interactions revisited. American Psychologist, 46, 6-15.

Fodor, E. M., Wick, D. P., \& Hartsen, K. M. (2006). The power motive and affective response to assertiveness. Journal of Research in Personality, 40, 598-610.

Fombrun, C. J. (1996). Reputation: Realizing value from the corporate image. Boston: Harvard Business School Press.

Gatewood, R. D., Gowan, M. A., \& Lautenschlager, G. J. (1993). Corporate image, recruitment image, and initial job choice decisions. Academy of Management Journal, 36, 414-427

Gioia, D. A., Schultz, M., \& Corley, K. G. (2000). Organizational identity, image and adaptive instability. Academy of Management Review, 25, 63-81.

Greer, C.R., \& Ireland, T.C. (1992). Organizational and financial correlates of a "contrarian" human resource investment strategy. Academy of Management Journal, 35, 956-984.

Greer, C.R., Ireland, T.C., \& Wigender, J.R. (2001). Contrarian human resource investments and financial performance after economic downturns. Journal of Business Research, 52, 249-261.

Gregory, P. J. \& Viswesvaran, C. (2009). A tale of two attributions: The relative importance of image to attraction. Poster session presented at the annual meeting of the Society for Industrial and Organizational Psychology, New Orleans, LA.

Greguras, G. J., \& Diefendorff, J. M. (2009). Different fits satisfy different needs: Linking person-environment fit to employee commitment and performance using self-determination theory. Journal of Applied Psychology, 94, 465-477.

Harrell, A.M. \& Stahl, M.J. (1981). A behavioral decision theory approach for measuring McClelland's trichotomy of needs. Journal of Applied Psychology, 66, 242-247. 
Highhouse, Lievens, \& Sinar (2003). Measuring attraction to organizations. Education and Psychological Measurement, 63, 986-1001.

Highhouse, S., Thornbury, E. E., \& Little, I. S. (2007). Social-identity functions of attraction to organizations. Organizational Behavior and Human Decision Processes, 103, 134-146.

Hogan, J. \& Holland, B. (2003). Using theory to evaluate personality and jobperformance relations: A socioanalytic perspective. Journal of Applied Psychology, 88, 100-112.

Hogan, R. T. (1991). Personality and personality measurement. In M. D. Dunnette, \& L. M. Hough (Eds.), Handbook of industrial and organizational psychology, vol. 2 (2nd ed.). (pp. 873-919). Palo Alto, CA, US: Consulting Psychologists Press.

Jackson, D. N. (1974). Manual for the Personality Research Form. Goshen, NY: Research Psychology Press.

Jang, J. (2003). Economic crisis and its consequences. Social Indicators Research, 62-63, 51-70.

Jex, S. M. \& Britt, T.W. (2008). Organizational Psychology: A Scientist-Practitioner Approach $\left(2^{\text {nd }}\right.$ ed.). Hoboken, NJ: John Wiley \& Sons.

Judge, T. A., \& Bretz, R.D. (1992). Effects of work values on job choice decisions. Journal of Applied Psychology, 79, 937-949.

Judge, T. A., \& Cable, D. M. (1997). Applicant personality, organizational culture, and organization attraction. Personnel Psychology, 50, 359-394.

Kanfer, R. (1990). Motivation theory and industrial/organizational psychology. In M.D. Dunnette \& L.M. Hough (Eds.), Handbook of industrial and organizational psychology ( $2^{\text {nd }}$ ed., Vol. 1, pp. 75-170). Palo Alto, CA: Consulting Psychologists Press.

Kristof, A. L. (1996). Person-organization fit: An integrative review of its conceptualizations, measurement, and implications. Personnel Psychology, 49, 149.

Lievens, F. (2006). Organizational Image/reputation. In. S. Rogelberg \& C.L. Reeve (Eds.) The Encyclopedia of Industrial and Organizational Psychology (pp.568570). New York: Sage.

Lievens, F., \& Highhouse, S. (2003). The relation of symbolic and instrumental attributes to company's attractiveness as an employer. Personnel Psychology, 56, 75-102. 
Lievens, F., Van Hoye, G., \& Anseel, F. (2007). Organizational identity and employer image: Towards a unifying framework. British Journal of Management, 18, S45S59.

Lievens, F., Van Hoye, G., \& Schreurs, B. (2005). Examining the relationship between employer knowledge dimensions and organizational attractiveness: An application in a military context. Journal of Occupational and Organizational Psychology, 78, 553-572.

Macky, K., Gardner, D. \& Forsyth, S. (2008). Generational differences at work: Introduction and overview. Journal of Managerial Psychology, 23, 857-861.

Maslow, A. H. (1943). A theory of human motivation. Psychological Review, 50, 370396.

Mayer, J.D., Faber, M.A., \& Xu, X. (2007). Seventy-five years of motivation measures (1930-2005): A descriptive analysis. Motivation and Emotion, 31, 83-103.

McClelland, D. C. (1961). The achieving society. New York: Van Nostrand.

McClelland, D. C. (1970). The two faces of power. Journal of International Affairs, 24, $29-47$.

McClelland, D. C. (1975). Power: The inner experience. New York: Irvington.

McClelland, D. C. (1979). That urge to achieve. In D. A. Kolb, I. M. Rubin, \& J. M. Mclntyre (Eds.), Organizational psychology: A book of readings. Englewood Cliffs, N.J.: Prentice-Hall.

McClelland, D. C., \& Winter, D. (1969). Motivating economic achievement. New York: Free Press.

McClelland, D. C., Atkinson, J., Clark, R., \& Lowell, E. (1976). The achievement motive. New York: Irvington.

McClelland, D.C. (1985). How motives, skills, and values determine what people do. American Psychologist, 40, 812-825.

McClelland, D.C., Koestner, R., \& Weinberger, J. (1989). How do self-attributed and implicit motives differ? Psychological Review, 96, 690-702.

McCrae, R. R., \& Sutin, A. R. (2007). New frontiers for the five-factor model: A preview of the literature. Social and Personality Psychology Compass, 1, 423-440. 
Mitchell, T. R. (1974). Expectancy models of job satisfaction, occupational preferences, and effort: A theoretical, methodological, and empirical appraisal. Psychological Bulletin, 81, 1053-1077.

Muchinsky, P. M . (1977). A comparison of within- and across-subjects analyses of the expectancy-value model for predicting effort. Academy of Management Journal, 20, 154-158.

Muchinsky, P.M. \& Monahan, C.J. (1987). What is person-environment congruence? Supplementary versus complementary models of fit. Journal of Vocational Behavior, 31, 268-277.

Muchinsky, P. M. \& Taylor, M. S. (1976). Intrasubjects predictions of occupational preference: The effect of manipulating components of the valence model. Journal of Vocational Behavior, 8, 185-195.

Ones, D. S., \& Viswesvaran, C. (1996). Bandwidth-fidelity dilemma in personality measurement for personnel selection. Journal of Organizational Behavior, 17, 609-626.

O'Reilly, C. A., Chatman, J., \& Caldwell, D. F. (1991). People and organizational culture: A profile comparison approach to assessing person-organization fit. Academy of Management Journal, 34, 487-516.

Phillips, J. M., \& Gully, S. M. (1997). Role of goal orientation, ability, need for achievement, and locus of control in the self-efficacy and goal--setting process. Journal of Applied Psychology, 82, 792-802.

Pinder, C. C. (2008). Work motivation in organizational behavior $\left(2^{\text {nd }}\right.$ ed.). The Psychology Press.

Resick, C. J., Baltes, B. B., \& Shantz, C. W. (2007). Person-organization fit and workrelated attitudes and decisions: Examining interactive effects with job fit and conscientiousness. Journal of Applied Psychology, 92, 1446-1455.

Rynes, S.L. (1991). Recruitment, job choice, and post-hire consequences: A call for new research direction. In M. D. Dunnette \& L.M. Hough (Eds.), Handbook of Industrial and organizational psychology (2 ${ }^{\text {nd }}$ ed., Vol. 2, pp. 399-444). Palo Alto, CA: Consulting Psychologists Press.

Saks, A.M., \& Ashforth, B.E. (2002). Is job search related to employment quality? It all depends on fit. Journal of Applied Psychology, 87, 646-654.

Schein, E. H. (1990). Organizational culture. American Psychologist. Special Issue: Organizational Psychology, 45, 109-119. 
Schneider, B., Goldstein, \& Smith (2006). The ASA framework: An update. Personnel Psychology, 48, 747-773.

Scott, S.G. \& Lane, V.R. (2000). A Stakeholder approach to organizational identity. Academy of Management Review, 25, 43-62.

Siguaw, J.A., Mattila, A., \& Austin, J. R. (1999). The Brand-Personality Scale. Cornell Hotel and Restaurant Administration Quarterly, 40, 48-55.

Singh, S. (1986). Values and personality correlates of projective measure of power motivation. British Journal of Projective Psychology \& Personality Study, 31, 3238.

Slaughter, J.E., Zickar, M.J., Highhouse, S., \& Mohr, D.C. (2004). Personality trait inferences about organizations: Development of a measure and assessment of construct validity. Journal of Applied Psychology, 89, 85-103.

Thoms, P., Chinn, S. J., Goodrich, J., \& Howard, G. (2004). Designing personable and informative job recruiting web sites: Testing the effect of the design on attractiveness and intent to apply. Psychological reports, 94, 1031-1042.

Twenge, J.M. \& Campbell, S.M. (2008). Generational differences in psychological traits and their impact on the workplace. Journal of Managerial Psychology, 23, 862877.

Turban, D. B., \& Keon, T. L. (1993). Organizational attractiveness: An interactionist perspective. Journal of Applied Psychology, 78, 184-193.

Van Eerde, W. \& Thierry, H. (1996). Vroom's expectancy models and work-related criteria: A meta-analysis. Journal of Applied Psychology, 81, 575-586.

Viswesvaran, C., \& Sanchez, J. I. (1997). Measurement equivalence of watson and clark's 18 surrogate measures of negative affectivity: Applying the principle of tetrad differences to an incomplete correlation matrix. Work \& Stress, 11, 362-368.

Vroom, V. H. (1964). Work and motivation. New York, NY: Wiley.

Vroom, V. H. (1995). Work and motivation (2 $2^{\text {nd }}$ ed.). New York, NY: Wiley.

Wanous, J. P., Keon, T. L., \& Latack, J. C. (1983). Expectancy theory and occupational/organizational choices: A review and test. Organizational Behavior and Human Performance, 32, 66-86. 
Wiesenfeld, B. M., Raghuram, S., \& Garud, R. (2001). Organizational identification among virtual workers: The role of need for affiliation and perceived work-based social support. Journal of Management, 27, 213-229.

Williamson, I.O., Lepak, D. P., \& King, J. (2003). The effect of company recruitment web site orientation on individuals' perceptions of organizational attractiveness. Journal of Vocational Behavior, 63, 242-263.

Winter, D. G., John, O. P., Stewart, A. J., Klohnen, E. C., \& Duncan, L. E. (1998). Traits and motives: Toward an integration of two traditions in personality research. Psychological Review, 105, 230-250.

Wong, M., Gardiner, E., Lang, W., \& Coulon, L. (2008). Generational differences in personality and motivation: Do they exist and what are the implications for the workplace? Journal of Managerial Psychology, 23, 878-890. 


\section{Appendices}

Appendix 1: Fortune 100 Name Recognition and Familiarity Ratings (Pilot 1)

\begin{tabular}{|c|c|c|c|}
\hline & Organization & $\begin{array}{l}\text { Name Recognition } \\
\text { (\% of } 91 \text { participants) }\end{array}$ & $\begin{array}{r}\text { Familiarity } \\
\text { (out of 5.0) }\end{array}$ \\
\hline 1. & Coca-Cola & 100 & 4.67 \\
\hline 2. & Wal-Mart Stores & 100 & 4.64 \\
\hline 3. & $A T \& T$ & 100 & 4.64 \\
\hline 4. & Walt Disney & 100 & 4.63 \\
\hline 5. & Comcast & 100 & 4.59 \\
\hline 6. & Walgreen & 100 & 4.58 \\
\hline 7. & Home Depot & 100 & 4.57 \\
\hline 8. & Target & 100 & 4.56 \\
\hline 9. & Chevron & 100 & 4.4 \\
\hline 10. & Motorola & 100 & 4.39 \\
\hline 11. & Allstate & 100 & 4.36 \\
\hline 12. & Johnson \& Johnson & 100 & 4.3 \\
\hline 13. & Best Buy & 98.9 & 4.66 \\
\hline 14. & Apple & 98.9 & 4.6 \\
\hline 15. & $F e d E x$ & 98.9 & 4.57 \\
\hline 16. & $M a c y ' s$ & 98.9 & 4.56 \\
\hline 17. & Microsoft & 98.9 & 4.53 \\
\hline 18. & Dell & 98.9 & 4.51 \\
\hline 19. & American Express & 98.9 & 4.49 \\
\hline 20. & Sprint Nextel & 98.9 & 4.33 \\
\hline 21. & Lowe's & 98.9 & 4.23 \\
\hline 22. & Bank of America Corp. & 97.8 & 4.47 \\
\hline 23. & Ford Motor & 97.8 & 4.43 \\
\hline 24. & State Farm Insurance Cos. & 97.8 & 4.42 \\
\hline 25 . & Exxon Mobil & 97.8 & 4.34 \\
\hline 26. & Costco Wholesale & 96.7 & 4.26 \\
\hline 27. & PepsiCo & 95.6 & 4.54 \\
\hline 28. & Kraft Foods & 95.6 & 4.33 \\
\hline 29. & General Motors & 95.6 & 4.13 \\
\hline 30. & CVS Caremark & 94.5 & 4.36 \\
\hline 31. & Citigroup & 94.5 & 3.8 \\
\hline 32. & Intel & 92.3 & 3.72 \\
\hline 33. & Verizon Communications & 90.1 & 4.31 \\
\hline 34. & Hewlett-Packard & 87.9 & 4.16 \\
\hline & J.P. Morgan Chase \& Co. & 87.9 & 3.41 \\
\hline 36. & Humana & 86.8 & 3.78 \\
\hline
\end{tabular}


37. Cisco Systems 86.8

38. General Electric

39. Hess

86.7

3.8

40. Tyson Foods

85.7

3.68

41. Sunoco

84.6

3.51

42. Sears Holdings

81.3

3.43

43. Wells Fargo

79.1

3.27

44. Liberty Mutual Insurance Group

79.1

2.9

45. MetLife

69.2

2.83

46. Time Warner

69.2

3.2

47. Marathon Oil

67

3.13

48. United Parcel Service

62.6

3.31

49. Sysco

60.4

2.89

50. UnitedHealth Group

60.4

2.8

51. Rite Aid

60.4

3.02

52. Morgan Stanley

58.2

2.6

53. Procter \& Gamble

2.53

54. Prudential Financial

54.9

2.49

55. Boeing

52.7

2.54

56. Caterpillar

50.5

2.51

57. Aetna

48.4

46.2

2.49

58. Valero Energy

45.1

2.4

59. Deere

44

2.37

60. Philip Morris International

44

2.25

61. Pfizer

41.8

2.52

62. Kroger

41.8

2.44

63. DuPont

38.5

2.15

64. GMAC

37.4

65. Enterprise GP Holdings

35.2

2.06

66. $3 \mathrm{M}$

34.1

34.1

2.06

67. Honeywell International

34.1

2.05

68. Emerson Electric

27.5

1.81

69. Berkshire Hathaway

26.4

1.82

70. Safeway

25.3

1.98

71. International Business Machines

23.1

2.08

72. New York Life Insurance

23.1

1.94

73. United Technologies

20.9

1.81

74. Dow Chemical

19.8

1.73

75. Medco Health Solutions

19.8

1.9

76. General Dynamics

19.8

1.76

77. Abbott Laboratories

18.7

1.73

78. Lockheed Martin

1.9 
79. News Corp.

18.7

1.81

80. ConocoPhillips

16.5

1.67

81. Murphy Oil

14.3

1.68

82. Cardinal Health

14.3

1.58

83. Goldman Sachs Group

13.2

1.73

84. International Paper

13.2

1.73

85. Dandy Toy's

11

1.68

86. WellPoint

9.9

1.84

87. Alcoa

9.9

1.61

88. Johnson Controls

8.8

1.78

89. Travelers Cos.

8.8

1.66

90. TIAA-CREF

8.8

1.64

91. Northrop Grumman

7.7

1.63

92. AmerisourceBergen

7.7

1.57

93. Supervalu

6.6

1.67

94. CHS

6.6

1.63

95. Ingram Micro

5.5

96. Tesoro

5.5

1.6

97. HCA

5.5

1.48

98. McKesson

3.3

1.36

99. Occidental Petroleum

3.3

1.48

100. Archer Daniels Midland

3.3

1.39

101. Plains All American Pipeline

2.2

1.35

1.46 
Appendix 2: Organizational Personality Ratings for Thirty Pilot Organizations (Pilot 2)

\begin{tabular}{|c|c|c|c|c|c|c|c|c|c|c|c|}
\hline Organization & $\begin{array}{l}\text { Rater } \\
\text { Count }\end{array}$ & $\begin{array}{c}\text { BS } \\
\text { Score } \\
\end{array}$ & $\begin{array}{c}\text { BS } \\
\text { Rank }\end{array}$ & $\begin{array}{c}\text { INV } \\
\text { Score }\end{array}$ & $\begin{array}{l}\text { INV } \\
\text { Rank }\end{array}$ & $\begin{array}{l}\text { DOM } \\
\text { Score }\end{array}$ & $\begin{array}{l}\text { DOM } \\
\text { Rank }\end{array}$ & $\begin{array}{c}\text { THR } \\
\text { Score }\end{array}$ & $\begin{array}{c}\text { THR } \\
\text { Rank }\end{array}$ & $\begin{array}{c}\text { STY } \\
\text { Score }\end{array}$ & $\begin{array}{l}\text { STY } \\
\text { Rank }\end{array}$ \\
\hline Allstate & 6 & 33.67 & 8 & 22.17 & 20 & 20.50 & 11 & 15.00 & 25 & 10.83 & 22 \\
\hline American Express & 11 & 32.18 & 18 & 25.18 & 10 & 22.27 & 4 & 14.82 & 26 & 14.55 & 6 \\
\hline Apple & 8 & 39.00 & 2 & 31.38 & 2 & 22.38 & 3 & 13.13 & 29 & 19.25 & 1 \\
\hline $\mathrm{AT} \& \mathrm{~T}$ & 10 & 33.30 & 12 & 24.00 & 13 & 21.30 & 7 & 15.80 & 22 & 14.30 & 7 \\
\hline Bank of America & 9 & 33.33 & 11 & 23.11 & 17 & 21.22 & 8 & 15.44 & 23 & 11.78 & 18 \\
\hline Best Buy & 12 & 32.83 & 15 & 24.50 & 12 & 20.17 & 14 & 16.17 & 21 & 13.17 & 12 \\
\hline Chevron & 7 & 26.86 & 29 & 20.14 & 26 & 16.29 & 30 & 20.57 & 3 & 10.86 & 21 \\
\hline Coca Cola & 11 & 33.00 & 13 & 27.55 & 5 & 21.00 & 9 & 17.18 & 15 & 14.18 & 8 \\
\hline Comcast & 12 & 31.33 & 21 & 23.67 & 15 & 19.83 & 16 & 16.83 & 17 & 11.75 & 19 \\
\hline Costco Wholesale & 5 & 30.20 & 26 & 18.20 & 30 & 20.40 & 12 & 21.20 & 2 & 6.40 & 30 \\
\hline CVS Caremark & 11 & 31.36 & 20 & 20.09 & 27 & 19.27 & 20 & 17.64 & 12 & 11.09 & 20 \\
\hline Dell & 15 & 32.40 & 17 & 24.87 & 11 & 18.40 & 27 & 16.60 & 20 & 13.27 & 11 \\
\hline Exxon Mobil & 14 & 26.71 & 30 & 21.64 & 22 & 19.50 & 18 & 18.21 & 9 & 9.21 & 27 \\
\hline FedEx & 7 & 28.00 & 28 & 21.29 & 24 & 16.71 & 29 & 20.14 & 4 & 10.14 & 24 \\
\hline Ford Motor & 14 & 30.29 & 25 & 22.07 & 21 & 18.86 & 21 & 18.00 & 10 & 12.64 & 17 \\
\hline Home Depot & 9 & 35.44 & 5 & 22.56 & 19 & 19.78 & 17 & 17.33 & 14 & 8.33 & 28 \\
\hline Johnson \& Johnson & 8 & 33.50 & 10 & 23.25 & 16 & 19.38 & 19 & 19.38 & 5 & 10.38 & 23 \\
\hline Kraft Foods & 14 & 34.36 & 7 & 27.07 & 7 & 18.79 & 22 & 16.64 & 19 & 13.36 & 10 \\
\hline Lowe's & 8 & 34.38 & 6 & 19.00 & 29 & 18.75 & 23 & 18.00 & 10 & 10.13 & 25 \\
\hline Macy's & 9 & 31.22 & 23 & 21.44 & 23 & 18.22 & 28 & 18.78 & 6 & 14.00 & 9 \\
\hline Microsoft & 12 & 33.00 & 13 & 26.92 & 8 & 21.58 & 6 & 15.08 & 24 & 13.08 & 14 \\
\hline Motorola & 16 & 31.25 & 22 & 23.81 & 14 & 18.50 & 26 & 18.25 & 8 & 12.88 & 15 \\
\hline PepsiCo & 14 & 33.64 & 9 & 27.71 & 4 & 22.50 & 2 & 13.57 & 28 & 16.07 & 4 \\
\hline Sprint Nextel & 8 & 30.63 & 24 & 23.00 & 18 & 18.63 & 25 & 17.38 & 13 & 12.75 & 16 \\
\hline State Farm Insurance Co. & 9 & 39.00 & 2 & 27.22 & 6 & 19.89 & 15 & 16.67 & 18 & 13.11 & 13 \\
\hline
\end{tabular}




\begin{tabular}{lccccccccccc} 
Target & 10 & 37.80 & 4 & 28.90 & 3 & 20.30 & 13 & 16.90 & 16 & 15.40 & 5 \\
Verizon Communications & 7 & 32.57 & 16 & 25.43 & 9 & 20.71 & 10 & 14.43 & 27 & 16.86 & 2 \\
Walgreen & 6 & 31.40 & 19 & 21.00 & 25 & 18.70 & 24 & 18.60 & 7 & 9.50 & 26 \\
Wal-Mart Stores & 10 & 29.17 & 27 & 19.33 & 28 & 21.67 & 5 & 23.83 & 1 & 6.50 & 29 \\
Walt Disney & 9 & 41.89 & 1 & 33.89 & 1 & 24.11 & 1 & 11.11 & 30 & 16.56 & 3 \\
\hline
\end{tabular}




\section{Appendix 3: Chevron Organizational Profile}

\section{Chevron Corporate Profile}

The Chevron Way explains who we are, what we do, what we believe and what we plan to accomplish. It establishes a common understanding not only for those of us who work here, but for all who interact with us.

\section{Vision}

At the heart of The Chevron Way is our vision... to be the global energy company most admired for its people, partnership and performance.

Our vision means we:

-Provide energy products vital to sustainable economic progress and human development throughout the world;

-Are people and an organization with superior capabilities and commitment;

-Are the partner of choice;

-Deliver world-class performance;

-Earn the admiration of all our stakeholders - investors, customers, host governments, local communities and our employees - not only for the goals we achieve but how we achieve them.

\section{Values}

Our company's foundation is built on our values, which distinguish us and guide our actions. We conduct our business in a socially responsible and ethical manner. We respect the law, support universal human rights, protect the environment, and benefit the communities where we work.

.Integrity

We are honest with others and ourselves. We meet the highest ethical standards in all business dealings. We do what we say we will do. We accept responsibility and hold ourselves accountable for our work and our actions.

\section{Trust}

We trust, respect and support each other, and we strive to earn the trust of our colleagues and partners.

\section{Partnership}

We have an unwavering commitment to being a good partner focused on building productive, collaborative, trusting and beneficial relationships with governments, other companies, our customers, our communities and each other.

Diversity

We learn from and respect the cultures in which we work. We value and demonstrate respect for the uniqueness of individuals and the varied perspectives and talents they 
provide. We have an inclusive work environment and actively embrace a diversity of people, ideas, talents and experiences.

\section{Ingenuity}

We seek new opportunities and out-of-the-ordinary solutions. We use our creativity to find unexpected and practical ways to solve problems. Our experience, technology, and perseverance enable us to overcome challenges and deliver value.

Protecting People and the Environment

We place the highest priority on the health and safety of our workforce and protection of our assets and the environment. We aim to be admired for world-class performance through disciplined application of our Operational Excellence Management System.

\section{High Performance}

We are committed to excellence in everything we do, and we strive to continually improve. We are passionate about achieving results that exceed expectations - our own and those of others. We drive for results with energy and a sense of urgency. 
Appendix 4: Verizon Organizational Profile

\section{Verizon Corporate Profile}

The Verizon Commitment and Values are the foundation for our culture and guide our every action.

\section{Customers First}

The Verizon Commitment is to put our customers first by providing excellent service and great communications experiences. This is what we do and this is why we exist. By focusing on our customers and being a responsible member of our communities, we will produce a solid return for our shareowners, create meaningful work for ourselves and provide something of lasting value for society. As a result, Verizon will be recognized as a great company.

In order to keep this commitment, we need to always honor our core values:

$\S$ Integrity

Integrity is at the heart of everything we do. We are honest, ethical and upfront because trust is at the foundation of our relationships with our customers, our communities, our stakeholders and each other.

$\S \underline{\text { Respect }}$

We know it is critical that we respect everyone at every level of our business. We champion diversity, embrace individuality and listen carefully when others speak.

$\S$ Performance Excellence

We hold ourselves to a very high standard of performance. We prize innovative ideas and the teamwork it takes to make them realities. We never stop asking ourselves how we can make the customer experience better, and every day, we find an answer.

$\S$ Accountability

We take responsibility for our actions as individuals, as team members, and as an organization. We work together, support one another and never let the customer-or our coworkers-down.

Great companies are judged by what they do, not by what they say. To be the best, we're going to keep pushing ourselves in new and exciting directions. These values guide our every action.

\section{Valuing Our Employees}

We protect the human rights of our employees through strong policies, direct and open communications, management systems and training on issues such as diversity, fair employment practices, non-discrimination and freedom from unlawful harassment, and environmental health and safety. 


\section{Diversity and Inclusion}

Respect for diversity is an integral part of the Verizon culture and a critical element in our strategy to compete and deliver the best customer experiences. We recognize the competitive advantage that comes from having employees with diverse backgrounds, life experiences and points of view who can relate to customers, speak their languages and reflect our markets.

\section{Compensation and Benefits}

We provide competitive compensation and benefits, extensive programs for balancing the demands of work and home, a safe and challenging work environment, and ample opportunities for learning and career advancement.

\section{Verizon Codes of Conduct}

Verizon is committed to the highest ethical standards, which are defined in Verizon's Codes of Conduct (for Verizon, Verizon Business, and Verizon Wireless). We share our Codes of Conduct with customers and business partners, and we train and certify every Verizon employee to promote compliance with these standards. All Verizon employees are bound by the Code of Conduct adopted by their business.

\section{Equal Opportunity Commitment}

Verizon is committed to attracting, developing, and retaining a highly qualified, diverse and dedicated work force. We strive to comply fully with all laws providing equal opportunity to all persons without regard to race, color, religion, gender, sexual orientation, age, national origin, disability, military status, veteran status, marital status, citizenship status, or any other protected category under all applicable law. For company business, Verizon uses facilities, sponsors events, and maintains memberships only at businesses or organizations that do not have exclusionary membership practices.

\section{Policy on Discrimination and Harassment}

Verizon does not tolerate discrimination, sexual harassment or other unlawful harassment based on race, color, religion, gender, sexual orientation, age, national origin, disability, military status, veteran status, marital status, citizenship status, or any other protected category under all applicable law. We consider harassment to include racist, sexist, or ethnic comments, jokes, gestures, or any action or statement creating an intimidating, hostile, or offensive work environment.

\section{Valuing Our Customers}

We build great networks that allow us to deliver communications, data and entertainment to our customers in ways that few companies can match. Our networks play a central role in energizing the marketplace, stimulating innovation and improving the quality of life for our customers. We use our technological expertise to develop products and services 
that extend the benefits of the digital age to all customers, while protecting their privacy and safety in the digital world.

\section{Protecting Customers' Privacy}

Digital technology is changing the way companies collect and use information about customers. Verizon requires all employees, partners and suppliers to protect the privacy of information about our customers.

Our Privacy Principles express Verizon's commitment to protecting customer privacy by notifying customers about how their data is being used and giving them choice and control over the use of their private information.

\section{Accessibility}

At Verizon, we are committed to providing products and services that are accessible to all people, including individuals with disabilities. We encourage our vendors and suppliers to develop and offer solutions that will enable our products and services to be more accessible to all.

To guide us in the effort, we embraced a set of principles in 1987 for creating products and services that are usable and accessible by the broadest range of customers, including youth, individuals with disabilities and seniors. These Universal Design Principles are now an integral part of the product design process throughout Verizon, and we employ these principles in our relationships with customers, employees, shareowners and suppliers.

\section{Family Safety}

Customers increasingly look to Verizon to help ensure a safe and secure online experience. Verizon's online safety programs set the industry benchmark for child safety and help raise consumer awareness and adoption of safe computing practices. We also support programs that use technology to promote awareness and prevention of domestic violence and provide support and services to victims. Impacting the epidemic of domestic violence is a priority issue for the Verizon Foundation. In addition, we have adopted a Content Policy to help us make content decisions consistent with our values - respect for customer choice, respect for customer privacy and security, respect for customer safety, and dedication to full compliance with the law. 
Appendix 5: Home Depot Organizational Profile

\section{The Home Depot Corporate Profile}

\section{Values}

The Home Depot's values guide the beliefs and actions of all associates on a daily basis. Our values are the fabric of the Company's unique culture and are central to our success. In fact, they are our competitive advantage in the marketplace. Associate pride and our "orangeblooded" entrepreneurial spirit are distinctive hallmarks of our culture.

1. Taking care of our people:

The key to our success is treating people well. We do this by encouraging associates to speak up and take risks, by recognizing and rewarding good performance and by leading and developing people so they may grow.

2. Giving back to our communities:

An important part of the fabric of The Home Depot is giving our time, talents, energy and resources to worthwhile causes in our communities and society.

3. Doing the right thing:

We exercise good judgment by "doing the right thing" instead of just "doing things right." We strive to understand the impact of our decisions, and we accept responsibility for our actions.

4. Excellent customer service:

Along with our quality products, service, price and selection, we must go the extra mile to give customers knowledgeable advice about merchandise and to help them use those products to their maximum benefit.

5. Creating shareholder value:

The investors who provide the capital necessary to allow our company to grow need and expect a return on their investment. We are committed to providing it.

6. Building strong relationships:

Strong relationships are built on trust, honesty and integrity. We listen and respond to the needs of customers, associates, communities and vendors, treating them as partners.

7. Entrepreneurial spirit:

The Home Depot associates are encouraged to initiate creative and innovative ways of serving our customers and improving the business and to spread best practices throughout the company.

8. Respect for all people:

In order to remain successful, our associates must work in an environment of mutual respect, free of discrimination and harassment where each associate is regarded as a part 
of The Home Depot team.

Our Leadership

At The Home Depot, dedication to serving our customer and providing the ultimate shopping experience is everyone's priority. Maintaining this focus and commitment is a leadership team that believes our company values and commitment to great customer service will create value for all our stakeholders. Working in a Store Support Center, rather than a corporate headquarters, our leadership knows that the most important people in the fabric of our company are the store associates and store leadership teams. 


\title{
Appendix 6: Coca Cola Organizational Profile
}

\section{Coca Cola Corporate Profile}

\author{
Mission, Vision \& Values
}

The world is changing all around us. To continue to thrive as a business over the next ten years and beyond, we must look ahead, understand the trends and forces that will shape our business in the future and move swiftly to prepare for what's to come. We must get ready for tomorrow today. That's what our 2020 Vision is all about. It creates a long-term destination for our business and provides us with a "Roadmap" for winning together with our bottler partners.

\section{Our Mission}

Our Roadmap starts with our mission, which is enduring. It declares our purpose as a company and serves as the standard against which we weigh our actions and decisions.

- To refresh the world...

- To inspire moments of optimism and happiness...

- To create value and make a difference.

\section{Our Vision}

Our vision serves as the framework for our Roadmap and guides every aspect of our business by describing what we need to accomplish in order to continue achieving sustainable, quality growth.

- People: Be a great place to work where people are inspired to be the best they can be.

- Portfolio: Bring to the world a portfolio of quality beverage brands that anticipate and satisfy people's desires and needs.

- Partners: Nurture a winning network of customers and suppliers, together we create mutual, enduring value.

- Planet: Be a responsible citizen that makes a difference by helping build and support sustainable communities.

- Profit: Maximize long-term return to shareowners while being mindful of our overall responsibilities.

- Productivity: Be a highly effective, lean and fast-moving organization.

\section{Our Winning Culture}

Our Winning Culture defines the attitudes and behaviors that will be required of us to make our 2020 Vision a reality.

\section{Live Our Values}

Our values serve as a compass for our actions and describe how we behave in the world.

- Leadership: The courage to shape a better future

- Collaboration: Leverage collective genius

- Integrity: Be real 
- Accountability: If it is to be, it's up to me

- Passion: Committed in heart and mind

- Diversity: As inclusive as our brands

- Quality: What we do, we do well

Focus on the Market

- Focus on needs of our consumers, customers and franchise partners

- Get out into the market and listen, observe and learn

- Possess a world view

- Focus on execution in the marketplace every day

- Be insatiably curious

Work Smart

- Act with urgency

- Remain responsive to change

- Have the courage to change course when needed

- Remain constructively discontent

- Work efficiently

\section{Act Like Owners}

- Be accountable for our actions and inactions

- Steward system assets and focus on building value

- Reward our people for taking risks and finding better ways to solve problems

- Learn from our outcomes -- what worked and what didn't

Be the Brand

- Inspire creativity, passion, optimism and fun 


\section{Appendix 7: American Express Organizational Profile}

\section{American Express Corporate Profile}

Today, American Express has never been more competitive. It is a world leader in providing charge and credit cards to consumers, small businesses and corporations. It is the world's largest travel agency, offering travel and related consulting services to individuals and corporations around the world. American Express operates in over 130 countries around the globe.

As it has throughout its long and varied past, American Express continues to deliver valuable and innovative services to its customers. It remains committed to its longstanding core values. And, as it was in 1850, it is poised to seize new opportunities in a rapidly changing industry and world.

Since its founding in 1850, American Express has conducted business according to several guiding principles that over the years have become inextricably linked with the company's brand, products, services and - perhaps most notably - its people.

Generations before the phrase "company values" entered the corporate lexicon, American Express employees across the organization were demonstrating the same core principles upheld by the company today:

\section{Customer Commitment}

We develop relationships that make a positive difference in our customers' lives.

Quality

We provide outstanding products and unsurpassed service that, together, deliver premium value to our customers.

Integrity

We uphold the highest standards of integrity in all of our actions.

\section{$\underline{\text { Teamwork }}$}

We work together, across boundaries, to meet the needs of our customers and to help the company win.

\section{$\underline{\text { Respect for People }}$}

We value our people, encourage their development and reward their performance.

\section{Good Citizenship}

We are good citizens in the communities in which we live and work.

$\underline{\text { A Will to Win }}$

We exhibit a strong will to win in the marketplace and in every aspect of our business. 
Personal Accountability

We are personally accountable for delivering on our commitments 
Appendix 8: Demographics Measure

FIU Panther ID\#

Gender

$\square$ Male
$\square$ Female

Ethnicity

Age

Marital Status

$\square$ Asian
$\square$ Caucasian
$\square$ Other
$\square$ Black
$\square$ Hispanic

Marital Status

\begin{tabular}{|l}
$\square$ Married \\
$\square$ Divorced \\
$\square$ Separated \\
$\square$ Single \\
$\square$ Widowed
\end{tabular}

Academic Year

$\square$ Freshman
$\square$ Junior
$\square$ Sophomore
$\square$ Senior

GPA

\begin{tabular}{|l}
$\square 3.5-4.0$ \\
$\square 3.0-3.49$ \\
$\square 2.5-2.99$ \\
$\square 2.0-2.49$ \\
$\square 1.5-1.99$ \\
$\square 1.0-1.49$ \\
$\square$ Less than a 1.0
\end{tabular}

SAT Score

Employment Status

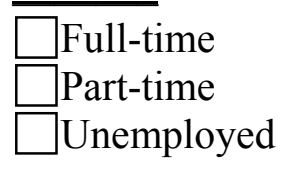

How many jobs have you had in the past?

How many years of work experience do you have? 
Appendix 9: P-O Fit Measure

Please use the scale below when responding to questions 1-4.

\begin{tabular}{ccccc}
\hline 1 & 2 & 3 & 4 & 5 \\
To a very little extent) & & & & (To a very large extent)
\end{tabular}

1. To what extent are the values of the organization similar to your own values?"

2. To what extent does your personality match the personality or image of the organization?

3. To what extent does the organization fulfill your needs?

4. To what extent is the organization a good match for you? 


\section{Appendix 10: Organizational Personality Measure}

Please describe the extent to which the following adjectives describe the organization presented using the following scale

$\begin{array}{ccccc}\longleftarrow 1 & 2 & 3 & 4 & 5 \\ \text { Strongly Disagree } & & & & \text { Strongly Agree }\end{array}$

Boy Scoutishness

1. Friendly

3. Pleasant

5. Cooperative

7. Helpful

9. Honest

Innovativeness

10. Interesting

12. Unique

14. Boring*

16. Original

Dominance

17. Successful

19. Dominant

21. Active

Thriftiness

22. Low budget

24. Simple

26. Sloppy

28. Undersized

Stylishness

30. Stylish

32. Hip

*Indicates reverse scored item.
2. Attentive to People

4. Family-oriented

6. Personal

8. Clean

11. Exciting

13. Creative

15. Plain*

18. Popular

20. Busy

23. Low class

25. Reduced

27. Poor

29. Deprived

31. Fashionable

33. Trendy 
Appendix 11: Applicant Attraction Measures

Please use the scale below when responding to questions 1-15.

$\begin{array}{ccccc}\longrightarrow & 2 & 3 & 4 & 5 \\ \text { (Strongly Disagree) } & & & & \text { (Strongly Agree) }\end{array}$

General attractiveness

1. For me, this company would be a good place to work.

2. I would not be interested in this company except as a last resort.*

3. This company is attractive to me as a place for employment.

4. I am interested in learning more about this company.

5. A job at this company is very appealing to me.

Intentions to pursue

6. I would accept a job offer from this company.

7. I would make this company one of my first choices as an employer.

8. If this company invited me for a job interview, I would go.

9. I would exert a great deal of effort to work for this company.

Reputation

10. I would recommend this company to a friend looking for a job.

11. Employees are probably proud to say they work at this company.

12. This is a reputable company to work for.

13. This company probably has a reputation as being an excellent employer.

14. I would find this company a prestigious place to work.

15. There are probably many who would like to work at this company.

*Indicates reverse scored item. 
Appendix 12: Expectancy Measure

1. Please indicate your belief concerning the likelihood that you would be offered a job if you apply to Organization X using the scale below. (Circle 1 option)

$\begin{array}{llllllll}1 & 2 & 3 & 4 & 5 & 6 & 7\end{array}$

no chance at all extremely good chance

2. If you decided that you would like to work for Organization X, what is the chance that you would be offered a job?

$\begin{array}{cccccc}1 & 2 & 3 & 4 & 5 & \begin{array}{c}6 \\ \text { no chance at all }\end{array} \\ & & & & & \text { extremely good chance }\end{array}$

3. If you made an effort to gain employment with Organization $X$, how likely is it that you would get a job with the company?

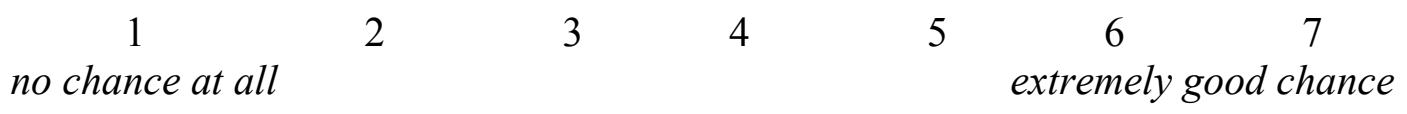


Appendix 13: Instrumentality Measure

Please indicate the extent to which you feel the following work related outcomes would be characteristic of Organization X:

\begin{tabular}{|c|c|c|}
\hline $1 \quad \ldots 2$ & 4 & $5 \quad 6$ \\
\hline Very uncharacteristic & & Very characteristic \\
\hline prestige & & security \\
\hline opportunities for advancement & & _warmth \\
\hline flexibility in practices & & chance to use creative abilities \\
\hline challenging work & & good benefits \\
\hline a good salary & & intellectual stimulation \\
\hline ability to help others & & honesty in business practices \\
\hline
\end{tabular}


Appendix 14: Valence Measure

Please indicate how important you feel being able to attain each of these work related outcomes are in deciding if you would work for an organization.

Rank the outcomes from 1 to 12 .

\section{Rank in terms of importance \\ $1=$ most important to $12=$ least important}

prestige

opportunities for advancement

flexibility in practices

challenging work

a good salary

ability to help others security

warmth

chance to use creative abilities

good benefits

intellectual stimulation

honesty in business practices 
Appendix 15.

Intercorrelations of Instrumentality of Work Related Outcomes and Attraction Measures in Student \& Working Adult Participants.

\begin{tabular}{lcccccccc} 
& \multicolumn{3}{c}{ Students } & & \multicolumn{3}{c}{ Working Adults } \\
\hline Variables & $\mathbf{1}$ & $\mathbf{2}$ & $\mathbf{3}$ & & $\mathbf{1}$ & $\mathbf{2}$ & $\mathbf{3}$ \\
\hline 1. General Attractiveness & --- & & & & --- & & \\
2. Intentions to Pursue & 0.84 & --- & & & 0.78 & --- & \\
3. Reputation & 0.65 & 0.69 & --- & & 0.57 & 0.65 & --- \\
4. Prestige & 0.46 & 0.41 & 0.53 & & 0.23 & 0.19 & 0.48 \\
5. Opportunities for Advancement & 0.47 & 0.51 & 0.58 & & 0.39 & 0.39 & 0.55 \\
6. Flexibility in Practices & 0.38 & 0.39 & 0.44 & & 0.31 & 0.34 & 0.42 \\
7. Challenging Work & 0.39 & 0.43 & 0.42 & & 0.42 & 0.49 & 0.40 \\
8. A Good Salary & 0.48 & 0.47 & 0.44 & & 0.34 & 0.46 & 0.48 \\
9. Ability to Help Others & 0.15 & 0.19 & 0.24 & & 0.38 & 0.38 & 0.38 \\
10. Job Security & 0.31 & 0.31 & 0.38 & & 0.29 & 0.24 & 0.36 \\
11. Warmth & 0.26 & 0.27 & 0.28 & & 0.27 & 0.29 & 0.35 \\
12. Chance to use Creative Abilities & 0.30 & 0.31 & 0.26 & & 0.38 & 0.35 & 0.37 \\
13. Good Benefits & 0.40 & 0.43 & 0.44 & & 0.28 & 0.24 & 0.28 \\
14. Intellectual Stimulation & 0.40 & 0.43 & 0.35 & & 0.49 & 0.45 & 0.28 \\
15. Honesty in Business Practices & 0.31 & 0.31 & 0.32 & & 0.49 & 0.42 & 0.48 \\
\hline
\end{tabular}


Appendix 16.

Univariate Analysis of Variance Comparing Students Valence Ratings by Applicant Quality.

\begin{tabular}{|c|c|c|c|c|c|c|c|c|c|}
\hline \multirow[t]{2}{*}{ Outcome } & \multirow[t]{2}{*}{$\mathbf{F}$} & \multirow[t]{2}{*}{ df } & \multirow[t]{2}{*}{$\mathbf{p}$} & \multicolumn{2}{|c|}{$\begin{array}{c}\text { High-Quality } \\
(\mathrm{N}=60)\end{array}$} & \multicolumn{2}{|c|}{$\begin{array}{c}\text { Medium-Quality } \\
(\mathbf{N}=\mathbf{8 2})\end{array}$} & \multicolumn{2}{|c|}{$\begin{array}{c}\text { Low-Quality } \\
(\mathrm{N}=\mathbf{5 5})\end{array}$} \\
\hline & & & & $\mathrm{M}$ & SD & $\mathrm{M}$ & SD & $\mathrm{M}$ & $\mathrm{SD}$ \\
\hline Prestige & 1.68 & 2 & .19 & 7.35 & 3.71 & 7.02 & 3.73 & 8.18 & 3.45 \\
\hline Opportunities for Advancement & .63 & 2 & .54 & 4.72 & 3.13 & 4.29 & 3.03 & 4.09 & 3.15 \\
\hline Flexibility in Practices & 1.99 & 2 & .14 & 6.80 & 3.01 & 7.66 & 3.11 & 6.78 & 2.83 \\
\hline Challenging Work & .91 & 2 & .40 & 7.25 & 3.26 & 7.60 & 3.03 & 8.04 & 3.12 \\
\hline A Good Salary & .03 & 2 & .97 & 3.68 & 2.71 & 3.73 & 2.98 & 3.60 & 3.15 \\
\hline Ability to Help Others & .01 & 2 & .99 & 6.42 & 2.92 & 6.49 & 3.22 & 6.42 & 3.13 \\
\hline Job Security & 4.32 & 2 & .01 & 6.75 & 3.31 & 5.32 & 2.84 & 5.60 & 2.68 \\
\hline Warmth & .57 & 2 & .57 & 8.67 & 2.76 & 8.38 & 3.02 & 8.09 & 2.87 \\
\hline Chance to use Creative Abilities & 5.23 & 2 & $<.01$ & 6.47 & 3.40 & 7.73 & 2.97 & 8.33 & 3.25 \\
\hline Good Benefits & .77 & 2 & .48 & 6.28 & 3.38 & 5.74 & 3.02 & 5.62 & 3.27 \\
\hline Intellectual Stimulation & .73 & 2 & .49 & 6.90 & 3.45 & 7.40 & 3.21 & 7.60 & 3.11 \\
\hline Honesty in Business Practices & 1.51 & 2 & .22 & 6.72 & 3.87 & 6.63 & 3.83 & 5.65 & 3.24 \\
\hline
\end{tabular}

Note: Lower rankings indicate greater valence 
Appendix 17.

Intercorrelations of Valence Rankings of Work Related Outcomes and SAT Score in Student Participants.

\begin{tabular}{ll}
\hline Variables & SAT Score \\
\hline 1. Prestige & 0.03 \\
2. Opportunities for Advancement & -0.03 \\
3. Flexibility in Practices & -0.09 \\
4. Challenging Work & 0.10 \\
5. A Good Salary & 0.05 \\
6. Ability to Help Others & 0.08 \\
7. Job Security & -0.07 \\
8. Warmth & 0.11 \\
9. Chance to use Creative Abilities & -0.09 \\
10. Good Benefits & -0.01 \\
11. Intellectual Stimulation & 0.00 \\
12. Honesty in Business Practices & -0.07
\end{tabular}

Note: All observed correlations are non-significant. 
VITA

\section{PAUL JOSEPH GREGORY}

December 18, 1978

$1997-2000$

2002-2007

$2007-2010$

2005-Present
Born, St. Andrew, Jamaica

B.A., Sociology

B.S. Psychology

University of Florida

Gainesville, FL

M.S., Industrial and Organizational Psychology

Florida International University

Miami, FL

Doctoral Candidate in Psychology

Florida International University

Miami, FL

Director of Research and Business Development

Physicians Development Program

Miami, FL

\section{PUBLICATIONS AND PRESENTATIONS}

Dechurch, L., Haas, C., Gregory, P.J. \& Batista, L. (2004). On the hunt for teamwork: The role of team planning process. Annual Convention of the Society for Industrial and Organizational Psychologists, Chicago, IL.

Gregory, P. J. \& Viswesvaran, C. (2009). A tale of two attributions: The relative importance of image to attraction. Poster session presented at the annual meeting of the Society for Industrial and Organizational Psychology, New Orleans, LA.

Hernandez, E., Gregory, P.J., \& Viswesvaran, C. (2008). Adaptability and intelligence: A metaanalysis. Poster session presented at the annual meeting of the American Psychological Association, Boston, MA.

Rotton, J., Gregory, P. J., \& Van Rooy, D. L. (2005). Behind the wheel: Construct validity of aggressive driving scales. In D. A. Hennessy, \& D. L. Wiesenthal (Eds.), Contemporary issues in road user behavior and traffic safety. (pp. 37-46). Hauppauge, NY: Nova Science Publishers.

Van Rooy, D. L., Rotton, J., \& Gregory, P. J. (2005). On the road: Situational determinants of aggressive driving. In D. A. Hennessy, \& D. L. Wiesenthal (Eds.), Contemporary issues in road user behavior and traffic safety. (pp. 61-70). Hauppauge, NY: Nova Science Publishers. 